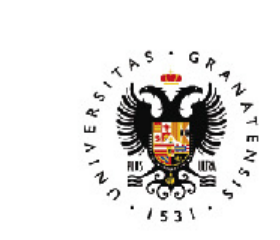
/ UGR/maes MÁSTER EN PROFESORADO ESO - BACHILLERATO - FP - IDIOMAS
GP Escuela Internacional de Posgrado

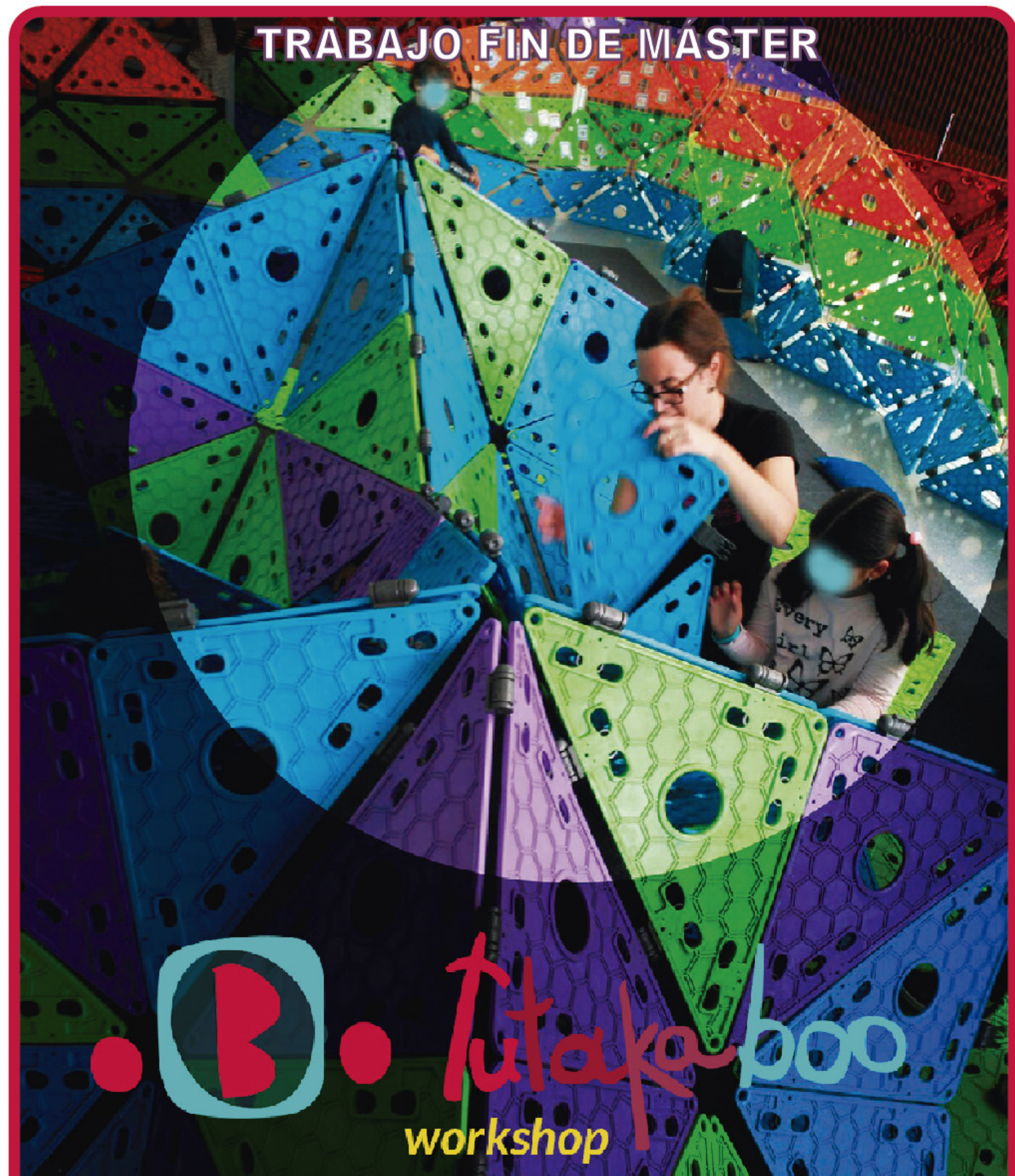

SENTIDO ESPACIAL Y DE IVIEDIDA EN TAREAS CON UN NUEVO IVIATERIAL PARA LA ENSENANZA DE LAS IVIATEIVIÁTICAS EN SECUNDARIA: TUUTAKABOO 
"Dime y lo olvido, enséñame y lo recuerdo, involúcrame y lo aprendo"

Benjamin Franklin.

A mi familia. 


\section{ÍNDICE}

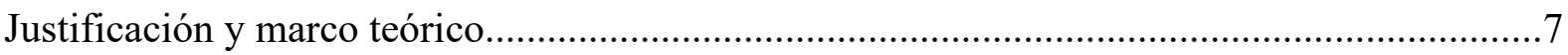

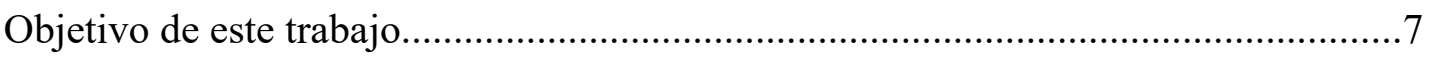

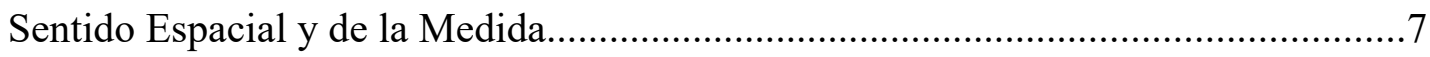

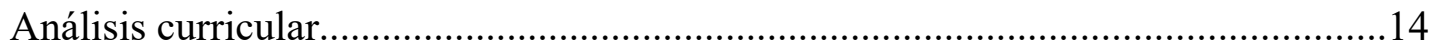

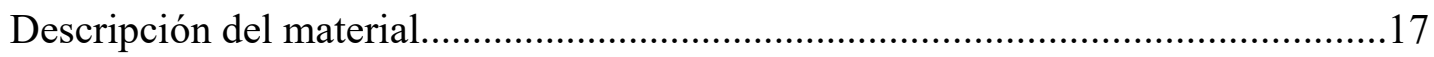

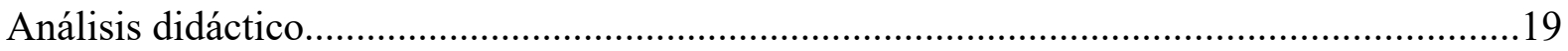

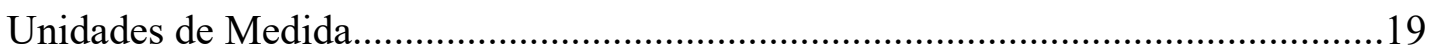

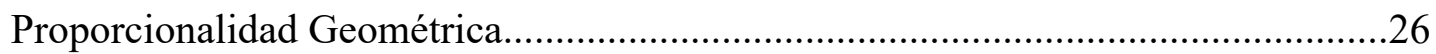

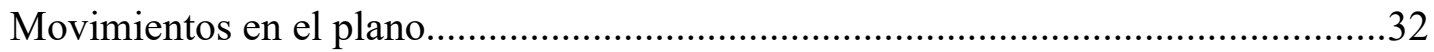

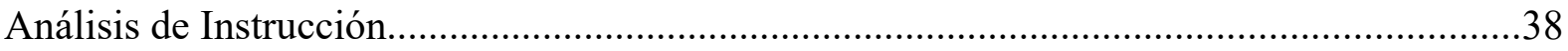

TAREA 1: Creamos nuestro Sistema de Medida: longitud, superficie y volumen....38

TAREA 2: Proyecto de intervención en el patio: diseño y escala.

TAREA 3: Azulejos de la Alhambra: transformaciones y teselaciones.

TAREA 4: Teorema de Pitágoras para triángulos isósceles y rectángulos.

TAREA 5: Teorema de Thales.

TAREA 6: Reflexiones sobre triángulos isósceles/rectángulos y cuadrados.

TAREA 7: Tangram: el puzzle de la pajarita.

TAREA 8: Sólidos platónicos y arquimedianos. .66 
TAREA 9: Desarrollo del cubo .68

Evaluación .72

Atención a la Diversidad .74

Trabajo con las dificultades.

Enriquecimiento educativo .75

Niveles de complejidad de la tarea. .76

Bibliografía. .77

Anexo I .79

Objetivos Generales .79

Contenidos, criterios de evaluación y estándares de aprendizaje evaluables .80

Anexo II.

Tarea 3: Sistema de cuerdas y tizas para el trabajo manipulativo con movimientos en el plano y piezas Tutakaboo.

Tarea 3: Fichas de mosaicos

Tarea 7: Ficha de desarrollo del cubo. .93

Tarea 8: Ficha de sólidos platónicos.

Tarea 8: Ficha de sólidos arquimedianos

Tarea 9: Ficha de desarrollo del cubo. .94

Anexo III .95

Tarea 1: Resultados de conservación de volumen. .95 


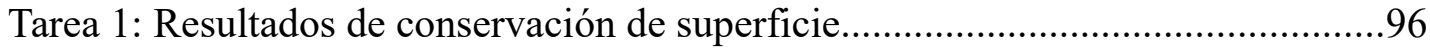

Tarea 9: Ejemplos de soluciones a la actividad: Desarrollos del cubo.......................97 


\section{Justificación y marco teórico}

\section{Objetivo de este trabajo}

El Trabajo Fin de Máster parte de un material, Tutakaboo, codiseñado por la autora, para su implementación en dinámicas de aula y tareas docentes con el objetivo de trabajar el Sentido Espacial y de la Medida en el alumnado de Enseñanza Secundaria Obligatoria, de forma manipulativa e intuitiva.

En este primer apartado, nos centraremos en los componentes de los sentidos matemáticos espacial y de la medida, así como en el análisis curricular dentro del marco normativo español y autonómico. Por último se cerrará con una descripción del material utilizado.

\section{Sentido Espacial y de la Medida}

La educación actual se ha orientado con la finalidad de formar a los estudiantes en competencias que les permitan emplear y poner en práctica los conocimientos adquiridos en las situaciones reales a las que se enfrentan o se encontrarán a lo largo de su vida. Esta competencia supone un aprendizaje a largo plazo en el conjunto de los niveles educativos obligatorios.

Para Lupiañez y Rico (2015), la competencia matemática, esa puesta en práctica de los conocimientos matemáticos, debe ser "racional, reflexiva y coherente", y llevarse a cabo en una "variedad de situaciones y contextos". Esa competencia matemática está íntimamente relacionada con el sentido matemático escolar, pues es este sentido el que "expresa y concreta las formas de conocer, comprender y usar las matemáticas que son necesarias para adquirir esa competencia matemática básica" (p.44). Las facetas en las que hay que incidir durante los años de la Educación obligatoria se concretan en estos cuatro puntos:

- Conocer, representar, comunicar, ejemplificar y usar los contenidos matemáticos.

- Identificar y describir situaciones en que los conceptos y procedimientos implicados se pueden poner en juego considerando sus condicionantes.

- Resolver problemas y cuestiones usando variedad amplia de estrategias en diferentes contextos.

- Cultivar una actitud crítica y constructiva para validar y contrastar los razonamientos seguidos y las soluciones encontradas. (Lupiañez y Rico, 2015, p. 45)

Atendiendo a la organización de los contenidos curriculares, estos autores identifican 
cuatro campos que configuran el sentido matemático:

- Sentido numérico.

- Sentido espacial.

- Sentido de la medida.

- Sentido estocástico.

Para la contextualización del Sentido Espacial y el Sentido de la Medida utilizaremos el texto de Flores y Rico (2015). Pese a ser un libro centrado en el alumnado de Primaria, tras el análisis curricular y los estándares y criterios aplicables a los diferentes niveles de la ESO (Anexo I), se considera que los componentes y directrices marcadas para el desarrollo de estos sentidos en nuestro alumnado de Secundaria son totalmente aplicables. Así, por ejemplo, dentro del Sentido Espacial, relacionado con ubicación y movimiento, encontramos los contenidos de movimiento en el plano y mosaicos, en $3^{\circ}$ de la ESO ; o en los diferentes cursos, los contenidos de áreas y volúmenes y su aplicación en la resolución de problemas, conectados con los componentes elementos geométricos y relaciones geométricas. En cuanto al Sentido de la Medida, es fundamental en secundaria trabajar con la experiencia en la medida y la estimación, cuya base se encuentra en el reconocimiento de las cualidades a comparar y la compresión del proceso de medir; y que como se verá más adelante, es de gran importancia para trabajar los errores y dificultades más habituales en el alumnado de secundaria.

En este TFM nos vamos a centrar en el Sentido Espacial y de Medida, como bases fundamentales que deben desarrollarse en el alumnado para adquirir y reflexionar los contenidos de geometría que se plantean en los diferentes cursos de la Enseñanza Secundaria Obligatoria. Conocer y trabajar los componentes de ambos sentidos va a dotar a los estudiantes de herramientas internas para la aplicación de los contenidos y el desarrollo de estrategias en los problemas cotidianos a los que se tengan que enfrentar a lo largo de su vida.

\section{Sentido Espacial}

Para Flores, Ramírez y del Río (2015), el Sentido Espacial es "un modo intuitivo de entender el plano y el espacio, para identificar cuerpos, formas y sus representaciones, que implica manejar relaciones y conceptos de geometría de forma no convencional, incluyendo la habilidad para reconocer, visualizar, representar y transformar formas geométricas". (p.29)

Estamos hablando por tanto de la adquisición de capacidades o competencias que 
debe adquirir el alumnado para desenvolverse en el mundo. Para trabajarlas en el aula hay que tener en cuenta que el sentido espacial tiene cuatro componentes:

- Conocer propiedades de formas y figuras. Incluye identificarlas a través del nombre, la definición y diversas representaciones, definirlas, construidas, caracterizarlas, identificar y proponer contraejemplos, etc. (...)

- Reconocer y establecer relaciones geométricas: Consiste en apreciar cualidades en las formas y cuerpos geométricos, como la congruencia, simetría, igualdad o equivalencia, características que permiten clasificarlas y diferenciarlas, etc. (...)

- La ubicación y los movimientos son elementos dinámicos de la geometría. Manejar estos conceptos consiste en disponer de referentes para situar los elementos en el plano y espacio, conocer y saber llevar a cabo los movimientos, así como detectar regularidades o los elementos que resultarían invariantes al moverlos. (...) (Flores et al., 2015, p.130-131)

- Visualización, como componente transversal.

\section{Destrezas de visualización}

Esta destreza la componen tanto la orientación como la visualización. El trabajo en el aula de estas habilidades debe tener como meta que el alumnado sea capaz de razonar con imágenes y poder llevar a cabo la resolución de problemas. Por ello es fundamental el uso de materiales manipulativos, que ayuden al estudiante a "descubrir relaciones espaciales con los elementos que componen su entorno", atendiendo al desarrollo de:

- Orientación: la orientación espacial es la destreza para comprender cómo están dispuestos los elementos en el espacio, y recordarlos sin confusión adoptando diferentes perspectivas. (...)

- Visualización: de modo general, entendemos que la capacidad visual en la geometría consiste en un amplio conjunto de imágenes, capacidades y habilidades necesarias y útiles para elaborar, analizar, transformar y comunicar información relativa a las posiciones entre figuras, objetos y modelos geométricos. (Flores et al., 2015, p.132-

Es imprescindible que, durante el proceso de enseñanza/aprendizaje, la destreza de visualización se vaya desarrollando a la par que se adquieren los conceptos geométricos formales. Ambos se conectan y retroalimentan, logrando que el alumnado adquiera un “dominio geométrico funcional, es decir, que facilite la ubicación en el espacio y el 
reconocimiento de relaciones espaciales y geométricas".

En la Figura 1 se muestran los puntos clave que trabajaremos en este TFM con el fin de que los estudiantes puedan desarrollar las competencias buscadas en el sentido espacial.

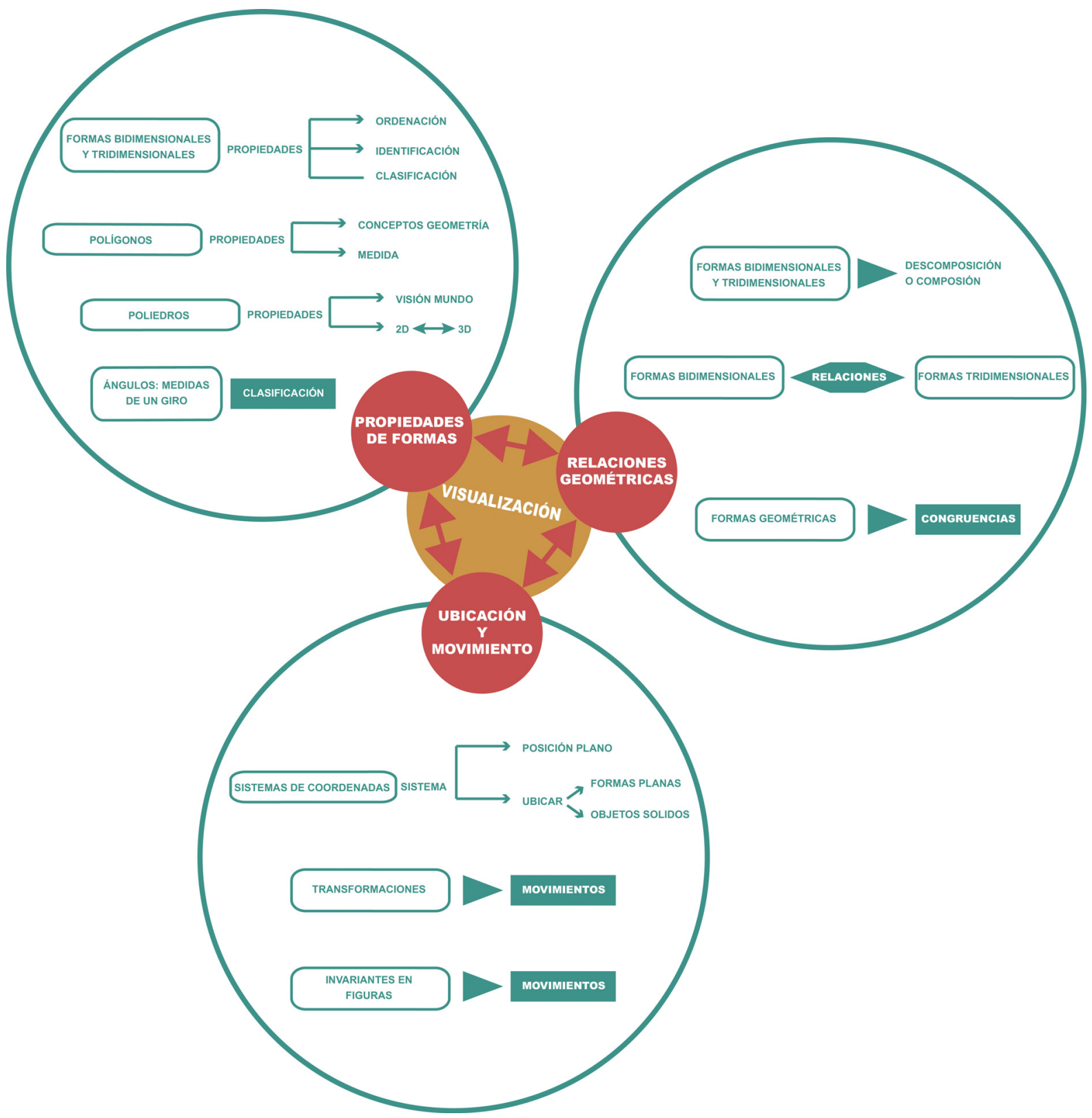

Figura 1. Esquema de componentes, su conexión y puntos clave a desarrollar. Fuente: adaptada de Flores et al. (2015)

Durante el proceso de enseñanza-aprendizaje la integración y conexión entre los tres componentes tiene que darse de forma continua, para ello la enseñanza debe basarse no sólo en la memorización de definiciones sino también en la comprensión de los conceptos clave. En ese sentido juega un papel fundamental la representación gráfica y la utilización de imágenes, de forma que el alumnado pueda interiorizar los conceptos y las definiciones con esa doble naturaleza. 


\section{Sentido de la Medida}

Moreno, Gil y Montoro (2015), nos hacen reflexionar sobre la complejidad del proceso de medida de una magnitud en los estudiantes. Un proceso "que se inicia con la construcción de la magnitud y se completa con sus instrumentos, sus técnicas de medida y las estrategias para su estimación" (p.151). El grado de comprensión de estos elementos en el alumnado y como se conectan entre sí muestra el desarrollo del Sentido de la Medida.

\section{Reconocimiento de cualidades comparables y medibles}

El primer paso para trabajar el concepto de medida parte de proporcionar a los estudiantes la capacidad de observar y percibir qué cualidades entre objetos pueden compararse. Para ello hay que generar experiencias y estímulos, que trabajen en el alumnado los procesos de abstracción de cualidades o atributos de los objetos imprescindibles para la adquisición de destrezas de medición.

Una vez seleccionadas esas magnitudes las tareas se centrarán en la comparación. En algunos casos es precisa la manipulación de objetos, en otros la percepción visual..., y en ocasiones requiere de actividades concretas que permitan interiorizarlas, como en el caso del tiempo. Siempre hay que trabajar con los estudiantes la verbalización de las comparaciones y el uso de vocabulario específico: largo-corto, ancho-estrecho, etc.

El trabajo de comparación debe conducir "a establecer un orden entre objetos, de acuerdo con una cualidad" (Moreno et al., 2015, p.152). Para ello podemos trabajar la comparación directa (colocando los objetos próximos), o la utilización de referentes e intermediarios (comparación de volúmenes sumergiendo objetos en agua). En esa comparación se ordenarán de mayor a menor valor de esa cualidad, se trabajará la comprensión de la transitividad, cuando haya tres o más objetos, para terminar encontrando los que coinciden por su valor en ese atributo.

Al llegar a la equivalencia de objetos de acuerdo con una cualidad, podemos clasificarlos por su coincidencia respecto al valor en una misma magnitud, lo que se denomina cantidad de magnitud, y sus valores son cantidades.

\section{Comprensión del proceso de medir}

Como se ha visto en el apartado anterior, comparando atributos se llega de forma natural a la necesidad de utilizar referentes, es decir, la utilización y el conocimiento de unidades para medir. 
El primer paso a dar en el aula será el uso de unidades antropomórficas (palmo, paso...) por ser sencillas de utilizar, estar disponibles y formar parte de nuestra cultura. Con ellas los estudiantes adquieren el significado del proceso de medir.

A continuación se verá la necesidad práctica de tener unas medidas consensuadas y estandarizadas que eviten errores al comunicarnos: las unidades convencionales. Es muy importante trabajar la imagen visual de las unidades, para que los estudiantes vayan desarrollando un buen sentido de la medida que les permita elegir las unidades idóneas para cada objeto.

El proceso de medir una cantidad sigue las siguientes etapas:

- Escoger una cantidad fija, que se llama unidad de medida

- Reiterar esta unidad tantas veces como sea preciso, sobre el objeto a medir

- Contar el número de veces que se ha iterado

- Asignar al objeto ese número, indicando a continuación la unidad utilizada

- La medida de una cantidad expresa las veces que ésta contiene a la unidad. (Moreno et al., 2015, p.155)

\section{Desarrollo de estrategias para estimar}

Se define estimar como la habilidad de apreciar sin la ayuda de instrumentos la cantidad de medida de un determinado elemento. Esta capacidad de estimar debe trabajarse en las aulas porque va a ser fundamentar en el alumnado para la aplicación del Sentido de la Medida en su vida diaria y su comunicación verbal. Además, deben ser capaces de decidir cuándo es imprescindible medir y cuándo puede estimarse.

Durante el proceso de estimación se utilizan:

- La unidad que se va a usar.

- El conocimiento de la relación entre esa unidad y otros objetos o unidades familiares.

- El conocimiento de la medida de objetos del entorno.

- Interés por realizar estimaciones lo más precisas posibles. (Moreno et al., 2015, p.156)

Al trabajar la estimación en el aula los estudiantes irán adquiriendo diferentes estrategias. Las tres más utilizadas son:

- Uso de referentes: utilizando cantidades conocidas.

- Trocear: dividir en partes más pequeñas y manejables.

- Fraccionar: dividir en partes iguales. 


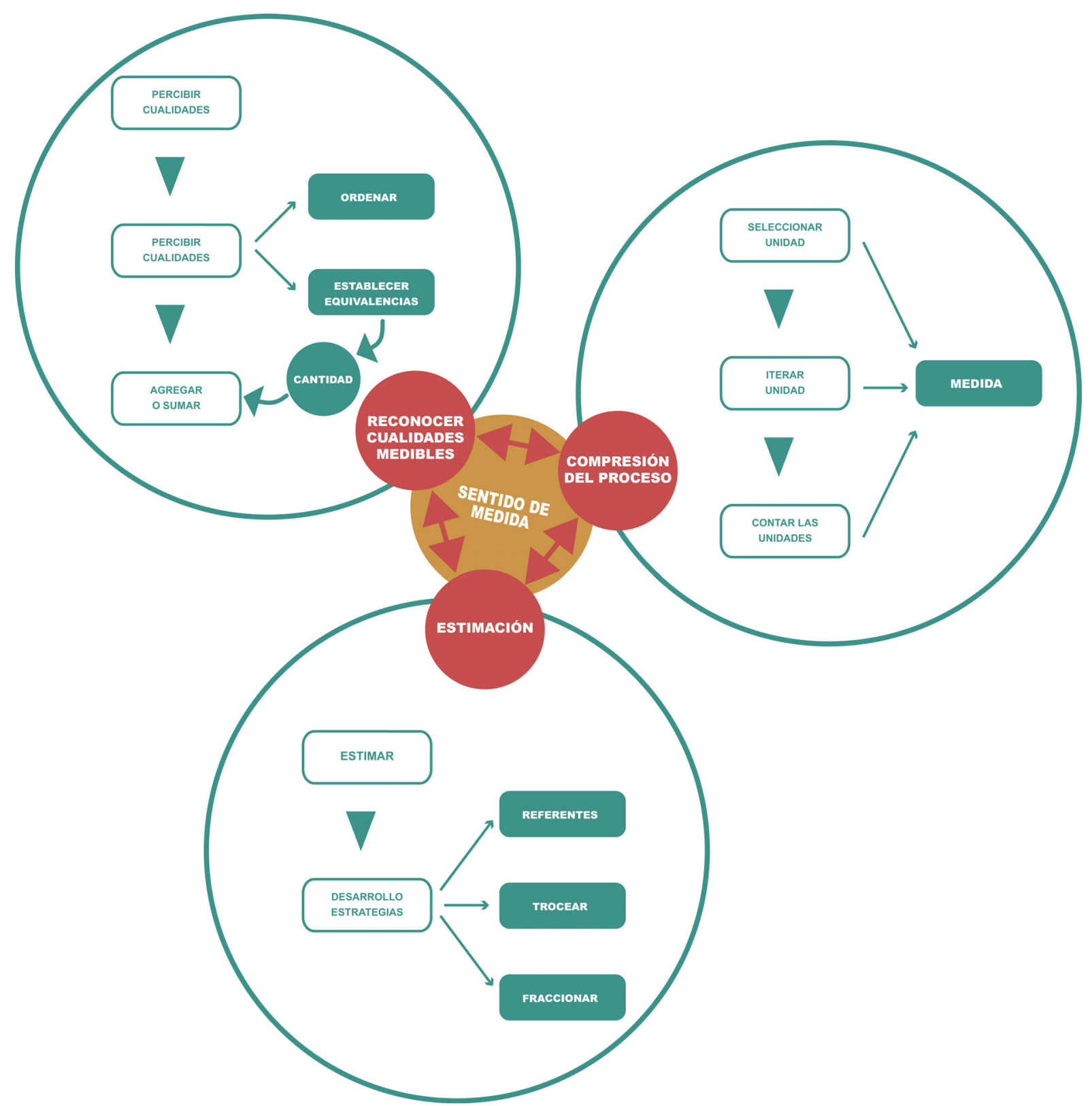

Figura 2. Esquema de componentes del Sentido de la Medida.

Fuente: adaptada de Moreno et al. (2015) 


\section{Análisis curricular}

La asignatura de Matemáticas es una materia troncal que se imparte en cada uno de los cursos de la ESO, aunque a partir de tercero ofrece dos opciones atendiendo al enfoque curricular que desee trazar el alumnado.

Las Matemáticas han formado parte de la cultura desde civilizaciones tan antiguas como la egipcia o desde el nacimiento de la cultura occidental como en la Grecia clásica, jugando un papel fundamental en el desarrollo y los avances de la humanidad. Por lo tanto, "podemos hablar del patrimonio matemático de la humanidad, que debemos conservar, divulgar y actualizar para adaptarnos y dar respuesta a las nuevas ofertas y necesidades profesionales." (BOJA 2016, p.203)

Hoy en día, adquirir conocimientos en esta materia es clave en un mercado laboral complicado y lleno de incertidumbres, en el que nos estamos encontrando con una gran demanda de profesionales vinculados a las matemáticas fundamentales para el actual mundo globalizado y de la información: probabilidad, análisis cuantitativo, espacialidad... La razón se encuentra en que "las matemáticas contribuyen de manera especial al desarrollo del pensamiento y razonamiento, en particular, el pensamiento lógico-deductivo y algorítmico, al entrenar la habilidad de observación e interpretación de los fenómenos, además de favorecer la creatividad o el pensamiento geométrico-espacial.” (BOE 2015,p.407) Estos aspectos tienen aplicación en numerosos contextos y áreas, especialmente en el ámbito científico y tecnológico, por lo que son muy versátiles.

La Unión Europea, como recoge el RD1105/2014, considera que la competencia matemática es clave en el desarrollo de los individuos al trabajar la capacidad de desarrollar y aplicar el razonamiento matemático en la resolución de problemas en la vida cotidiana. Por otro lado, fomentar el pensamiento matemático en el alumnado ayuda en la adquisición del resto de competencias, su desarrollo intelectual y mejora su forma de desenvolverse en el ámbito personal y social.

Para el análisis curricular, se ha analizado a nivel estatal el Real Decreto 1105/2014, de 26 de diciembre, por el que se establece el currículo básico de la Educación Secundaria Obligatoria y del Bachillerato y dentro de la Comunidad Autónoma Andaluza la Orden de 14 de julio de 2016, por la que se desarrolla el currículo correspondiente a la Educación Secundaria Obligatoria en la Comunidad Autónoma de Andalucía, se regulan determinados aspectos de la atención a la diversidad y se establece la ordenación de la evaluación del proceso de aprendizaje del alumnado. 
El estudio engloba los cuatro cursos de la ESO y para $3^{\circ}$ y $4^{\circ}$ las modalidades Académicas y Aplicadas.

\section{Objetivos generales y estrategias metodológicas en la normativa vigente.}

Los Objetivos Generales que marca la comunidad andaluza (BOJA 2016, p. 189-211), aunque se desglosan para cada curso y modalidad se repiten debido a su carácter amplio y genérico, puesto que buscan "desarrollar en los alumnos y alumnas las capacidades", en definitiva el saber hacer, las competencias. Como en este TFM nos centramos en el Sentido Espacial y de la Medida, se ha considerado, atendiendo a dichos objetivos, conseguir en el alumnado:

- "Identificar las formas y relaciones espaciales que encontramos en nuestro entorno, analizar las propiedades y relaciones geométricas implicadas y ser sensible a la belleza que generan, al tiempo que estimulan la creatividad y la imaginación." (BOJA 2016, p.19)

- Tener una actitud positiva hacia las matemáticas e integrar sus conocimientos en el conjunto de saberes, para ser aplicados de forma creativa, analítica y crítica.

- Valorar las matemáticas dentro de la cultura andaluza.

Los objetivos extraídos del BOJA pueden consultarse en el Anexo I de este documento.

Por otro lado, también dentro de la Normativa de Andalucía, se aconseja utilizar unas estrategias metodológicas basadas en un proceso de enseñanza-aprendizaje competencial, así como transversal, dinámico e integral. Dentro de estas orientaciones se recomienda la utilización de contextos geométricos y especialmente en el Bloque de Geometría y la introducción de dinámicas que favorezcan la experimentación a través de la manipulación (tangram, geoplanos...). Se hace una llamada a establecer relaciones con otros ámbitos como la arquitectura o el diseño y fomentando las alusiones a la historia y cultura andaluza.

Además, se destaca que "la utilización de metodologías como el ABP (Aprendizaje Basado en Problemas), formulando preguntas al alumnado a partir de las cuales desarrollarán su aprendizaje, trabajando con técnicas de aprendizaje cooperativo, o el ABI (Aprendizaje Basado en la Investigación) a través de la resolución de problemas, son muy útiles a la hora de elaborar tareas relacionadas con la semejanza, el Teorema de Tales o la proporción cordobesa." (BOJA 2016, p. 144) 


\section{Contenidos, criterios de evaluación y estándares de aprendizaje evaluables}

Las tablas elaboradas a partir de la Normativa Estatal y Autonómica, en las que se recogen los Contenidos, Criterios de Evaluación y Estándares de Aprendizaje Evaluables seleccionados pueden consultarse en el Anexo I de este documento.

En este Trabajo Fin de Máster se han tenido en cuenta aquellos contenidos y los correspondientes criterios y estándares del Bloque 1 que se fundamentan principalmente en el desarrollo de estrategias, fomento de la investigación, la reflexión y el espíritu crítico. También se resalta el proceso de matematización y modelización en contextos reales o el saber comunicar y compartir.

En cuanto a los contenidos específicos, tras el análisis de la normativa vigente se ha detectado que en la Educación Secundaria Obligatoria no se separa la medida de los contenidos de Geometría: medida de áreas y volúmenes, cálculo de medidas indirectas...

En todos los cursos se repite como objetivo el uso de herramientas informáticas.

Para el Primer Ciclo de Secundaria, la normativa española contempla los contenidos, criterios y estándares a alcanzar al final del ciclo. A nivel andaluz sí se desglosan los criterios para Primero y Segundo de forma individual, a partir de los cuales se pueden extraer los Estándares Evaluables para cada curso (Ver Anexo I).

En Primero de la ESO se trabaja sobre todo el reconocer y describir las propiedades y elementos de las formas planas; y la aplicación de este conocimiento para la resolución de problemas de distancias, perímetros o áreas.

En Segundo de la ESO se amplía el contenido de las propiedades y elementos para introducir los cuerpos geométricos, los desarrollos planos y problemas de cálculo de volumen. Además, estas propiedades son la base para el trabajo de la semejanza, las escalas y la razón de semejanza. Por otro lado se introduce el Teorema de Pitágoras y su aplicación para resolver problemas con longitudes desconocidas.

En Tercero de la ESO encontramos las Matemáticas Orientadas a Enseñanzas Aplicadas y las Académicas. En ambas se trabaja el Teorema de Tales y su aplicación para el cálculo de medidas indirectas o la división de un segmento en partes iguales, aplicando a triángulos los contenidos de segundo de semejanza. También aparecen los movimientos en el plano y su aplicación en obras de arte, la naturaleza o diseños cotidianos. En las Enseñanzas Aplicadas el contenido se amplía para abarcar la geometría plana y del espacio, con problemas de áreas y volúmenes contextualizados.

En Cuarto de la ESO la parte de Geometría sufre una reducción de contenido, 
especialmente en las Matemáticas Académicas. Estas se centran sobre todo en la aplicación de problemas de medida en el mundo físico con cálculo de áreas, volúmenes, medida de longitud y aplicación de semejanza. La parte de Enseñanzas aplicadas se centra en las aplicaciones de los Problemas de Tales y Pitágoras para la resolución de problemas; así como en la utilización de fórmulas para la resolución de problemas de la geometría plana y espacial.

\section{Descripción del material}

Tutakaboo es un juego de construcción a gran escala basado, en la forma de plegado del origami para favorecer la experimentación y el uso intuitivo de la creación de formas planas y volumétricas.

Diseñado por Andrey V. García Corredor y Patricia Medina Quero, con Patente Española ES2559113. Se fabrica en Andalucía y cuenta con el marcado CE.

Fue Premio Nacional de Emprendimiento 2013 por el INJUVE. Se han realizado numerosos talleres de geometría manipulativa en centros de Infantil y Primaria, talleres educativos y familiares en Parque de las Ciencias de Granada, Museo de Memoria Histórica Caja Granada o Noche de los Investigadores 2015, entre otros.

El juego se compone de tres piezas:

- Unión plana.

- Bisagra con dos o tres alas, con giro libre o bloqueado.

- Triángulo isósceles y rectángulo $64 \mathrm{~cm}$ de hipotenusa y $33 \mathrm{~cm}$.
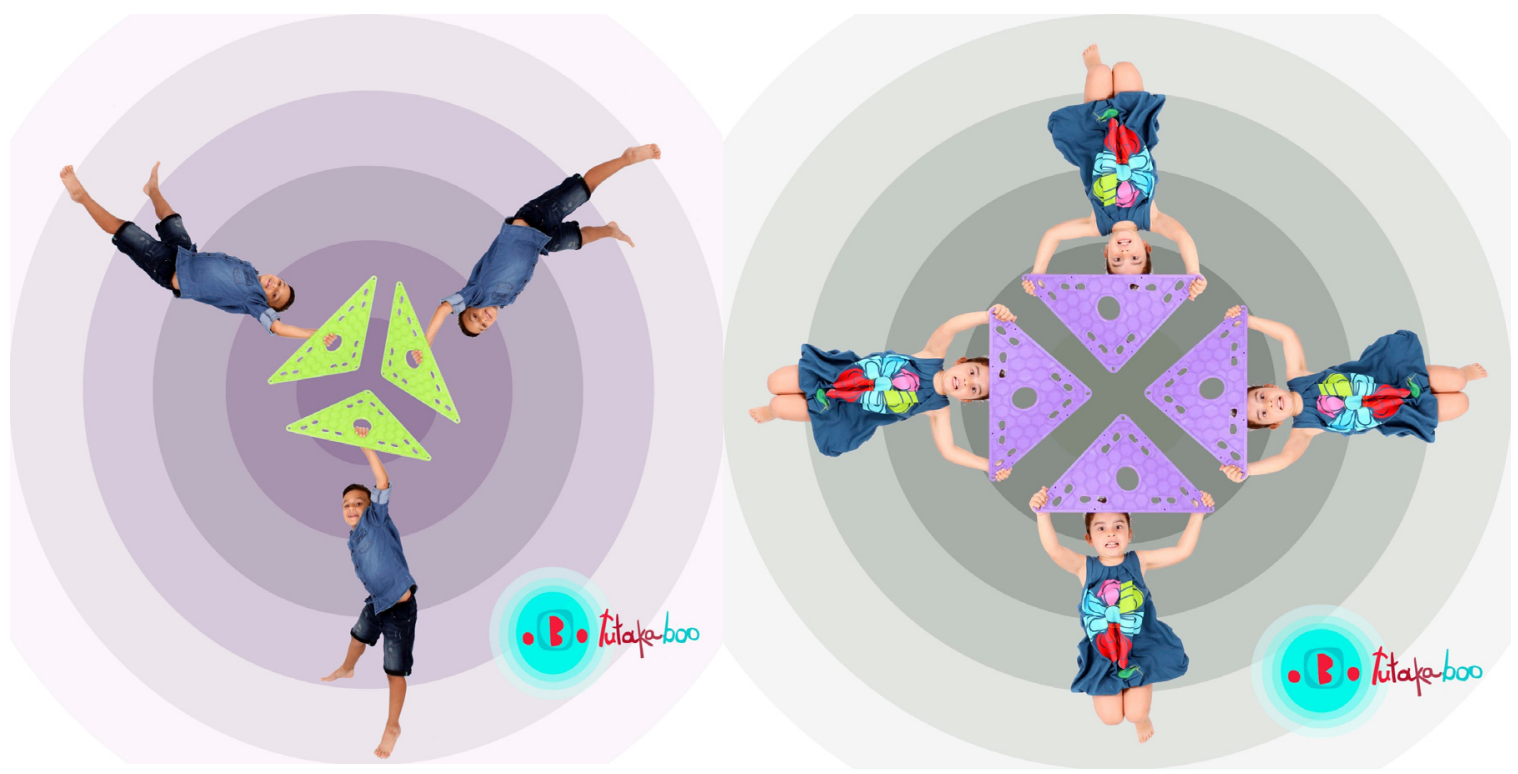


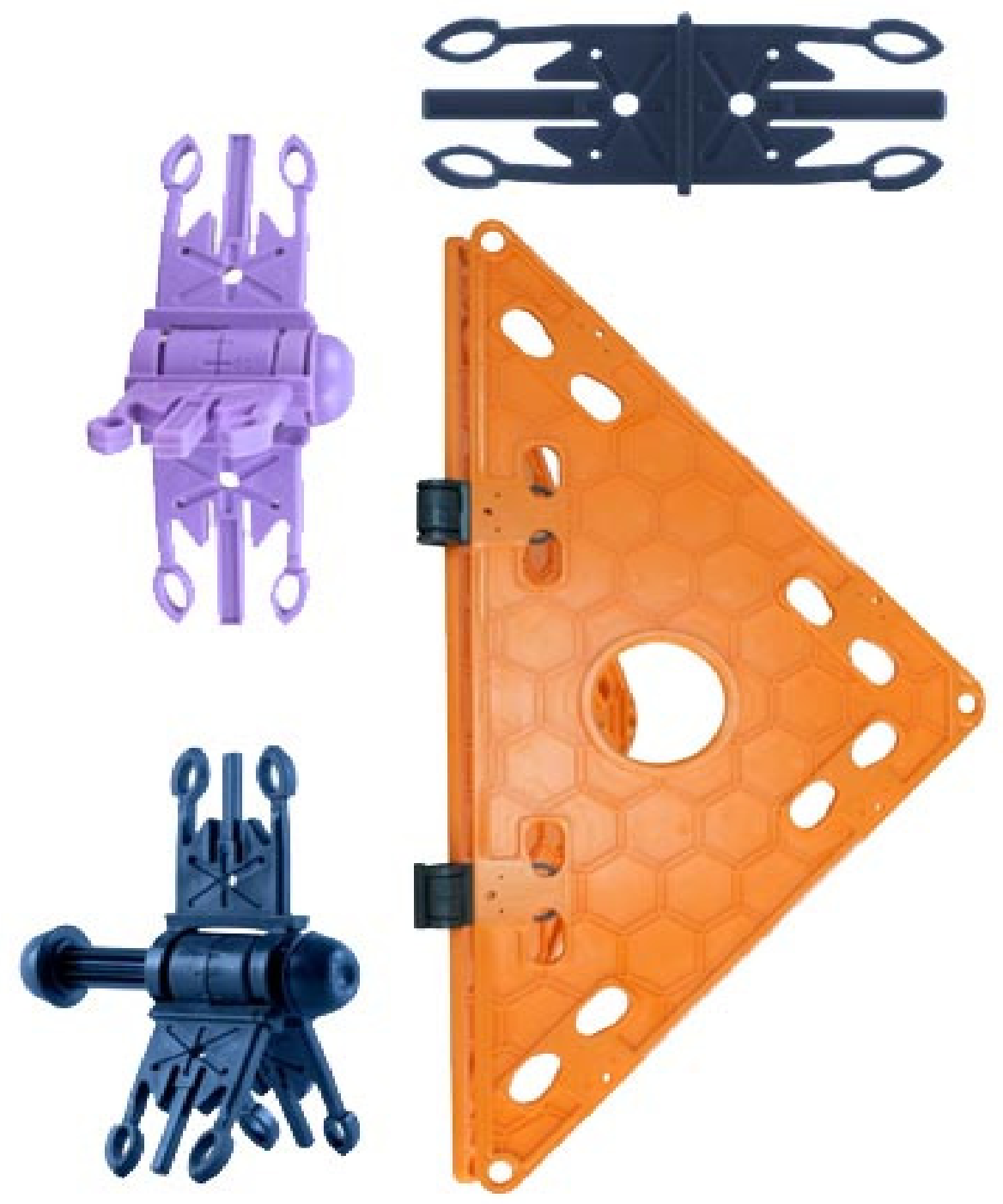

Figura 3. Piezas Tutakaboo

Fuente: https://www.tutakaboo.com 


\section{Análisis didáctico}

Tras el estudio del Sentido Espacial y de Medida, el análisis curricular y atendiendo a las posibilidades educativas de Tutakaboo como material manipulativo para la enseñanza de la geometría, se han considerado tres contenidos didácticos sobre los que se trabajará en este apartado:

- Unidades de Medida.

- Proporcionalidad Geométrica.

- Movimientos en el Plano.

Con la intención de diseñar y analizar tareas asociadas a estos temas, vamos a realizar un análisis de contenido y cognitivo (Moreno y Rico, 2016) sintetizando los apartados más específicos.

En el Análisis de Contenido nos centraremos en identificar el conjunto de conceptos, estructuras, procedimientos y actitudes que engloban los tres bloques didácticos. Se llevará a cabo de forma esquemática, puesto que este TFM se centra en la utilización de un nuevo material didáctico y no en el desarrollo de una UD. El fin principal de este análisis será la búsqueda de relaciones y conexiones entre los diferentes elementos que componen el contenido, de ahí la elaboración de mapas conceptuales.

\section{Unidades de Medida}

\section{Análisis de Contenido}

\section{Conceptual}

Hechos

\section{$\underline{\text { Términos }}$}

Magnitud, unidad de medida, medida, estimación, longitud, superficie, volumen, cambio de unidades, conversión de medidas, medidas no convencionales, medidas convencionales, instrumentos de medida, errores de medida, múltiplos y submúltiplos de unidades, precisión, estimación de una medida.

\section{Notaciones}

$\mathrm{m}, \mathrm{m}^{2}, \mathrm{~m}^{3}$

Notación científica con índice estándar, para números muy grandes o muy pequeños

$3000=3 \times 1000=3 \times 10^{3}$

$0,003=3 \times 10^{-3}$ 


\section{Convenios}

Sistema Internacional de Medida: $M K S$

Sus siete unidades básicas: metro (m), segundo (s), kilogramos (kg), amperios (A), grados kelvin $\left({ }^{\circ} \mathrm{K}\right)$, mol y candela $(\mathrm{cd})$.

Los múltiplos y submúltiplos tienen un salto de 10 veces respecto a la anterior o posterior.

Hay que considerar que la unidad internacional es el metro. Entre múltiplos y submúltiplos el salto es de 10. En el caso de superficie, componemos la unidad $\mathrm{m} \times \mathrm{m}, \mathrm{m}^{2}$, con lo que el salto de de 100. Para el volumen, sería $\mathrm{m}^{3}$ y el salto entre múltiplos y submúltiplos de 1000 .

Hay un convenio de nomenclatura, independiente de los idiomas, para reducir a una o dos letra, mayúsculas o minúsculas, todas las unidades del sistema internacional, así como sus múltiplos y submúltiplos.

\section{$\underline{\text { Resultados }}$}

El grado de exactitud de nuestra medida dependerá del instrumento de medida utilizado y de las unidades con las que se trabaje. Los redondeos y aproximaciones en los cálculos con esas medidas deben ser acordes con el error estimado posible.

Conceptos, estructuras, destrezas, razonamientos y estrategias

En la primera parte de este apartado, se analizan los conceptos y sus relaciones (Fernández, 2016). Se ha considerado que la mejor forma de mostrar la interconexión entre los mismos y transformarlo en un elemento útil para los docentes es la realización de un mapa conceptual. Además, se han incluido las destrezas asociadas al contenido de Unidades de Medida y las estrategias.

Debido a la importancia que el Sentido de Medida toma en este bloque didáctico, se ha plasmado también la relación de los conceptos, estrategias y destrezas con los componentes del Sentido de la Medida. De este modo, se aprecia como este sentido cobra una gran relevancia en el trabajo con la estimación y el proceso de medida, siendo además el conector entre estimación y magnitud el desarrollo de estrategias de medida basadas en la adopción de referentes o el troceado y fraccionado. 


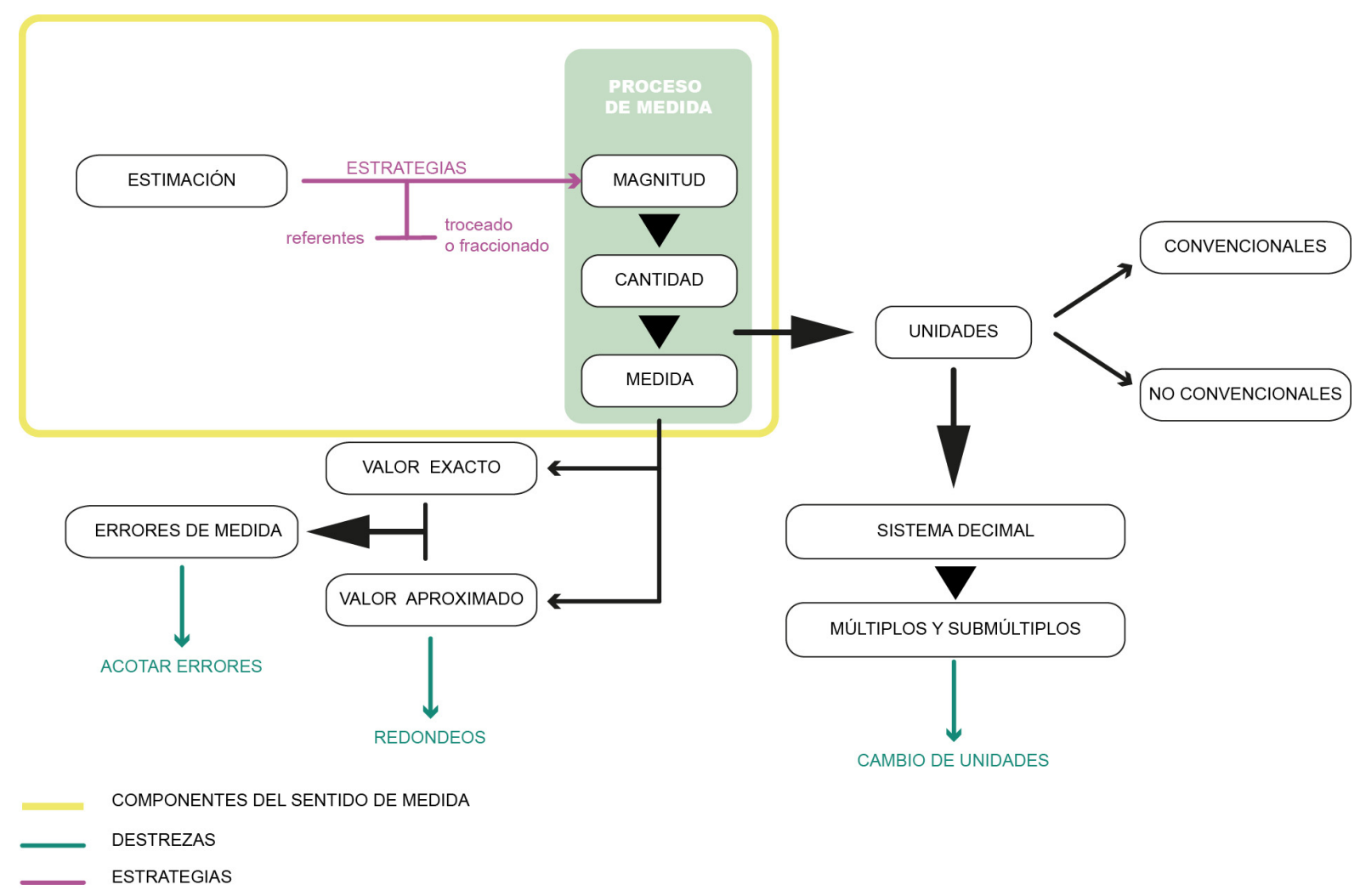

Figura 4. Mapa conceptual de Sistemas de Medida. Elaboración propia. Contenidos, destrezas y estrategias: su relación con el Sentido de la Medida.

Dentro de los razonamientos para Unidades de Medida incluimos los que señala Fernández (2016), asociados a los errores en el proceso de medida:

- "Identificar operaciones a las que aplicar una misma regla de estimación".

- "Deducir cotas de error absoluto y relativo en métodos iterativos" (p.111).

Además introducimos el poder reconocer que una misma medida puede expresarse de forma compleja o incompleja, siendo la misma cantidad.

\section{Sistema de Representación}

Según Lupiáñez (2016) los sistemas de representación permiten trabajar de una forma más profunda el significado de los contenidos y nociones matemáticas. En el trabajo de aula debe fomentarse el uso de diferentes formas de representación para mejorar la comprensión de los contenidos y la adquisición de las destrezas en el alumnado.

Dentro de las Unidades de Medida destacamos:

Escaleras de conversión de medidas

Puede trabajarse con escaleras. Las hay en horizontal y en vertical. Favorecen en el alumnado el cómputo de los "escalones" o veces que deben multiplicar o dividir por 10 para 
hacer la conversión.

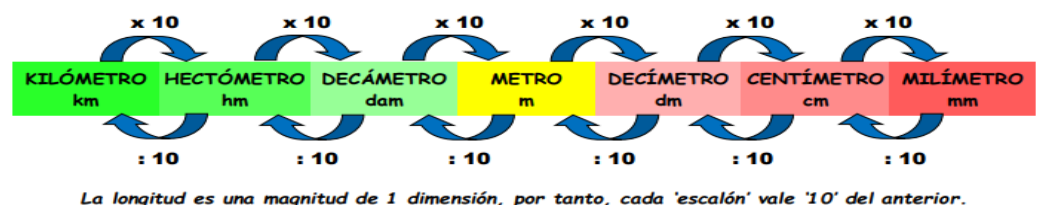

Figura 5. Escalera de conversión horizontal para medidas de longitud.

Fuente: http://www.juntadeandalucia.es/averroes/centros-tic/21003232/helvia/sitio/upload/ 12 _longit_mas_capac_superf_volumen_pa_inet.pdf

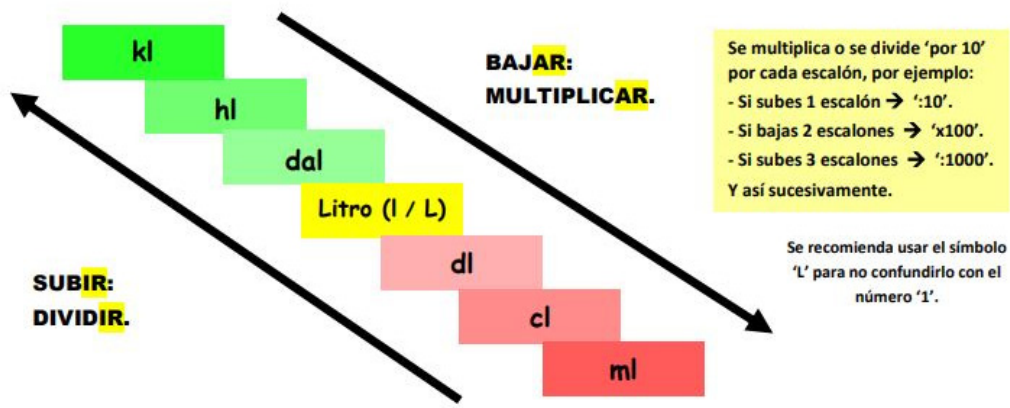

Figura 6. Escalera de conversión vertical para medidas de longitud.

Fuente: http://www.juntadeandalucia.es/averroes/centros-tic/21003232/helvia/sitio/upload/ 12 _longit_mas_capac_superf_volumen_pa_inet.pdf

\section{Ábacos de conversión de medidas}

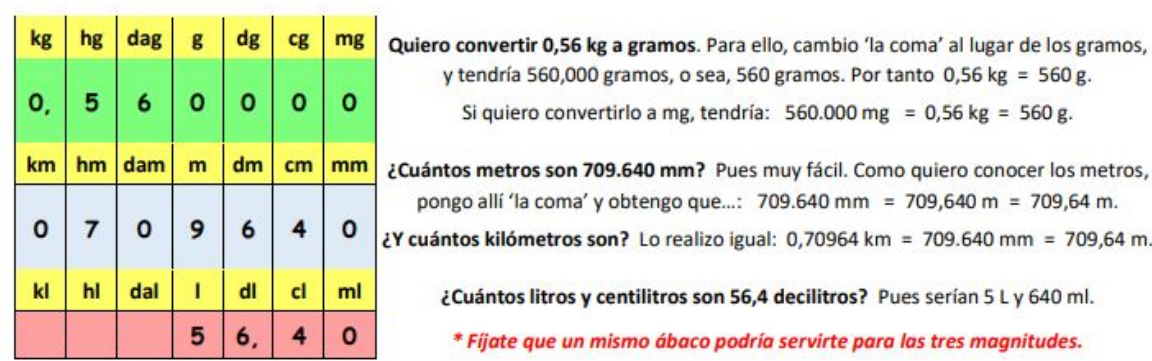

Figura 7. Ábaco de conversión de medidas.

Fuente: http://www.juntadeandalucia.es/averroes/centros-tic/21003232/helvia/sitio/upload/1 2 _longit_mas_capac_superf_volumen_pa_inet.pdf

Representación de longitud, superficie y volumen

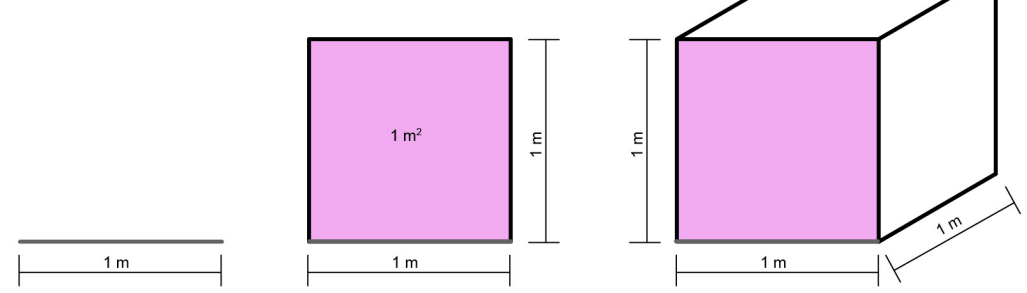

Figura 8. Relación entre unidad de longitud, superficie y volumen. Elaboración propia. 


\section{Focos conceptuales}

Los focos conceptuales seleccionados para Unidades de Medida con los que se trabajará:

Foco 1: Medida y estimación de una magnitud.

Foco 2: Unidades de medida.

Foco 3: Errores de medida.

\section{Análisis Cognitivo}

En este apartado nos adentramos en reflexionar sobre para qué llevamos a cabo nuestra propuesta formativa, qué capacidades vamos a trabajar en el alumnado y sus propósitos. (Flores y Lupiáñez, 2016)

Además de definir los objetivos didácticos y relacionarlos con las Competencias PISA, se han introducido como nuevas variables los componentes del Sentido de la Medida que se trabajan en cada uno de ellos.

\section{Objetivos Didácticos}

Como ya se ha tratado en el primer apartado de Justificación y puede revisarse en el Anexo I, se ha analizado la normativa educativa vigente en España y Andalucía por curso, ciclo y modalidad. En el Anexo I se recogen los Objetivos Generales que están relacionados con el Sentido de la Medida y la Geometría, así como los Contenidos, Estándares y Criterios con los que se trabajan en la ESO.

Tras este estudio, y atendiendo a los componentes del Sentido de la Medida a trabajar se han establecido los siguientes objetivos didácticos agrupados según los Focos:

Foco 1: Medida y estimación de una magnitud

O1. Comparar objetos por cualidades: longitud, superficie y volumen.

O2. Comprender el proceso de medir.

O3. Establecer equivalencias: Sistemas de Medida.

O4. Aprender a desarrollar estrategias de Estimación: distancias, áreas, perímetros y volúmenes.

Foco 2: Unidades de medida

O3. Establecer equivalencias: Sistemas de Medida.

O5. Entender la utilidad y estructura de los sistemas de medida: unidad, múltiplos, submúltiplos. 
O6. Realizar conversiones y cambios de unidades.

Foco 3: Errores de medida

O7. Estimar errores de medida.

El Objetivo 3 se ubica en el Foco 1 y 2 y es el que sirve de conexión entre ambos: de medidas equivalentes se pasa a adoptar una de ellas como unidad de medida y de ahí a la configuración de un Sistema de Medida.

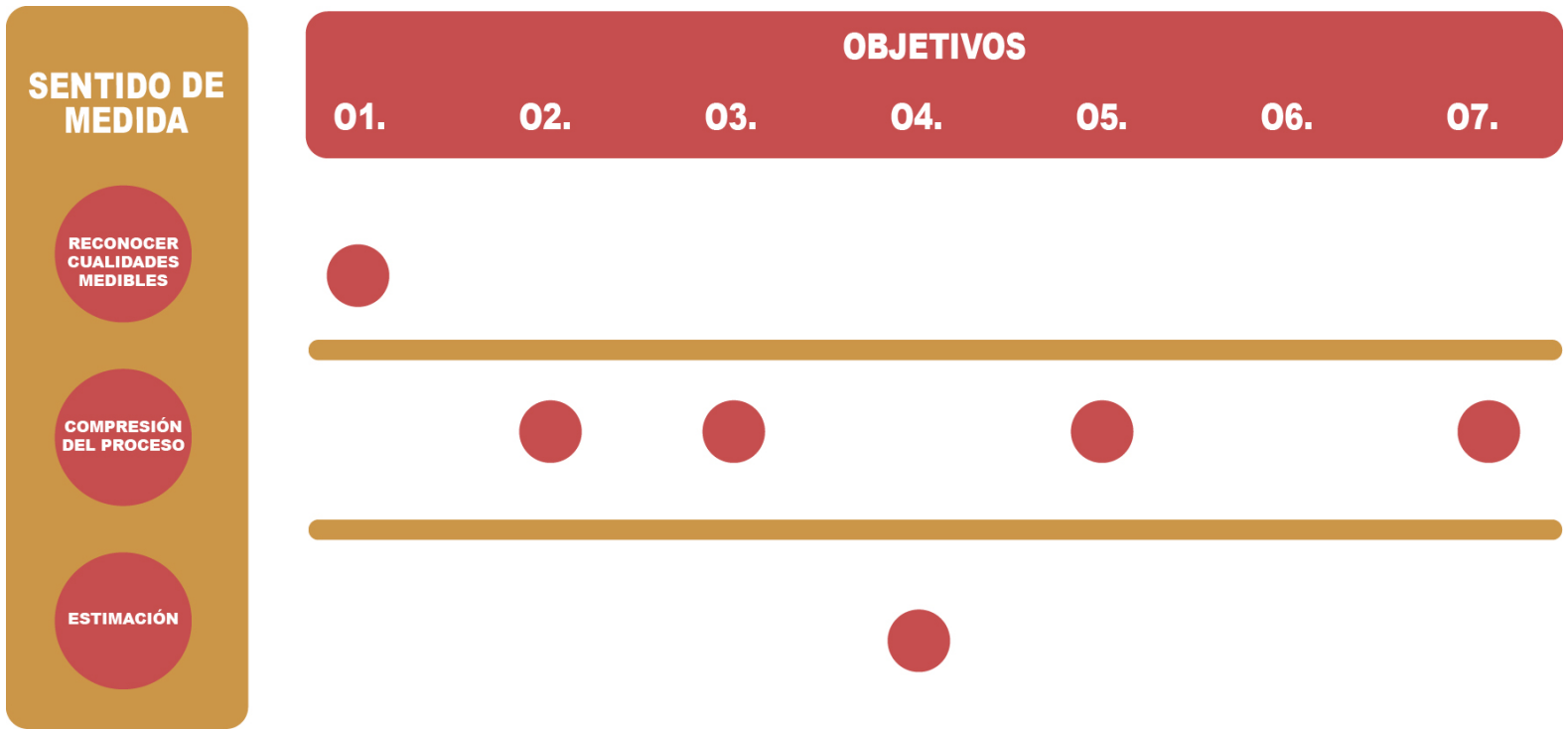

Figura 9. Relación entre Objetivos Didácticos y componentes del Sentido de la Medida. Elaboración propia.
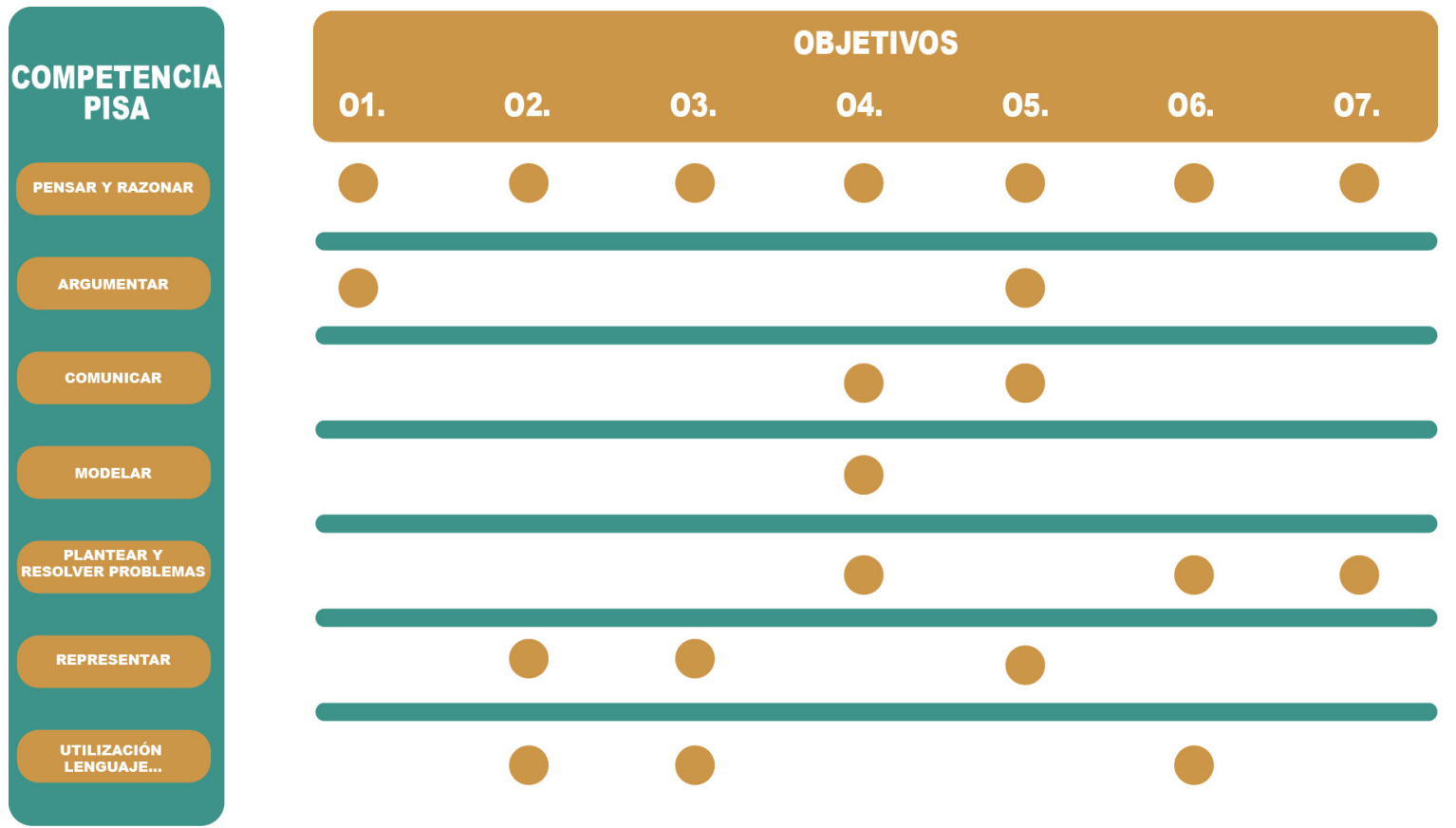

Figura 10. Relación entre Objetivos Didácticos y Competencias Pisa.

Elaboración propia. 
Tras el análisis de los objetivos y su relación con el Sentido de Medida y las competencias, destaca el importante papel que juega la comprensión del proceso de medida. Por otro lado, la competencia pensar y razonar se encuentra en cada uno de los objetivos, siendo también importantes representar y utilización de lenguaje (conocer unidades, múltiplos..., saber representar la realidad en diferentes sistemas), así como su aplicación con la competencia plantear y resolver problemas.

\section{Errores y dificultades}

Se ha realizado una búsqueda de los errores y dificultades en el alumnado dentro de los contenidos del Sistema de Medida. A continuación se destacan los más específicos para cada contenido:

D. 1. Confusión entre perímetro y área. Según Wagman 1982, un tercio de los sujetos investigados confundían estos términos. Los errores típicos detectados :

E. 1.1.: Al calcular área y perímetro a una misma figura, asignar siempre el valor mayor al área.

E. 1.2.: Considerar que si dos figuras tienen la misma superficie también lo es su perímetro.

D. 2. No aprecian la conservación de área y volumen. En 1984, Hart llevó a cabo un estudio que concluía que la conservación del área no la dominaban una cuarta parte de los alumnos de 12 a 14 años.

D. 3. Uso erróneo de los sentidos. Para M.A. del Olmo (1993), gran parte de las dificultades se encuentran en problemas presentes en la percepción de la cualidad a medir, que como ya se a analizado en la justificación, representa el primer paso para comenzar a trabajar el Sentido de la Medida con el alumnado.

D. 4. Uso de instrumentos inadecuados. Es fundamental que los alumnos conozcan diferentes instrumentos, sus aplicaciones e idoneidad de uso.

D.5. Confunden exactitud de las medidas con error de medida.

E. 5.1.: Rechazar las aproximaciones como soluciones válidas.

E. 5.2.: Considerar que un valor entero es más exacto que uno con decimales. D. 6. No contar con las estrategias suficientes para estimar y medir objetos. El desarrollo de estrategias de estimación es otro de los componentes del Sentido de la Medida. 


\section{Proporcionalidad Geométrica}

\section{Análisis de Contenido}

Al igual que hemos realizado con Unidades de Medida, en este apartado nos centraremos en identificar el conjunto de conceptos, estructuras, procedimientos y actitudes para el Bloque de Proporcionalidad Geométrica.

\section{Conceptual}

Hechos

\section{$\underline{\text { Términos }}$}

Razón, proporción, paralelismo, semejanza, segmento, escala, homotecia.

\section{$\underline{\text { Notaciones }}$}

En un polígono se denotan:

- Lados: por letras minúsculas como a, b, c...

- Vértices: por mayúsculas como A, B, C...

Los segmentos: $\overline{A B}$

Los ángulos: $\widehat{A B}$

Los puntos y segmentos proporcionales se denotan con una como: $A B>>A^{\prime} B^{\prime} a / b$ expresa razón

1:100 hace referencia a la escala

El símbolo $\sim$ denota la semejanza de figuras .

\section{Convenios}

$\mathrm{a} / \mathrm{b}$ se lee como a es a b

La razón de semejanza recibe el nombre de escala en planos, mapas y maquetas.

1:100 se lee uno es a 100 .

En una razón, el numerador se llama antecedente y el denominador consecuente.

\section{$\underline{\text { Resultados }}$}

Si la razón de semejanza, $\mathrm{k}$, entre dos figuras:

- $\mathrm{k}>1$, la figura se amplía.

- $\mathrm{k}<1$, la figura se reduce.

\section{Conceptos, estructuras, destrezas, razonamientos y estrategias}

Se ha llevado a cabo un mapa conceptual con los conceptos fundamentales de la Proporcionalidad Geométrica en el que se reflejan las conexiones entre los mismos. Se han incluido las destrezas asociadas y las estrategias. 

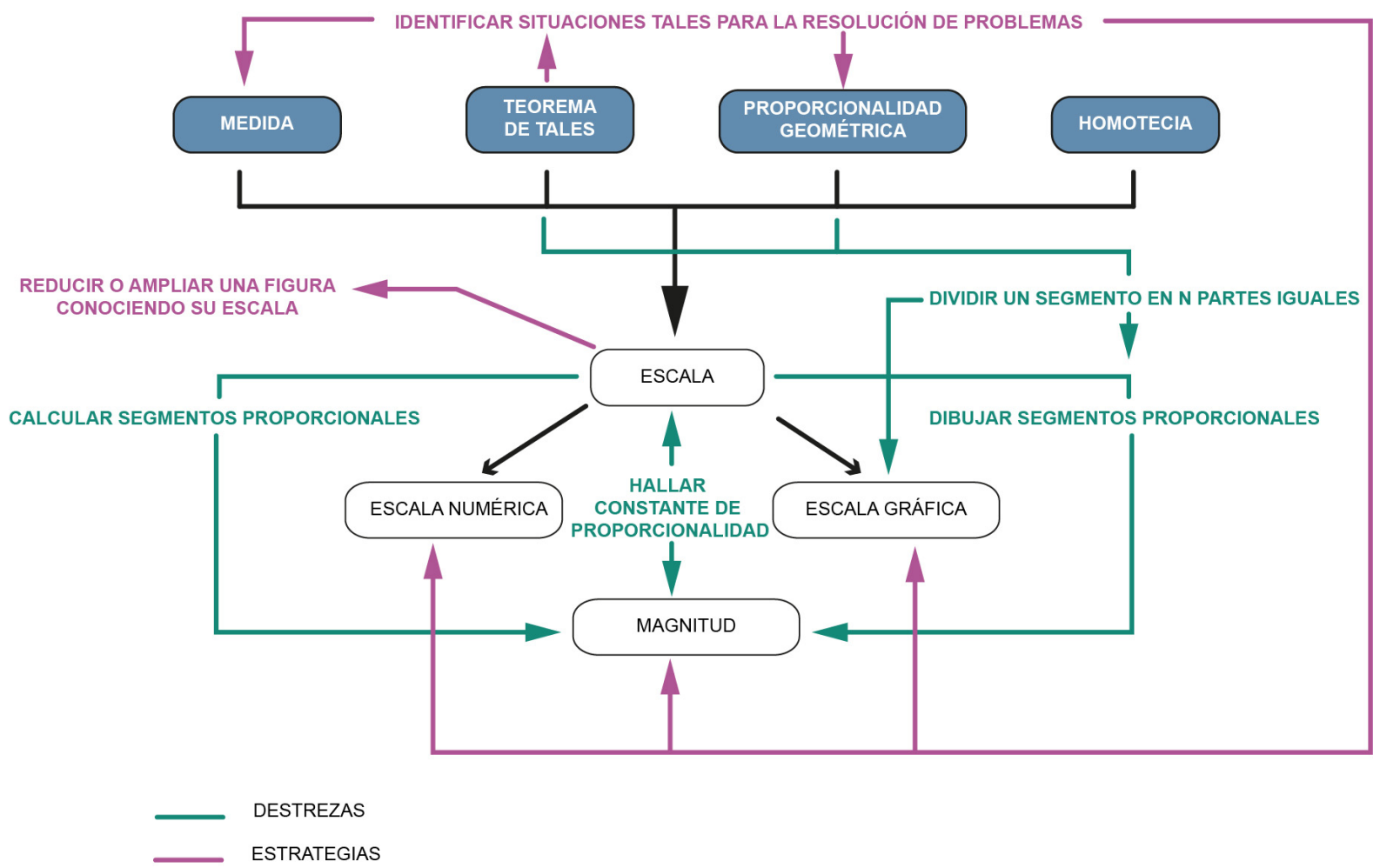

Figura 11. Mapa conceptual: Proporcionalidad Geométrica. Elaboración propia. Contenidos, destrezas y estrategias.

Dentro de los razonamientos para Proporcionalidad Geométrica se han incluido:

- Expresar verbalmente el procedimiento seguido para la resolución de un problema.

- Razonar por qué dos triángulos son semejantes.

- Aplicar triángulos en posición de Thales para el cálculo de segmentos.

\section{Sistema de Representación}

En esta ocasión se han incluido elementos manipulativos y gráficos.

\section{Manipulativos}

\section{Pantógrafo}

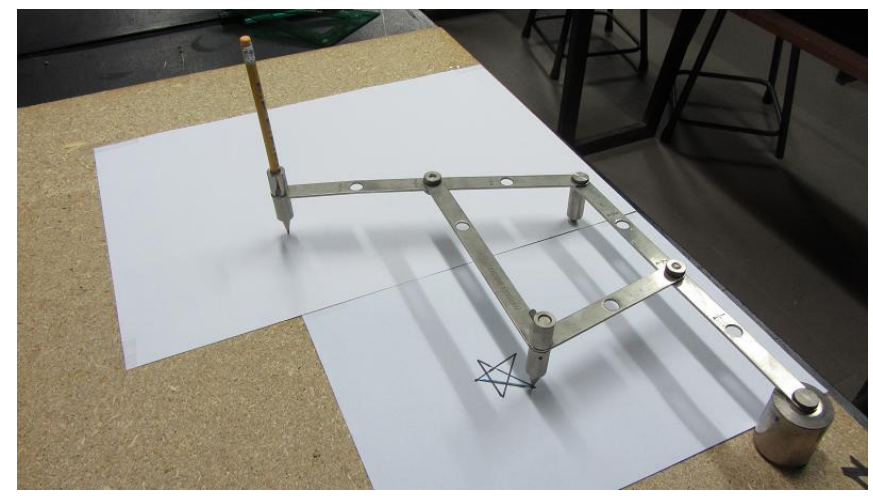

Figura 12. Pantógrafo.

Fuente: https://www.lasalleteruel.es/museo_virtual/pantografo.html 


\section{Escalímetro}

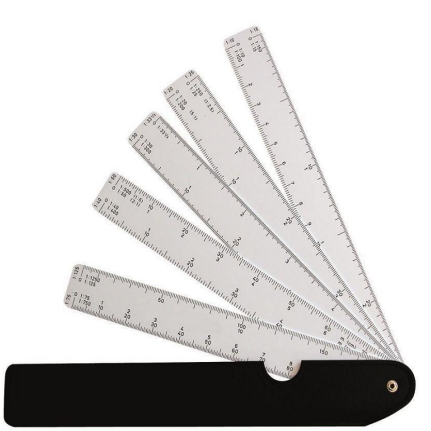

Figura 13. Escalímetro

Fuente: http://www.papeleriakarpet.es/Escalimetro-Abanico-Pardo

\section{Gráfico}

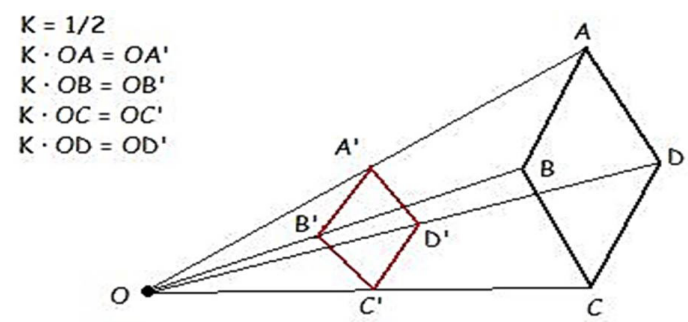

Figura 14. Homotecia

Fuente: http://matematicas-tec31.blogspot.com/2015/08/

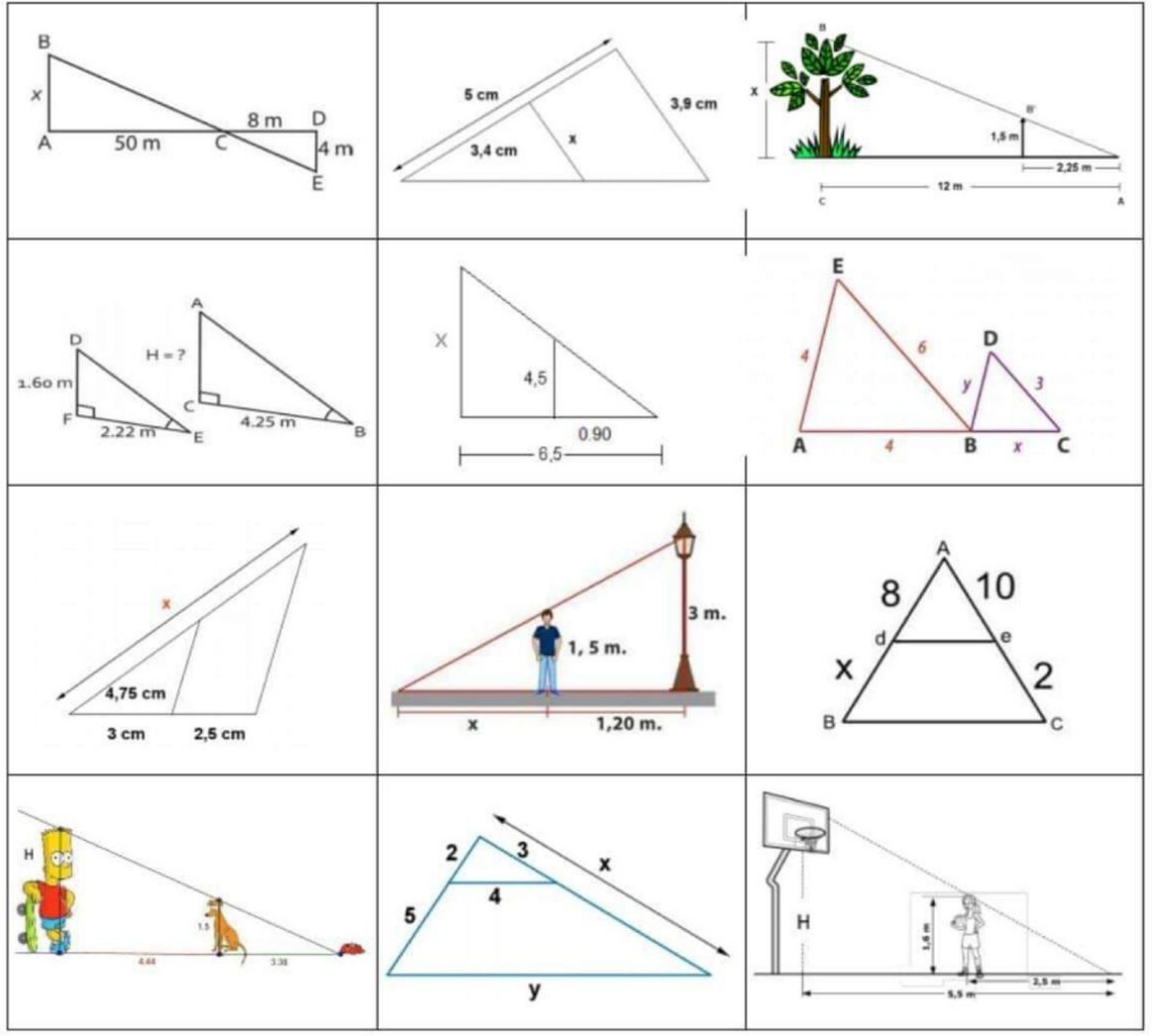

Figura 15. Distintas representaciones del Teorema de Tales

Fuente: https://brainly.lat/tarea/11688009 


\section{Focos conceptuales}

En este bloque didáctico solo se ha considerado un foco:

Proporcionalidad Geométrica.

\section{Análisis Cognitivo}

Como se ha llevado a cabo con el bloque previo, en este apartado se definen los objetivos didácticos y se relacionan con las Competencias PISA. Además, se han introducido como nuevas variables los componentes del Sentido de la Medida y el Sentido Espacial que se trabajan en cada uno de ellos.

\section{Objetivos Didácticos}

En el Anexo se recogen los Objetivos Generales que están relacionados con el Sentido de la Medida y la Geometría, así como los Contenidos, Estándares y Criterios con los que se trabajan en la ESO.

Se han establecido los siguientes objetivos:

Foco 1: Proporcionalidad Geométrica

O1. Integrar los conocimientos matemáticos para la resolución de una situación real de forma creativa, analítica y crítica.

O2. Medir distancias indirectas con Tales.

O3. Medir con instrumentos adecuados.

O4. Construir escalas gráficas utilizando Tales.

O5. Ampliar y reducir figuras geométricas, dada una razón de proporcionalidad.

O6. Determinar magnitudes a partir de una representación, utilizando escalas gráficas y numéricas y viceversa. 


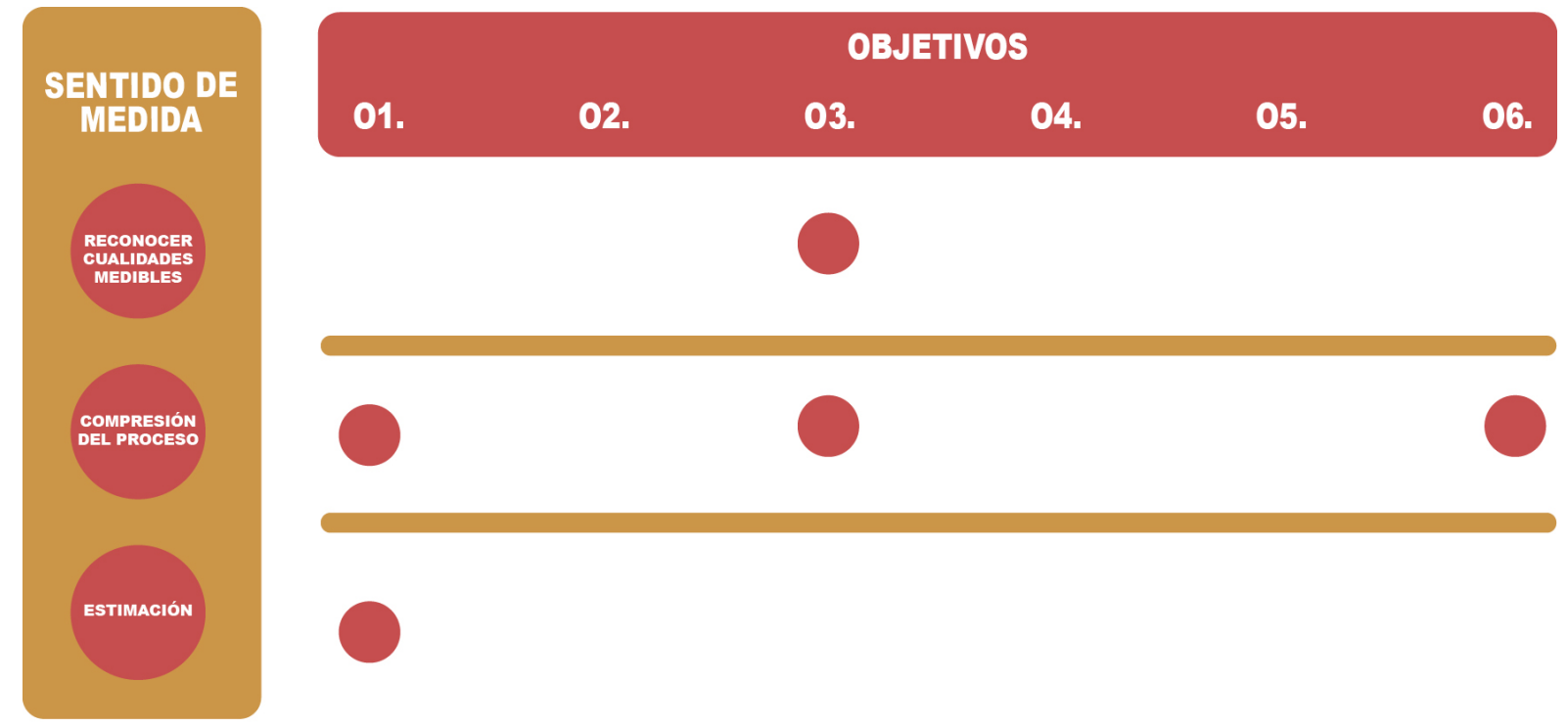

Figura 16. Relación entre Objetivos Didácticos y componentes del Sentido de la Medida Elaboración propia.
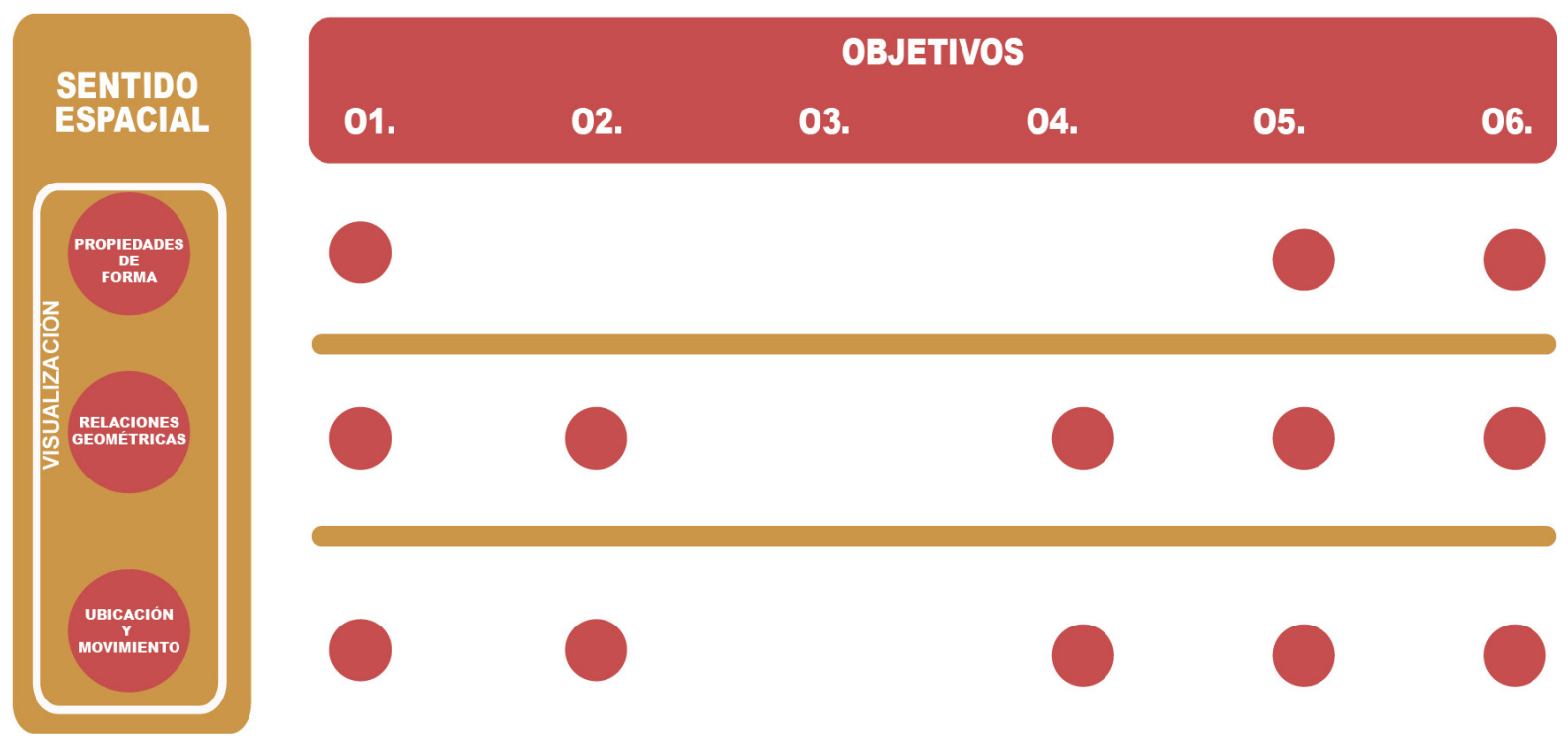

Figura 17. Relación entre Objetivos Didácticos y componentes del Sentido de la Espacial Elaboración propia. 


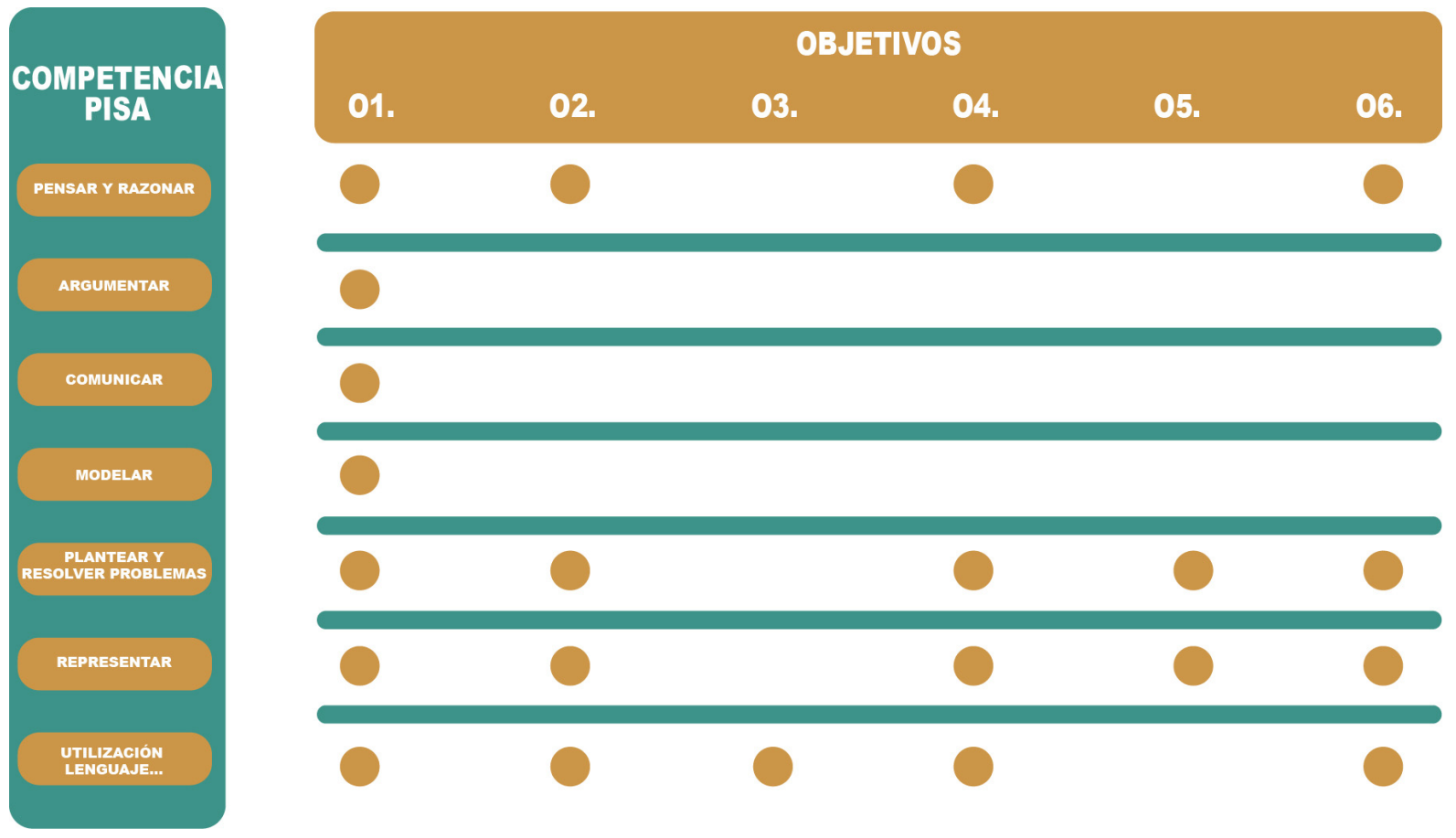

Figura 18. Relación entre Objetivos Didácticos y Competencias Pisa

Elaboración propia.

La componente comprensión del proceso dentro del Sentido de Medida es nuevamente la más significativa. En lo que respecta al Sentido Espacial, la distribución de las componentes es más simétrica o equilibrada. Las competencias que más se trabajan son pensar y razonar junto con plantear y resolver problemas. Ambas están vinculadas al razonamiento y aplicación de los contenidos. Por otro lado, representar y utilización de lenguaje, juegan también un importante papel y son fundamentales para la adquisición de los contenidos.

\section{Errores y dificultades}

Para el desarrollo de este apartado se han tenido en cuenta las experiencias de Gualdrón, (2016) con alumnos colombianos de 14 y 15 años, así como experiencias previas de docentes.

\section{Dificultades}

D.1: Comprender la relación entre escala y proporcionalidad.

D. 2: El alumnado presenta dificultades para entender que puede darse esa proporción entre dos razones o una razón con una constante.

D. 3: Realizar gráficamente ampliaciones y reducciones que guarden la relación entre sus lados. 
D. 4: Reconocer la semejanza entre dos figuras cuando la relación no son múltiplos enteros.

Errores

E. 1: Asociar el concepto de proporcionalidad el hecho de multiplicar magnitudes (doblar, triplicar).

E. 2: No aplicar o deducir correctamente la razón de semejanza.

E. 3: Aplicar Tales cuando no se cumplen las hipótesis.

E. 4: Identificar incorrectamente los segmentos proporcionales.

E. 5: Cuando se calculan distancias indirectas, no interpretar correctamente la distancia a calcular.

E. 6: No aplicar la proporción a todos los lados.

E. 7: Aplicar una relación de tipo aditivo cuando se lleva a cabo una ampliación. Por ejemplo, si al obtener la proporción del primer lado hay que sumar 5, le suman esta cantidad al resto de lados.

\section{Movimientos en el plano}

\section{Análisis de Contenido}

El fin principal de este análisis será la búsqueda de relaciones y conexiones entre los diferentes elementos que componen el contenido, que han quedado plasmadas en los mapas conceptuales elaborados.

\section{Conceptual}

Para el análisis conceptual hemos utilizado el Trabajo Fin de Máster Movimientos en el arte. Teselaciones (Carmona, 2019).

\section{Hechos}

\section{Términos}

Elementos del plano: punto, segmento, recta, plano, distancia, vector (origen, extremo, módulo, dirección y sentido), ejes de coordenadas, componentes coordenadas.

Movimientos geométricos: suma de vectores, movimiento, traslación, composición, giro (centro, amplitud o ángulo), simetría (eje de simetría y centro de simetría). 
Arte: Teselaciones, frisos y mosaicos. (Carmona,2019)

\section{Notaciones}

Puntos: A $(\mathrm{x}, \mathrm{y})$

Vectores: $\overline{A B}=\left(\mathrm{b}_{1}-\mathrm{a}_{1}, \mathrm{~b}_{2}-\mathrm{a}_{2}\right)$, con origen en punto $\mathrm{A}\left(\mathrm{a}_{1}, \mathrm{a}_{2}\right)$ y extremo en punto $\mathrm{B}$ $\left(b_{1}, b_{2}\right)$

Módulo de un vector: $|\bar{v}|$

Traslación de un vector: $\tau(\mathrm{v})$, y subíndices para diferenciar una traslación de otra.

Giro de centro A y amplitud $\alpha$ como: $\theta(\mathrm{A}, \alpha)$ y subíndices para diferenciar un giro de otro.

Simetría de recta r como: S(r).

Letras griegas en minúscula para referirnos a ángulos, comenzando por: $\alpha, \beta, \gamma, \ldots$

\section{$\underline{\text { Convenios }}$}

Ejes de coordenadas: dos ejes perpendiculares entre sí. El horizontal, llamado de abscisas, es el eje X; el vertical, o de coordenadas, es el eje Y.

El sentido de giro positivo es el de las agujas del reloj.

\section{$\underline{\text { Resultados }}$}

Dos vectores son equivalentes cuando tienen el mismo módulo, dirección y sentido. Las transformaciones preservan el tamaño y la forma.

La composición de traslaciones da una traslación.

En una traslación no hay puntos invariantes.

Una composición de giros será un giro sólo si los primeros tienen el mismo centro. Una composición de simetrías no será nunca una simetría. Podrá ser un giro o una traslación.

Conceptos, estructuras, destrezas, razonamientos y estrategias

Para este apartado se ha desarrollado un mapa conceptual. Además, se han incluido las destrezas asociadas al contenido de Transformaciones en el Plano y las estrategias. 


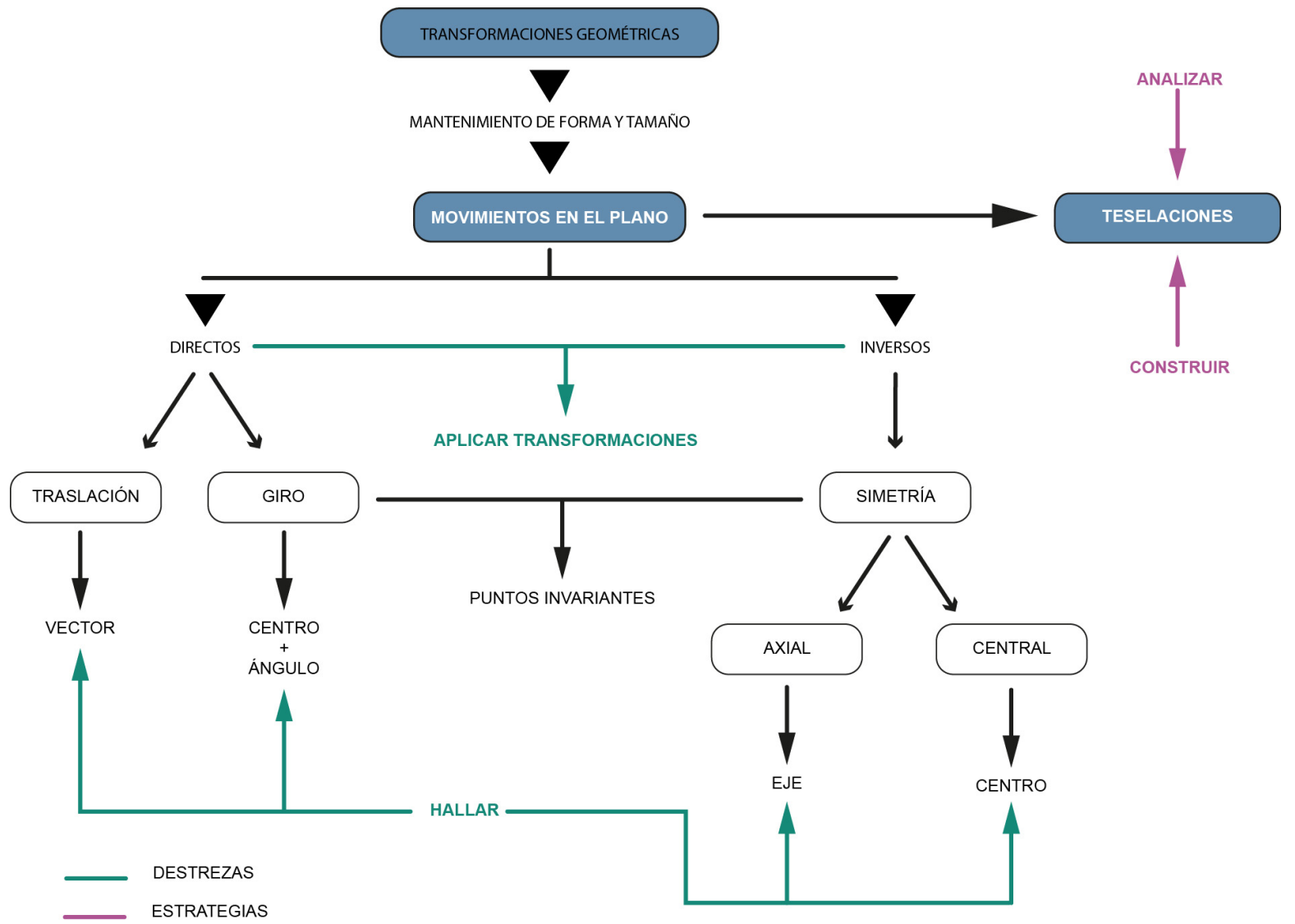

Figura 19. Mapa conceptual de Movimientos en el Plano. Elaboración propia. Contenidos, destrezas y estrategias.

Dentro de los razonamientos incluimos los que señala Carmona (2019) :

- Dadas dos figuras isométricas, reconocer y justificar los movimientos que llevan de una figura a otra.

- Deducir el resultado tras aplicar un movimiento.

\section{Sistema de Representación}

En este bloque de Movimientos en el Plano vamos a distinguir entre:

\section{Registro analítico}

La composición de los movimientos a través de las notaciones matemáticas

$$
\overline{O P}=\overline{O P^{\prime}} \text { y } \widehat{P O P^{\prime}}=\alpha
$$

Registro gráfico

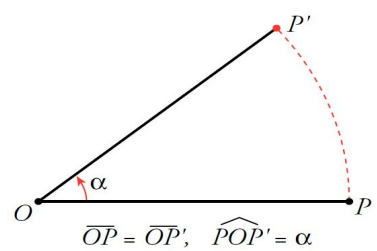

Figura 20. Representación gráfica de un giro con la expresión algebraica Fuente: Libro Anaya $3^{\circ}$ ESO. Adaptación curricular. p. 325 


\section{Representación manipulativa}

Dentro de este apartado encontramos herramientas informáticas como GeoGebra o Cabri y lo que se conoce como dibujo técnico (compás, transportador, reglas, escuadra y cartabón...).

\section{Focos conceptuales}

Los focos conceptuales seleccionados para trabajar han sido:

Foco 1: Trasformaciones en el Plano

Foco 2: Teselaciones

\section{Análisis Cognitivo}

Este apartado incluye para qué llevamos a cabo nuestra propuesta formativa. Además de definir los objetivos didácticos y relacionarlos con las Competencias PISA, se han introducido como nuevas variables los componentes del Sentido Espacial.

\section{Objetivos Didácticos}

En el Anexo I, se ha analizado la normativa educativa vigente en España Andalucía por curso, ciclo y modalidad y se recogen los Objetivos Generales, así como los Contenidos, Estándares y Criterios con los que se trabajan en $3^{\circ}$ de ESO el bloque de las Transformaciones en el Plano.

Tras este estudio, y atendiendo a los componentes del Sentido Espacial a trabajar se han establecido los siguientes objetivos didácticos agrupados según los Focos:
Foco 1: Trasformaciones en el Plano
O1. Identificar figuras congruentes.
O2. Construir y describir la transformada de una figura.
O3. Reconocer: vector, centro, ángulo o eje.
O4. Determinar los elementos invariantes.
O5. Componer movimientos y deducir su resultado

\section{Foco 2: Teselaciones}

O6. Integrar los conocimientos matemáticos para la resolución de una situación real de forma creativa, analítica y crítica. 


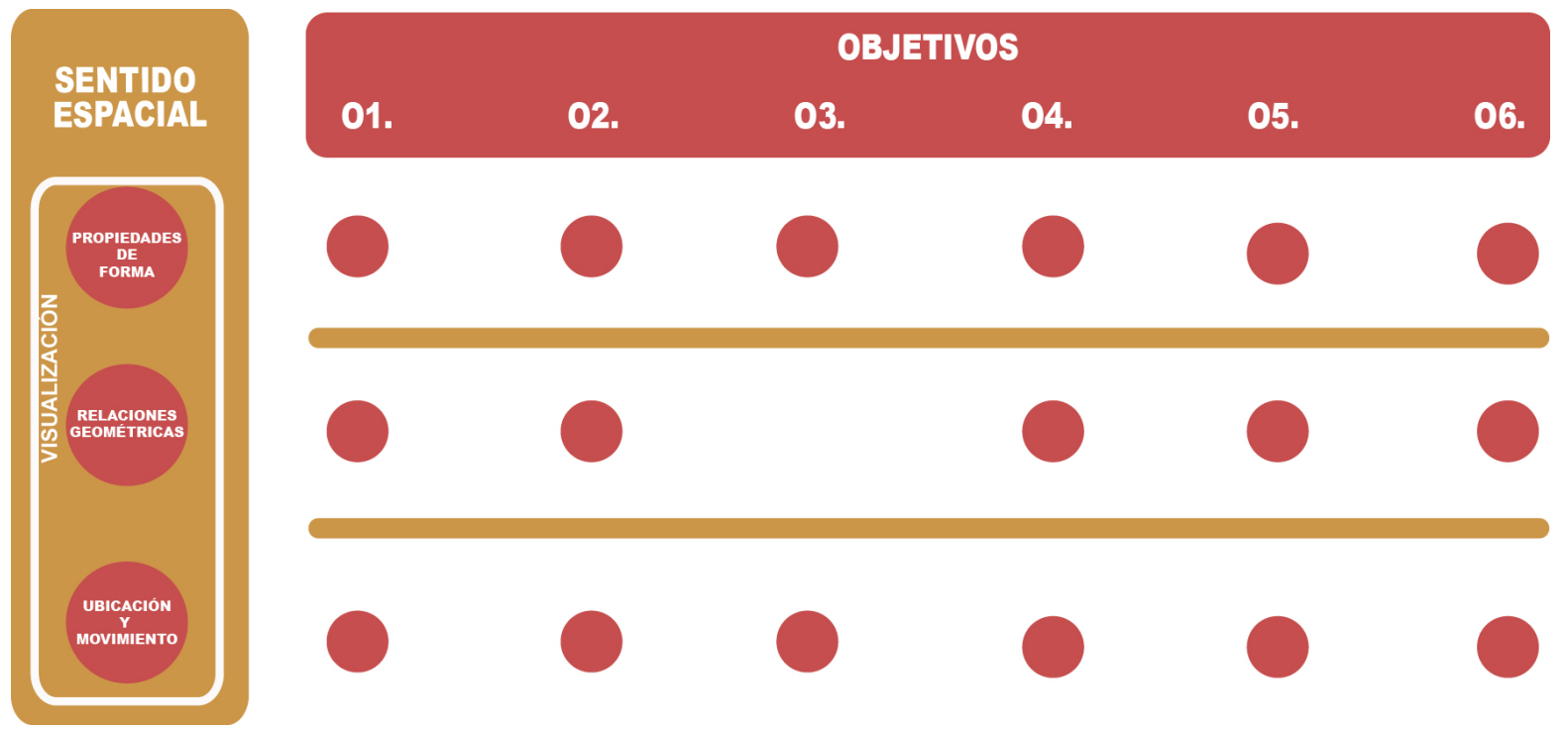

Figura 21. Relación entre Objetivos Didácticos y componentes del Sentido Espacial Elaboración propia.
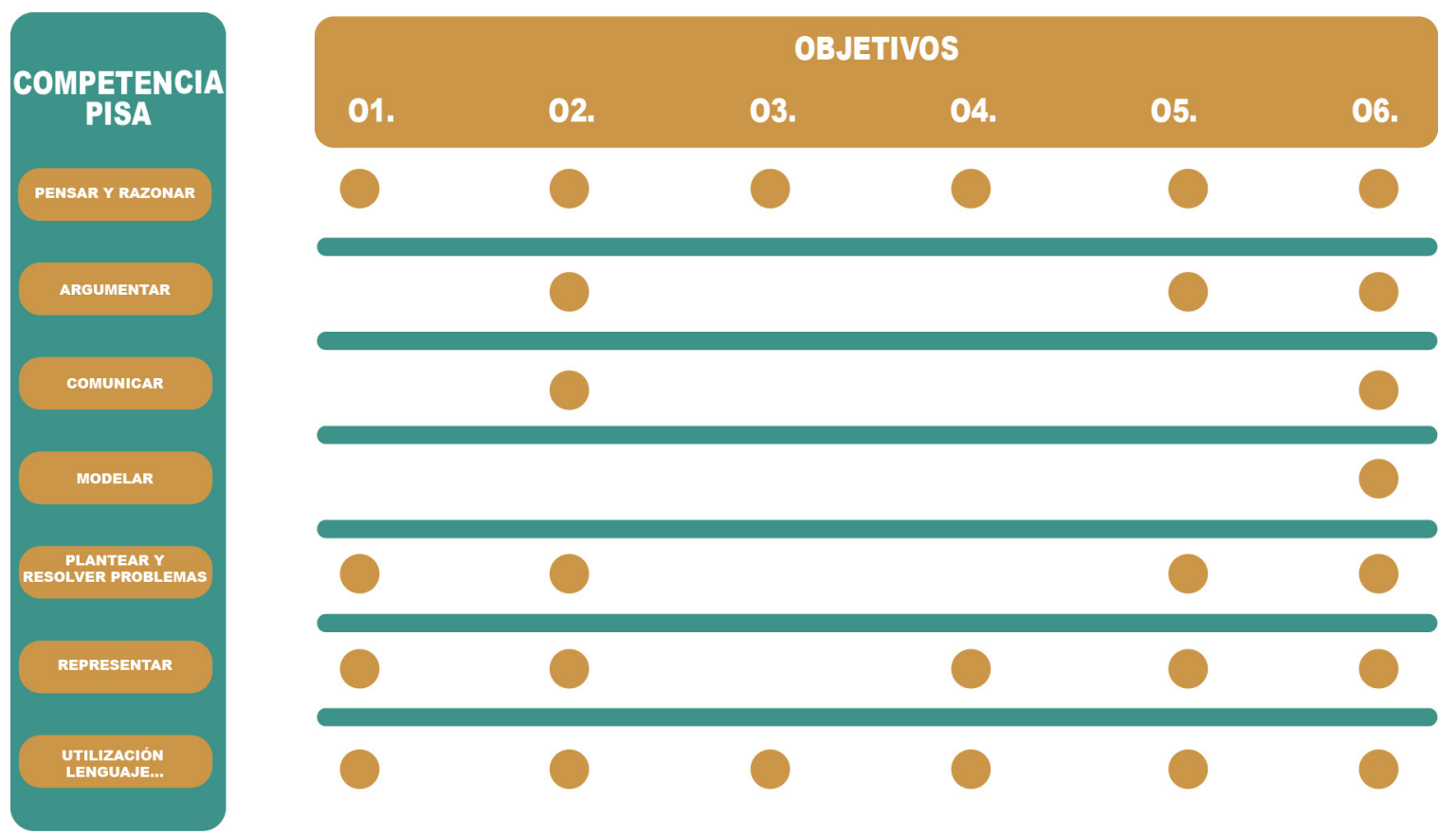

Figura 22. Relación entre Objetivos Didácticos y Competencias Pisa.

Elaboración propia.

Los tres componentes del Sentido Espacial son fundamentales para el desarrollo de los objetivos vinculados a esta unidad de movimientos en el plano. En lo que respecta a las competencias, puede comprobarse que las que siguen entrando en juego de una forma más significativa siguen siendo las de razonamiento (pensar y razonar/ plantear y resolver problemas) y las que están vinculadas a la representación (representar/ utilización lenguaje). 


\title{
Errores y dificultades
}

Para conocer los errores y dificultades más significativos hemos utilizado el Trabajo Fin de Máster El sentido espacial de la enseñanza de la geometría: análisis de un libro de texto (Serrano, 2019)

\author{
Dificultades \\ D.1. Representar imágenes con un eje de simetría que no sea paralelo a ningún eje \\ de coordenadas. \\ D.2. Identificar el ángulo formado por dos figuras congruentes que no se tocan. \\ D.3. Realizar el giro de una figura que no contiene el centro de giro. \\ D.4. Comprender el concepto de vector libre asociado a una traslación. \\ D.5. Realizar transformaciones en las que las imágenes finales se solapan con la \\ figura original. \\ D.6. Realizar traslaciones de formas poligonales con el vector traslación paralelo a \\ uno de sus lados. \\ D.7. Encontrar el motivo mínimo de un mosaico, friso o rosetón.
}

\section{Errores}

E.1. Al realizar una simetría, no mantener las equidistancias al eje entre los puntos y sus respectivas imágenes.

E.2. No respetar la perpendicularidad del segmento que une un punto respecto al eje de simetría y su imagen.

E.3. No reconocer el eje de simetría inclinado y hacer un desplazamiento vertical u horizontal de la figura.

E.4. Realizar el giro como traslación al girar únicamente uno de los puntos de la figura.

E.5. Utilizar sólo los extremos del vector de traslación al desplazar una figura.

E.6. No usar las propiedades matemáticas, sólo las visuales.

E.7. Realizar un movimiento que no conserva forma o tamaño.

E.8. Asociar la propiedad conmutativa a la composición de movimientos. 


\section{Análisis de Instrucción}

Para el diseño y estructuración de las tareas se ha seguido a Moreno y Ramírez (2016) sobre las variables y funciones de las tareas matemáticas, atendiendo a sus clasificaciones y desgloses.

\section{TAREA 1: Creamos nuestro Sistema de Medida: longitud, superficie y volumen}

\section{CURSO: Primero de la ESO.}

Se ha planteado como una tarea significativa, que parte de las nociones de medida que ha desarrollado el alumnado en Primaria para afianzar el Sentido de la Medida mediante el reto de crear un sistema propio de medida que abarque longitud, superficie y volumen. Con esta tarea se pretende que el alumnado profundice en el significado de los conceptos y reflexione sobre las conexiones entre los contenidos desde la experiencia directa y la necesidad de solventar los problemas y retos que se van planteando a lo largo de la tarea. Al mismo tiempo, pretende trabajar con el alumnado la evolución histórica y social del proceso de medir desde el uso intuitivo de medidas no convencionales a la necesidad de establecer un sistema internacional.

Esta tarea ha sido diseñada como proyecto que se articule a lo largo de la unidad didáctica de Medidas de Magnitudes.

Tabla 1. Elaboración propia.

Análisis de Tarea: Creamos nuestro Sistema de Medida.

\begin{tabular}{ll}
\hline Meta & \multicolumn{1}{c}{ ELEMENTOS } \\
\hline Formulación & $\begin{array}{l}\text { Profundizar en el concepto de Sistema de Medida, unidad, múltiplos, } \\
\text { submúltiplos y escalas de conversión. }\end{array}$ \\
\hline "Vamos a crear un sistema de medida de longitud, superficie y volumen, \\
$\begin{array}{l}\text { cuya unidad de longitud es el lado corto del triángulo. ¿Cómo lo hacemos? } \\
\text { ¿ué necesitamos?" }\end{array}$ \\
\hline Recursos & $\begin{array}{l}\text { Piezas Tutakaboo (triángulos y uniones), útiles de escritura, reglas, escua- } \\
\text { dra y cartabón, cartulinas, pizarra digital, patio del centro. }\end{array}$ \\
\hline Agrupamiento & Individual, parejas y grupo. \\
\hline Situación & Aula, domicilio y patio del centro. \\
\hline Temporalización & Varias sesiones de trabajo: 6-7 \\
\hline Contenido & VARIABLES \\
\hline Situaciones & Cantidad. \\
\hline Dificultad & Reflexión. \\
\hline
\end{tabular}




\begin{tabular}{ll}
\hline & \multicolumn{1}{c}{ FASE } \\
\hline Fases & Tarea de desarrollo y cierre. \\
\hline Función & Autorregulación y regulación, síntesis y estructuración. \\
\hline Acción & $\begin{array}{l}\text { Construcción de aprendizaje, apropiación de criterios, relacionar y recapi- } \\
\text { tular. }\end{array}$ \\
\hline Propósito & $\begin{array}{l}\text { Trabajo de estrategias de éxito, autonomía, representación grupal e indivi- } \\
\text { dual. }\end{array}$ \\
\hline Foco & Foco 1: Medida y estimación de una magnitud. \\
& Foco 2: Unidades de medida. \\
& Foco 3: Errores de medida. \\
\hline O1. Comparar objetos por cualidades: longitud, superficie y \\
volumen. \\
O2. Comprender el proceso de medir. \\
O3. Establecer equivalencias: Sistemas de Medida. \\
O4. Aprender a desarrollar estrategias de Estimación: distancias, \\
áreas, perímetros y volúmenes. \\
O5. Entender la utilidad y estructura de los sistemas de medida: \\
unidad, múltiplos, submúltiplos. \\
O6. Realizar conversiones y cambios de unidades. \\
O7. Estimar errores de medida \\
\hline
\end{tabular}

\section{Gestión de la Tarea}

\section{Trabajar la longitud: comparación, estimaciones}

El proyecto comienza con trabajo en gran grupo y las siguientes cuestiones a plantear:

"¿Qué es medir?"

“¿Por qué medimos?”

“No tenemos metros, reglas..., ¿Cómo medimos?"

"iiVamos a medir!!"

Enfocaremos la reflexión sobre los problemas de comunicación de las unidades no convencionales guiando las preguntas:

"Pablo, ¿cuánto mide el ancho de la pizarra? ¿Y para tí?, María."

Se concluirá:

"¿Qué necesitamos para que nos podamos entender mejor y de forma más precisa cuando hablamos de medidas?" 
Respuesta a concluir: "Que todos midamos con la misma referencia: vamos a crear nuestro sistema de medida para la clase."

\section{Tarea para trabajo individual}

Tarea 1.1

"¿Qué se necesita para construir un sistema de medida de longitud?"

\section{La unidad de longitud}

Se comenzará en gran grupo con la puesta en común de la tarea de reflexión individual. El docente guiará la sesión para concluir que las características que debe tener una unidad de medida según Moreno et al. (2015) son:

- Universal, conocida por toda la población o una comunidad.

- Contrastable.

- Inalterable.

- Construible, para adaptarse a diferentes usos y esté a disposición de todos.

Y se enunciará que la unidad elegida es el lado corto del triángulo de las piezas del material Tutakaboo, que ese día se han llevado al aula.

A continuación, en grupos heterogéneos de 4-5 estudiantes se crearán situaciones de medida con esa nueva unidad, se trabajará el tanteo y se hará la comprobación utilizando diferentes piezas alineadas. La intención es reflexionar la idoneidad de una unidad según determinados objetos atendiendo a la cualidad a medir, en este caso la longitud.

La dinámica planteada desembocará en una reflexión en gran grupo que con ayuda del docente enmarcará unas conclusiones:

"Hemos dejado de tener el problema de que el palmo o los pasos de cada uno de vosotros sean diferentes."

"Para un proceso de medida óptimo, la unidad debe ser menor que el objeto a medir sin llegar a que sea tan pequeña que implique un número muy grande de unidades."

"Para llegar a obtener una gran precisión es necesario utilizar distintas unidades (múltiplos y submúltiplos), por los elementos del aula, veremos que lo ideal es hacer submúltiplos."

\section{Cierre}

“Por lo tanto, para afinar la medición debemos hacer partes más pequeñas de nuestra 
unidad".

\section{Tareas para trabajo individual}

Tarea 1.2

Ver un video sobre como dividir un segmento en partes iguales con regla: https://www.youtube.com/watch?v=7UIzCTVZydE

Tarea 1.3

Analizar cómo son los múltiplos y submúltiplos en el Sistema Internacional de Medida y el Sistema Anglosajón de Unidades.

\section{Unidad, múltiplos y submúltiplos}

Se comienza en gran grupo con la puesta en común de la tarea de reflexión para casa. El docente guiará la sesión para tratar las siguientes cuestiones:

"¿Qué diferencias se han encontrado entre el sistema internacional y el anglosajón? Ventajas e inconvenientes."

"¿Qué sistema vamos a adoptar? Decimal u otro."

“¿Cuántos grados de submúltiplos se precisan. En este punto se tratará el tema de errores de medida y la relación de proporcionalidad inversa entre tamaño de unidad y medida: a unidades más pequeñas el resultado de medir es mayor y viceversa?”

“Cuántos múltiplos?”

\section{Cierre}

"Hemos concluido que nuestra unidad tendrá x submúltiplos y x múltiplos".

\section{Construimos un instrumento de medida}

Esta tarea se realizará individualmente. Se llevará a cabo la construcción de una regla rígida de una unidad base (cartulina) y una flexible de 5 unidades (cinta), atendiendo a la división de un segmento en partes iguales.

Una vez en clase, con los instrumentos aportados por los alumnos se trabajará en gran grupo cómo funcionan los instrumentos de medida y los errores de los propios aparatos y unidades.

Posteriormente, en parejas se medirán con sus propios instrumentos diferentes objetos y se analizará el error de cada regla o cinta de medir. 


\section{Unidad de superficie y volumen}

El docente llevará a la sesión piezas triangulares y uniones tanto planas como bisagras. Esta sesión será en el patio del centro educativo.

En grupos de 4-5 alumnos se construirán unidades de superficie y de volumen basadas en el lado corto unidad de longitud establecida. Se reflexionará de forma manipulativa sobre el significado de $\mathrm{X}$ como unidad de longitud, $\mathrm{X}^{2}$ de superficie y $\mathrm{X}^{3}$ de volumen.

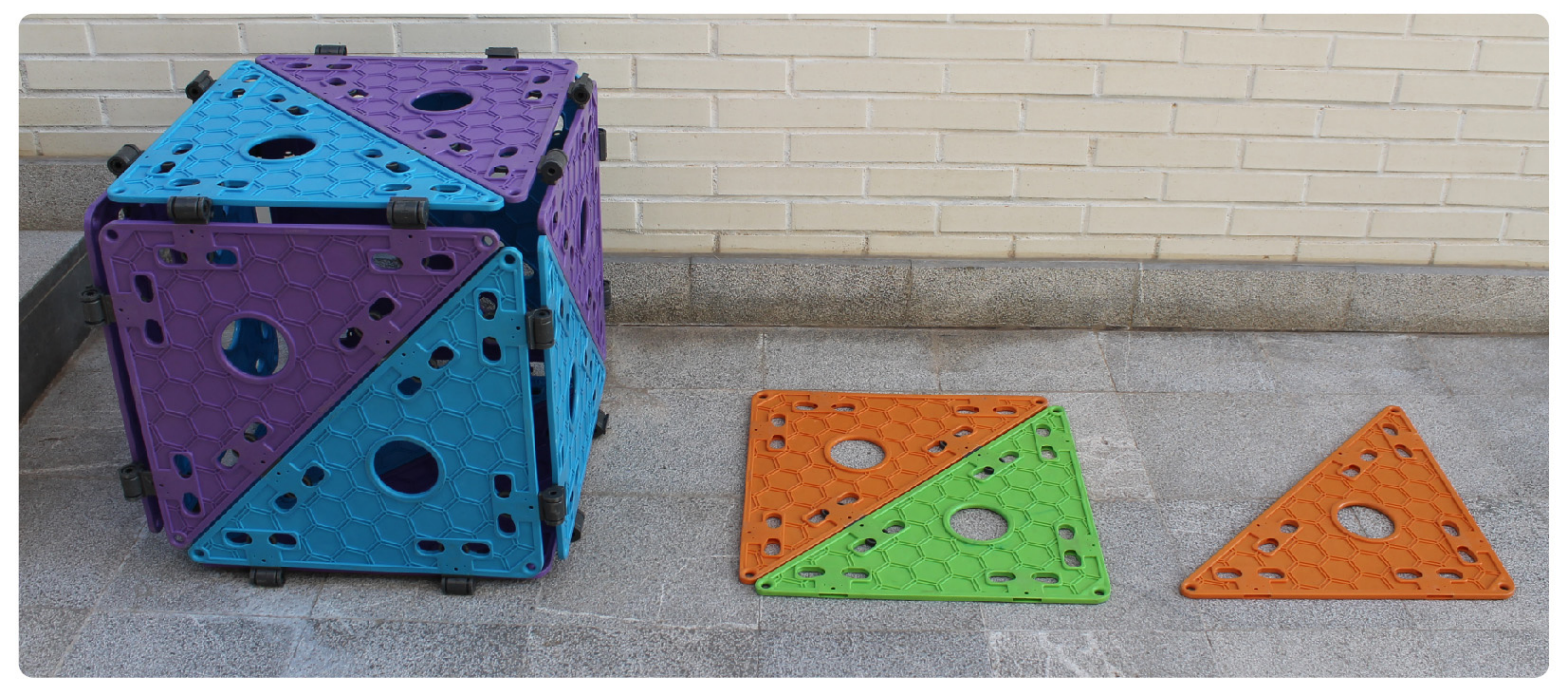

Figura 23. Unidad de volumen, unidad de superficie y longitud

Se procederá a realizar tanteos y estimaciones de medidas de superficie y volumen. Además, se llevarán a cabo diferentes construcciones tanto en superficie como en volumen, en las que gracias a partir del triángulo base, se concluirán las siguientes reflexiones en gran grupo:

"Perímetro y área no crecen por igual."

"Volumen y envolvente no crecen del mismo modo."

Ver Anexo III: Resultados conservación de volumen y superficie.

\section{Tareas para trabajo individual}

Tarea 1.4

Creación de ábacos de conversión con los múltiplos y submúltiplos creados en nuestro sistema.

Tarea 1.5

Razonar y generar un factor de cambio de unidades entre metro, metro cuadrado y metro cúbico y nuestras unidades de longitud, superficie y volumen. 


\section{Ejercitamos las conversiones y cambios de unidades}

En parejas se revisarán y corregirán los ábacos y factores de cambio trabajados de forma individual y se realizarán ejercicios de conversiones y cambio de unidades. Se contrastarán las medidas tomadas con la nueva unidad de medida (el lado corto del material) con las del Sistema Internacional, reflexionando sobre el grado de precisión de ambas.

\section{Cierre Tarea}

En gran grupo se llevará a cabo una reflexión conjunta de todos los puntos tratados en el proyecto. Se enfatizará de forma especial el análisis de los pros y contras del nuevo sistema creado frente al internacional de medida o el anglosajón, así como el uso en general de sistemas no convencionales.

En todas las fases de la tarea será fundamental la utilización de un vocabulario de la medida de forma precisa. Se cuidará la expresión de oral y escrita. Cada estudiante llevará un diario de sesiones en el que resumirá lo trabajado ese día y resolverá las tareas concretas planteadas. Al final de la tarea se entregará un documento recopilatorio, en el que podrá utilizar imágenes y montajes. El formato de entrega debe ser digital, favoreciendo el uso de recursos abiertos y colaborativos como Google Classroom.

\section{Aporte}

La tarea se ha diseñado para proporcionar experiencias significativas que permitan a los escolares escoger referentes de comparación en su entorno e iniciarles en el proceso de uso por iteración. (Moreno et al, 2015, p.161)

El material, permite trabajar de manera manipulativa la longitud como cualidad a medir, llevando a cabo comparaciones y visualizando las partes del proceso de medida. Tras la longitud, el alumnado puede construir fácilmente con Tutakaboo las unidades de superficie y volumen, apreciando cómo se forman a partir de la longitud y se relacionen entre si. Con esas nuevas unidades se volverán a realizar actividades de comparación, para afianzar esta base del Sentido de la Medida.

Por otro lado, este material es una excelente ayuda para trabajar las estimaciones, trabajando el uso de referentes y la estrategia de trocear o fraccionar piezas, tanto de longitud como de volumen o superficie. También permite ayudar a visualizar la conservación de volumen y área independientemente de su forma, de manera natural e intuitiva, al poder contar los triángulos que componen la superficie o los cubos que forman los volúmenes. 


\section{TAREA 2: Proyecto de intervención en el patio: diseño y escala}

CURSO: Segundo de la ESO.

Según Moreno et al. (2015) para construir modelos a escala o interpretar medidas de un plano se requiere además del Sentido de la Medida, dominar el razonamiento proporcional, también las relaciones entre las unidades de las distintas magnitudes y el uso de fórmulas.

“Al construir objetos según unas dimensiones dadas se pone de manifiesto el grado de competencia matemática alcanzado (...). La acción de construir es la manifestación y expresión de ser competentes, de dar respuesta a la tarea donde aparece una medida, encontrando y movilizando los recursos disponibles"(p.167).

Atendiendo a estas pautas se realiza este proyecto de actuación en el centro, que puede ser integrado junto con la asignatura de Tecnología. Además, puede contextualizarse a un evento del centro, como el Día del Libro y proponer el diseño de rincones de lectura.

Tabla 2. Elaboración propia.

Análisis de Tarea: Intervención en el patio: diseño y escala

\section{ELEMENTOS}

\begin{tabular}{ll}
\hline Meta & $\begin{array}{l}\text { Aplicar la escala al proceso de diseño de elementos, su construcción e im- } \\
\text { plantación real. }\end{array}$ \\
\hline Formulación & $\begin{array}{l}\text { "Necesitamos diseñar rincones de lectura en las pistas deportivas para el } \\
\text { Día del Libro" }\end{array}$ \\
\hline Recursos & $\begin{array}{l}\text { Piezas Tutakaboo (triángulos y uniones), instrumentos de medida (medidor } \\
\text { láser, cinta...) útiles de escritura, reglas, escuadra y cartabón, cartulinas, } \\
\text { pizarra digital, patio del centro. }\end{array}$ \\
\hline Agrupamiento & Grupo. \\
\hline Situación & Aula, domicilio y patio del centro. \\
\hline Temporalización & Varias sesiones de trabajo: 4 \\
\hline VARIABLES & Cantidad. Espacio y forma. \\
\hline Contenido & Educativa y laboral. \\
\hline Situaciones & Reflexión \\
\hline Dificultad & \\
\hline FASE & Cierre. \\
\hline Fases & Síntesis y estructuración. \\
\hline Función & $\begin{array}{l}\text { Construcción de aprendizaje, apropiación de criterios, relacionar y recapi- } \\
\text { tular. }\end{array}$ \\
\hline Acción & Representación grupal e individual. \\
\hline Propósito &
\end{tabular}




\begin{tabular}{ll}
\hline ADECUACIÓN & \multicolumn{1}{c}{ Foco: Proporcionalidad Geométrica. } \\
\hline Foco & \multicolumn{1}{c}{ O1. Integrar los conocimientos matemáticos para la resolución de una si- } \\
tuación real de forma creativa, analítica y crítica. & O2. Medir distancias indirectas con Tales. \\
& O3. Medir con instrumentos adecuados. \\
& O4. Construir escalas gráficas utilizando Tales. \\
& O5. Ampliar y reducir figuras geométricas dada una razón de proporciona- \\
& lidad. \\
& O6. Determinar magnitudes a partir de una representación, utilizando esca- \\
& las gráficas, numéricas y viceversa. \\
\hline
\end{tabular}

\section{Gestión de la Tarea}

\section{Introducción a la tarea}

En gran grupo, el docente expondrá la tarea:

"Se aproxima el Día del Libro y la Comunidad Educativa ha decidido llevar a cabo una jornada de fomento de la lectura, en la que se pretende que diseñemos mobiliario para el patio. Debemos crear rincones de lectura individuales y áreas para comentar lecturas en grupos de 10 personas. Nosotros nos vamos a encargar de su diseño e implantación en las pistas deportivas utilizando el material del que disponemos."

Posteriormente se darán unas pautas básicas para croquizar:

- Dibujo a mano alzada.

- Descomposición en formas sencillas.

- Medir triangulando.

- Uso de láser y cinta.

\section{Analizamos la Zona de Actuación}

En las pistas deportivas se divide al alumnado en grupos de 4-5 personas. Unos grupos llevarán láser y otros cinta, de forma que puedan comprobar cómo se utilizan cada uno de los instrumentos de medida, qué errores dan...

Se dividirá la zona de actuación en partes de forma que cada zona sea medida por al menos dos grupos y puedan luego comprobarse los resultados.

El docente revisará y guiará el trabajo en grupo.

\section{Analizamos los datos y los trasladamos a planos y maquetas}

Los grupos que han medido una misma zona se reunirán en el aula para consensuar medidas. Finalmente en gran grupo se integrará un plano conjunto con todas las medidas que 
se croquizará en la pizarra.

También en gran grupo, se elegirá la escala más idónea para trabajar planos y maquetas, teniendo en cuenta que albergarán construcciones de piezas Tutakaboo a escala que deben poder manipular.

Se trabajará en clase el plano a escala.

\section{Tarea grupal}

Cada grupo de 4-5 alumnos realizarán una maqueta a escala de las pistas.

\section{Diseño y desarrollo creativo}

El profesor introduce la sesión con unas nociones básicas de ergonomía y medidas clave.

Con cartulinas el alumnado recortará triángulos a la escala de las maquetas, con los que diseñar rincones de lectura y ver como se organizan esos prototipos en la maqueta de conjunto.

En el cierre de esta fase, en gran grupo, se elegirán los prototipos de rincones más idóneos y su ubicación en las canchas gracias a las maquetas.

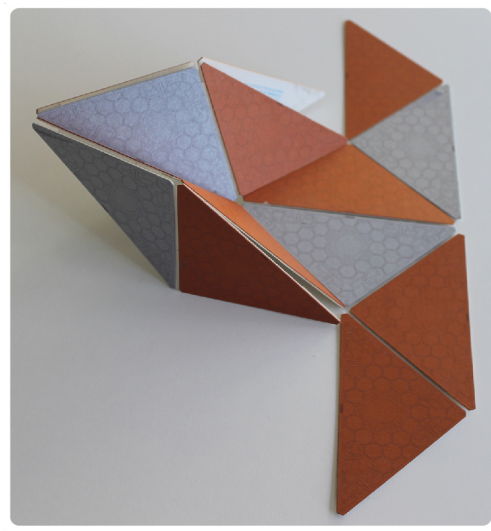

Figura 24. Construcción origami con piezas a escala

\section{Construcción real de la propuesta}

Esta sesión se realizará en las pistas deportivas con piezas Tutakaboo, tanto triángulos como uniones y bisagras. También se utilizarán cintas de medir para ubicar en su sitio las construcciones.

Se trabajan por grupos de 4-5 personas. Cada grupo se encargará de realizar el montaje a escala real de unas determinadas piezas. Se irán insertando en su ubicación definitiva. 


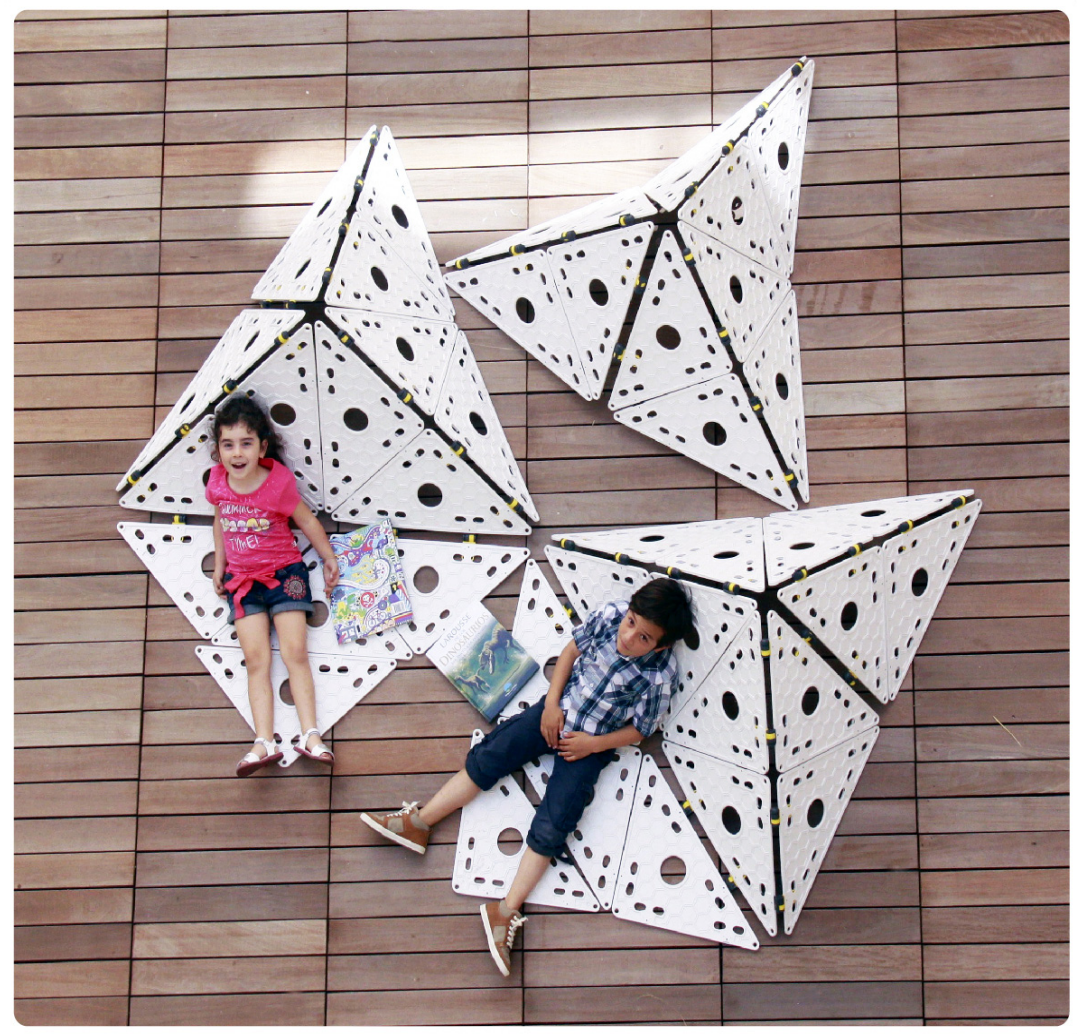

Figura 25. Construcción de rincones de lectura.

Fuente: banco imágenes de Tutakaboo

\section{Cierre Tarea}

El día del evento cada grupo realizará una observación de la forma en la que se ha utilizado el montaje por el alumnado del centro y llevará a cabo cinco encuestas elaboradas por ellos analizando utilidad, sensaciones, mejoras...

Cada grupo deberá llevar un diario sintetizando el trabajo de cada sesión, sus reflexiones y documentación gráfica... al que añadirá las entrevistas y observaciones del día de la inauguración.

En gran grupo, cada equipo expondrá su diario y montaje en formato digital. Se establecerá un debate conjunto como cierre de la actividad.

\section{Aporte}

Gracias al material, con un sistema de montaje inspirado en el origami, puede trabajarse con el alumnado la realización de maquetas de papiroflexia y su posterior montaje a piezas reales con Tutakaboo. Esto le permite un acercamiento al proceso real de prototipado y maquetación a escala, que se lleva a cabo en los campos del diseño de producto o la construcción, en los que se trabaja con planos y maquetas como pasos previos.

Por otro lado, comprobarán como las maquetas y planos suponen una abstracción de 
la realidad con los consiguientes ajustes que conlleva el paso de uno a otro, lo que favorece el diseño de estrategias y la resolución de problemas, valorando las soluciones y con la aplicación del sentido crítico.

Además es un material que permite trabajar la visualización, ubicación y movimientos, dentro del Sentido Espacial, partiendo desde el plano para formar las tres dimensiones. Por su facilidad de montaje y el uso intuitivo de las piezas, fomenta el desarrollo de la creatividad y la experimentación de las formas geométricas: Además, el tamaño de las piezas permite interactuar con las construcciones (entrar, apoyarse, sentarse...) trabajando la espacialidad de una forma global y analizando las diferencias con la experiencia directa, entre unas formas u otras.

Al ser un material que está basado en el origami, el alumnado puede manipular y comprobar con la práctica cómo el plegado de la geometría, basado en los triángulos isósceles y rectángulos ayuda a conseguir construcciones autoportantes. Al igual que una hoja de papel, al doblarla se mantiene en pie, ocurre lo mismo con las piezas, de este modo, se pueden crear construcciones que crezcan en altura o a lo largo, sin necesidad de apoyo.

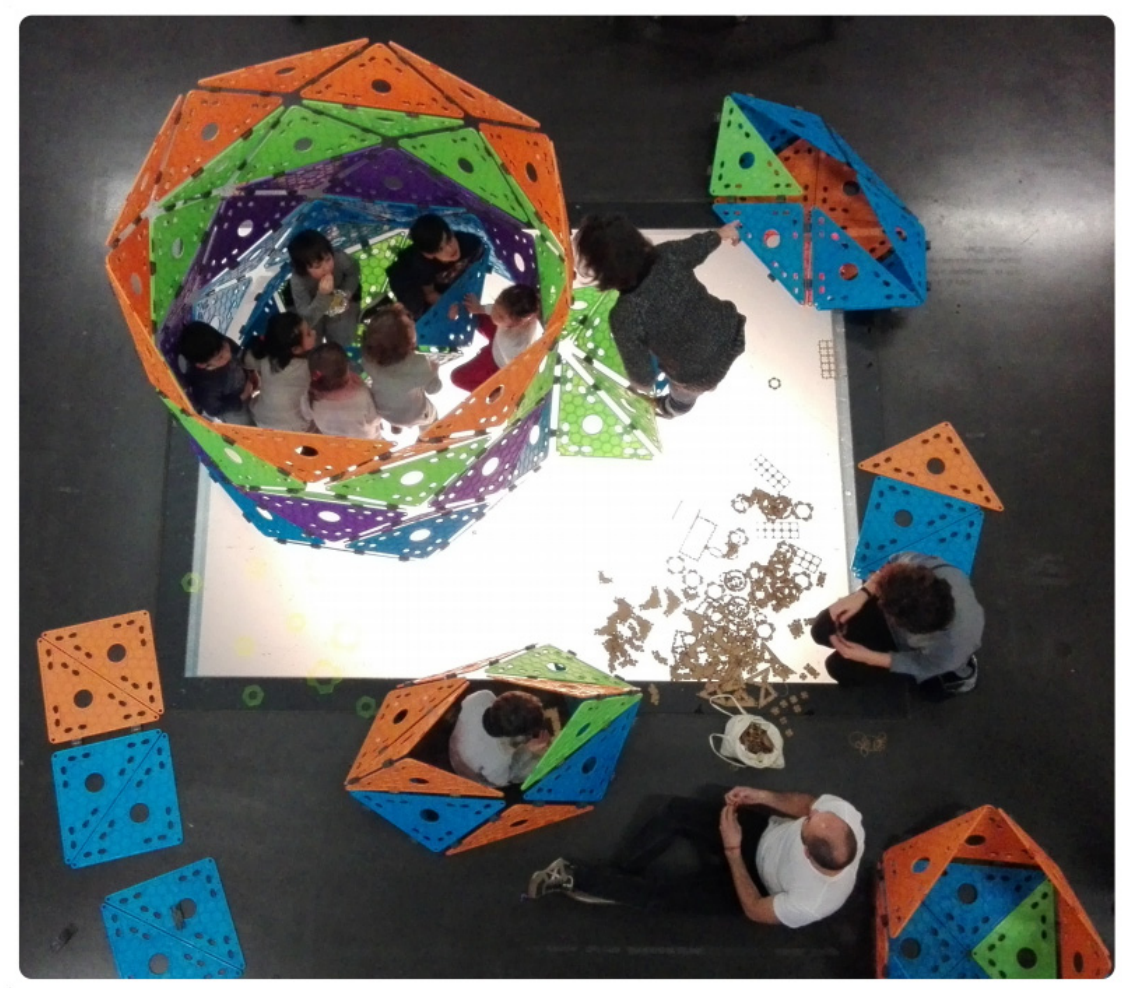

Figura 26. Construcción de rincones de lectura.

Fuente: banco imágenes de Tutakaboo. Taller MediaLabs-Prado, Madrid. 


\section{TAREA 3: Azulejos de la Alhambra: transformaciones y teselaciones}

CURSO: Tercero de la ESO.

Tabla 3. Elaboración propia.

Análisis de Tarea: Azulejos de la Alhambra

\begin{tabular}{|c|c|}
\hline \multicolumn{2}{|r|}{ ELEMENTOS } \\
\hline Meta & Aplicar los movimientos en el plano al análisis y creación de teselaciones \\
\hline Formulación & $\begin{array}{l}\text { "Vamos a analizar de forma manipulativa los movimientos en el plano y } \\
\text { como con ellos se generan teselaciones" }\end{array}$ \\
\hline Recursos & $\begin{array}{l}\text { Piezas Tutakaboo (triángulos y uniones), útiles de escritura, cuerdas y ti- } \\
\text { zas, pizarra digital, patio del centro. }\end{array}$ \\
\hline Agrupamiento & Individual, parejas y grupo. \\
\hline Situación & Aula, domicilio y patio del centro. \\
\hline Temporalización & Varias sesiones de trabajo: $3-4$ \\
\hline \multicolumn{2}{|r|}{ VARIABLES } \\
\hline Contenido & Espacio y forma. \\
\hline Situaciones & Pública. \\
\hline Dificultad & Reflexión. \\
\hline \multicolumn{2}{|r|}{ FASE } \\
\hline Fases & Tarea de desarrollo y cierre. \\
\hline Función & Autorregulación y regulación, síntesis y estructuración. \\
\hline Acción & $\begin{array}{l}\text { Construcción de aprendizaje, apropiación de criterios, relacionar y recapi- } \\
\text { tular. }\end{array}$ \\
\hline Propósito & $\begin{array}{l}\text { Trabajo de estrategias de éxito, autonomía, representación grupal e indivi- } \\
\text { dual. }\end{array}$ \\
\hline \multicolumn{2}{|r|}{ ADECUACIÓN } \\
\hline Foco & $\begin{array}{l}\text { Foco 1: Transformaciones en el plano. } \\
\text { Foco 2: Teselaciones. }\end{array}$ \\
\hline O. Didácticos & $\begin{array}{l}\text { O1. Identificar figuras congruentes. } \\
\text { O2. Construir y describir la transformada de una figura. } \\
\text { O3. Reconocer: vector, centro, ángulo o eje. } \\
\text { O4. Determinar los elementos invariantes. } \\
\text { O5. Componer movimientos y deducir su resultado. } \\
\text { O6. Integrar los conocimientos matemáticos para la resolución de una si- } \\
\text { tuación real de forma creativa, analítica y crítica. }\end{array}$ \\
\hline
\end{tabular}

\section{Gestión de la Tarea}

\section{Movimientos en el plano}

En el patio del centro educativo se dispondrán piezas de Tutakaboo, tizas y cuerdas.

El alumnado se agrupará en equipos de trabajo heterogéneos de 4-5 estudiantes. 
Trabajarán de forma manipulativa los movimientos en el planos con las directrices que se marcan en el Anexo II.

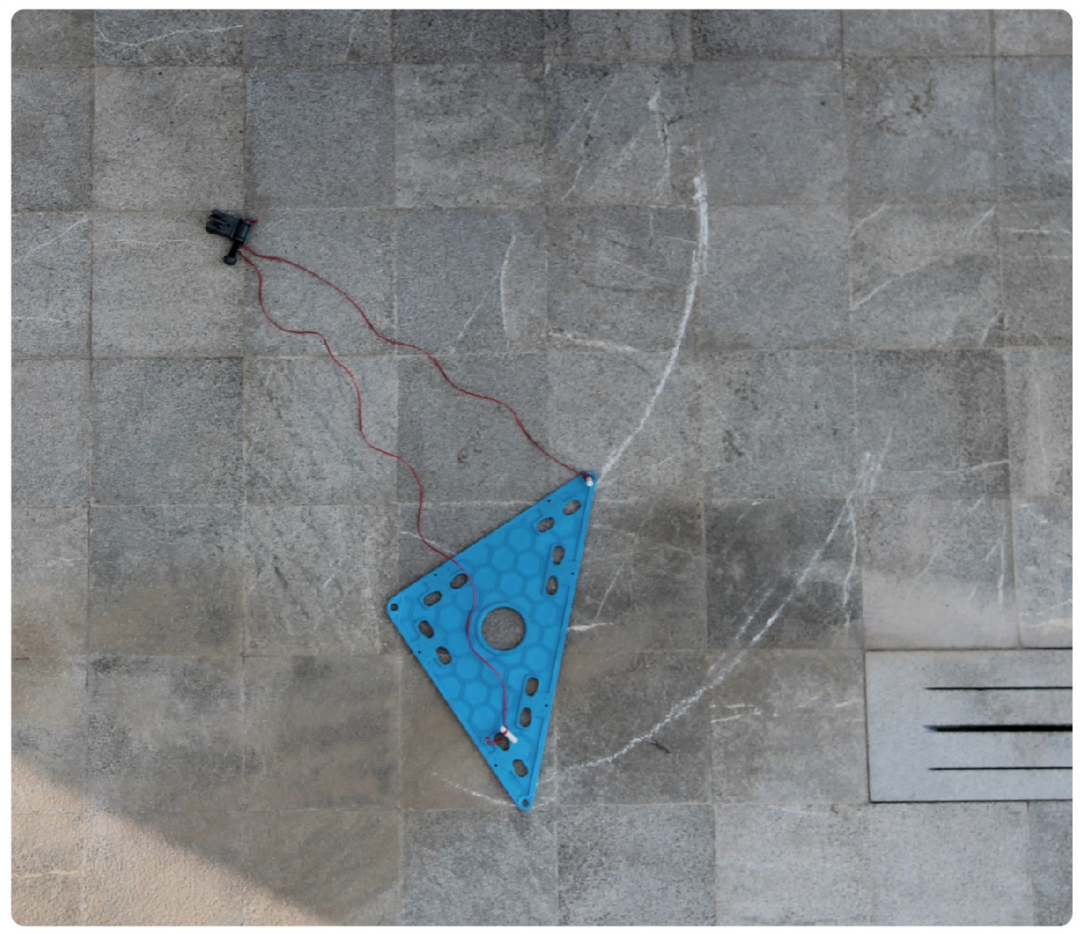

Figura 27. Actividad de giro: tizas, cuerdas, bisagra y triángulo

\section{Tarea para trabajo individual}

\section{Tarea 3.1}

Investigar el concepto teselaciones.

\section{Teselaciones}

En el patio del centro educativo se dispondrán piezas: triángulos y uniones planas.

Se harán grupos heterogéneos de 4-5 estudiantes.

Cada grupo llevará a cabo construcciones de unidades base de teselas de los azulejos de la Alhambra. Posteriormente, utilizando las de todos los grupos, se compondrán las distintas composiciones de azulejos.

Para la realización de esta actividad se seguirán las fichas de trabajo del Anexo II (Fichas de mosaicos). 


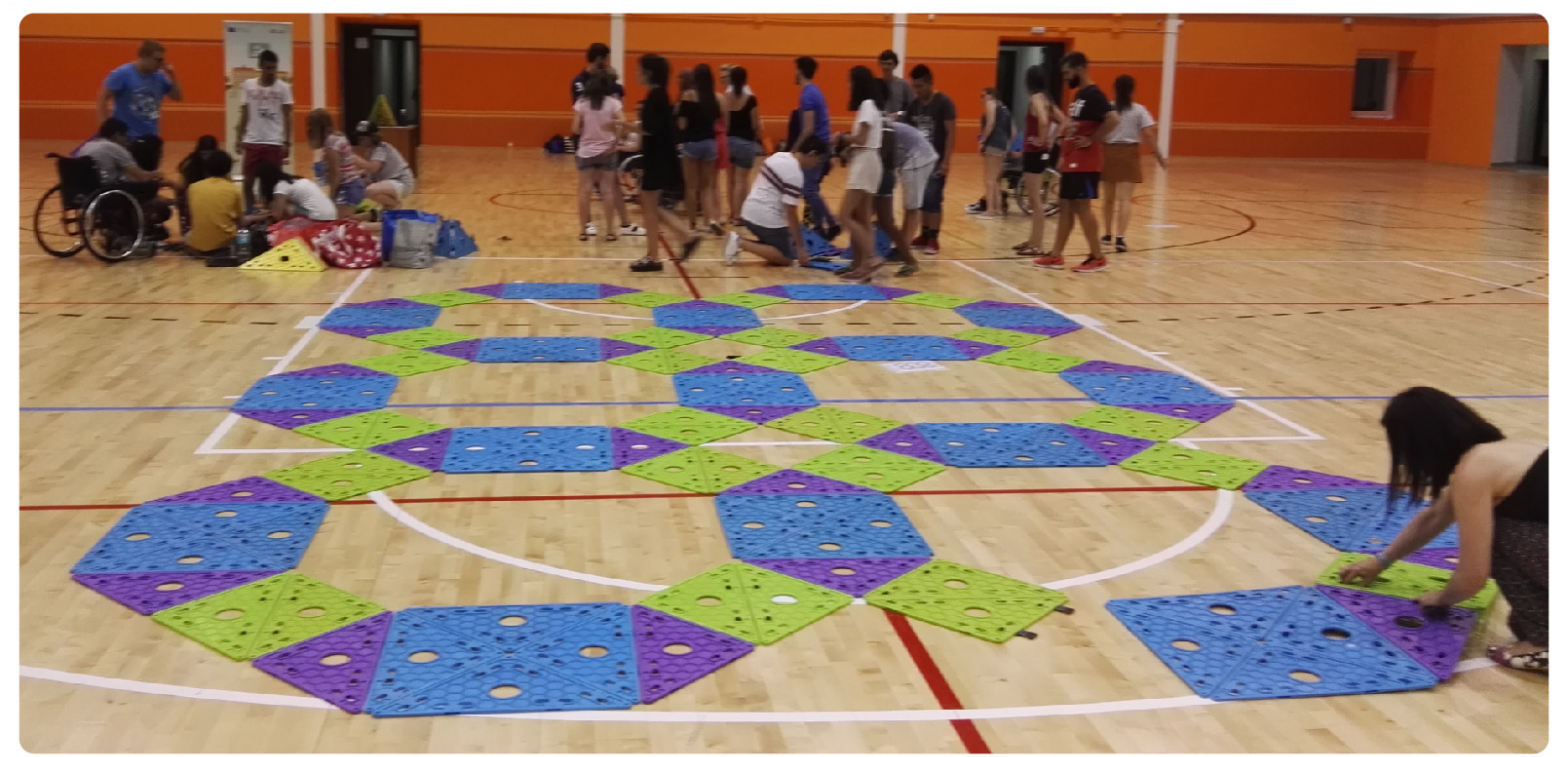

Figura 28. Construcción azulejo rombo.

Fuente: banco imágenes de Tutakaboo. Taller INNET campus, UGR.

\section{Tarea para trabajo individual}

Tarea 3.2

Análisis personal de las diferentes unidades de tesela que se han podido formar con el triángulo isósceles/rectángulo. Reflexión sobre la relación lleno vacío y sus posibilidades.

\section{Creaciones propias}

En el patio del centro educativo se dispondrán piezas: triángulos y uniones planas.

Se harán grupos heterogéneos de 4-5 estudiantes.

Se les propone el siguiente reto:

"Vamos a crear de pavimento para jardín basado en triángulos que son isósceles y rectángulos. Debéis diseñar un módulos base y jugar con diferentes agrupaciones del mismo para generar riqueza compositiva de forma que las áreas vacías sean zonas de vegetación, juegos... y los llenos, los caminos de paseo."

\section{Tarea para trabajo individual}

Tarea 3.3

Recrear en GeoGebra la composición realizada en grupo con las variantes individuales que cada estudiante considere oportunas. 


\section{Cierre}

Se analizará una selección de las composiciones del alumnado y de los diferentes patrones utilizados.

\section{Aporte}

Se ha planteado una tarea que integra la práctica manipulativa de los movimientos en el plano, que ya conoce el estudiante para su revisión y comprensión, siendo complementaria de la notación matemática y las representaciones gráficas, con las que va a seguir trabajando durante el desarrollo de la misma.

Posteriormente se procede a integrar esos movimientos en la composición de los Mosaicos de la Alhambra. De este modo, se aplican estos conocimientos al análisis del arte y la arquitectura andaluces.

La tarea ha buscado la aplicación de los contenidos en un caso práctico de recreación de una teselación como solución a un diseño concreto, trabajando el análisis crítico, la creatividad, el desarrollo de estrategias y la resolución de problemas.

El material facilita trabajar de forma manipulativa las composiciones y movimientos en el plano. Gracias a las perforaciones circulares de las esquinas y el centro de los triángulos, pueden utilizarse cuerdas y tizas para reconstruir giros, traslaciones o simetrías. De este modo los componentes del Sentido Espacial se trabajan de forma conjunta con la visualización como articuladora del movimiento, las propiedades de las formas y las relaciones geométricas.

Por otro lado, su diseño está basado en el triángulo isósceles/rectángulo, la mitad de un cuadrado, lo que permite construir las teselaciones.

Finalmente, el tamaño de las piezas favorece el trabajo en equipo, así como el desarrollo experimental. Al trabajar con Tutakaboo las creaciones propias, se desarrolla de forma creativa la aplicación de los contenidos y se trabaja de forma dinámica y aplicada el Sentido Espacial. Además, permite construir a escala vivencial, con lo que el alumnado trabaja el sentido crítico y funcional de su diseño, favoreciendo la autocorrección. 


\section{TAREA 4: Teorema de Pitágoras para triángulos isósceles y rectángulos}

Esta tarea está basada en la demostración para triángulos isósceles y rectángulos planteada en la web http://sinewton.org/numeros/numeros/69/ideas_03.pdf

Tabla 4. Elaboración propia.

Análisis de Tarea: Teorema de Pitágoras para triángulos isorectángulos

\begin{tabular}{ll}
\hline Meta & \multicolumn{1}{c}{ ELEMENTOS } \\
\hline Formulación & $\begin{array}{l}\text { Aplicar la demostración del Teorema de Pitágoras en triángulos isósceles y } \\
\text { rectángulos }\end{array}$ \\
\hline Recursos & $\begin{array}{l}\text { "Conocemos la demostración gráfica del Teorema de Pitágoras, ¿cómo po- } \\
\text { déis llevarla a cabo en el caso de triángulos isósceles y rectángulos?" }\end{array}$ \\
\hline Agrupamiento & Piezas Tutakaboo (triángulos y uniones) \\
\hline Situación & Grupo. \\
\hline Temporalización & Patio del centro. \\
\hline Contenido & Media sesión \\
\hline Situaciones & Espacio y forma. \\
\hline Dificultad & Educativa. \\
\hline & Conexión. \\
\hline Fases & Tarea de desarrollo. \\
\hline Función & Autorregulación. \\
\hline Acción & Construcción de aprendizaje. \\
\hline Propósito & Autonomía. \\
\hline Foco & Foco: Teorema de Pitágoras. \\
\hline O. Didácticos & O. Razonar el significado del Teorema de Pitágoras. \\
\hline
\end{tabular}

\section{Gestión de la Tarea}

En el patio del centro educativo se dispondrán piezas de Tutakaboo.

El alumnado se agrupará en equipos de trabajo heterogéneos de 4-5 estudiantes.

El docente planteará la actividad:

“Conocemos la demostración gráfica del Teorema de Pitágoras, ¿cómo podéis llevarla a cabo en el caso de triángulos isósceles y rectángulos?”

Se guiará el proceso trabajando a partir del enunciado del teorema y el uso de dos o tres colores. 


\section{Aporte}

El material permite trabajar de forma manipulativa en dos dimensiones poniendo en juego los componentes del Sentido Espacial con la visualización, las propiedades de las formas y las relaciones geométricas.

El alumnado analiza el significado del teorema de Pitágoras para poder llevar a cabo una demostración del mismo y aplicar el razonamiento para el caso particular de los triángulos isósceles y rectángulos.

Por otro lado, se trabaja el Sentido de la Medida, favoreciendo tanto las medidas indirectas (fórmulas utilizando el Teorema de Pitágoras) como medidas directas al comparar las áreas obtenidas por superposición. El uso de colores en las piezas puede facilitar la comparación de áreas y composición de formas, aplicando las estrategias de trocear y fraccionar.

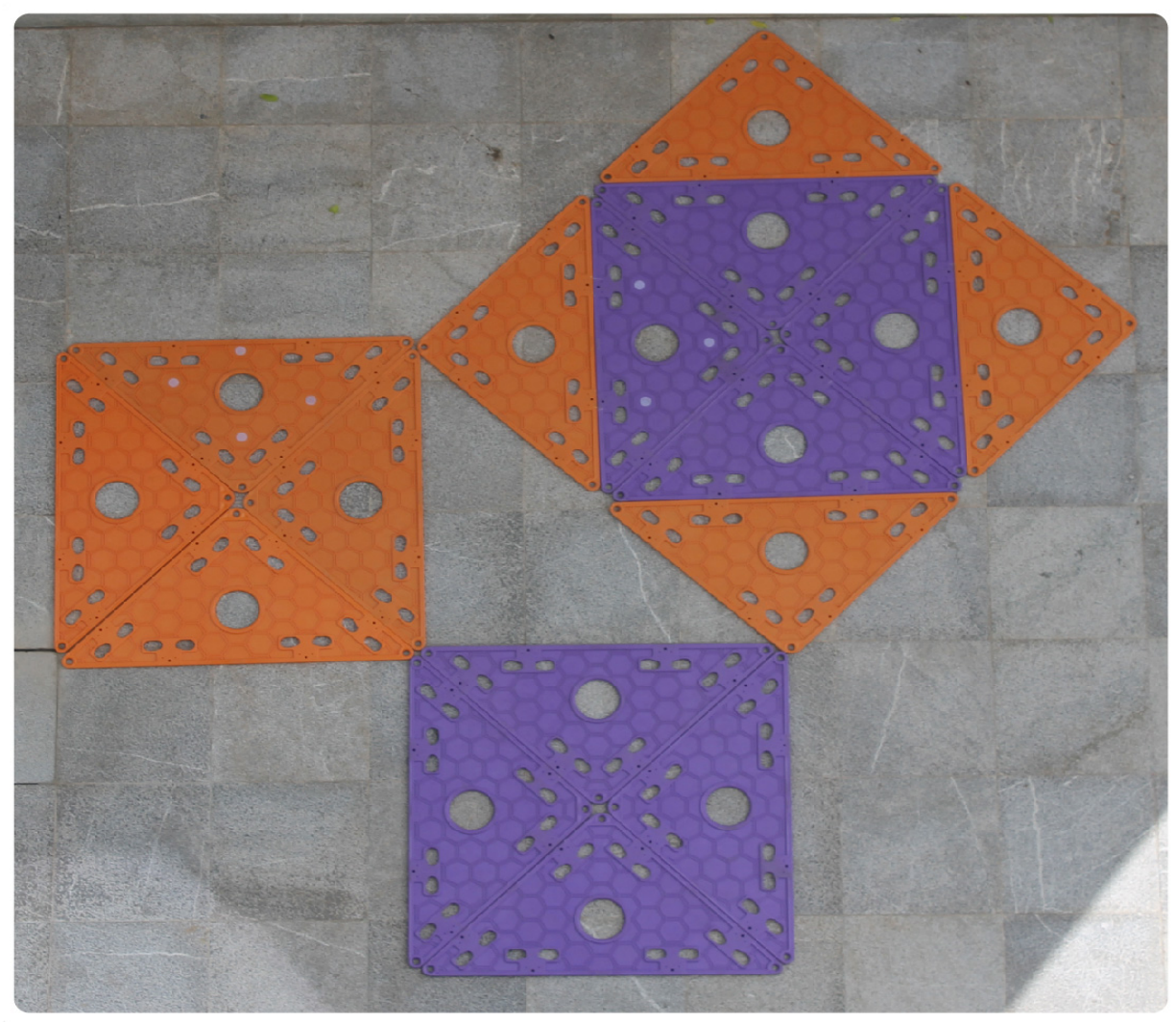

Figura 29. Resolución de Teorema Pitágoras 


\section{TAREA 5: Teorema de Thales}

A partir de la historia de cómo surgió el Teorema de Thales, se crean tres situaciones diferentes de relaciones de triángulos para la obtención de una medida indirecta.

Tabla 5

Análisis de Tarea: Teorema de Thales

\begin{tabular}{ll}
\hline & \multicolumn{1}{c}{ ELEMENTOS } \\
\hline Meta & Aplicar el Teorema de Thales para cálculo de distancias indirectas \\
\hline Formulación & $\begin{array}{l}\text { "Conocemos el enunciado del Teorema de Tales, vamos a ponerlo en prác- } \\
\text { tica para medir distancias indirectas" }\end{array}$ \\
\hline Recursos & $\begin{array}{l}\text { Piezas Tutakaboo (triángulos y uniones), cintas de medir, útiles de escritura } \\
\text { y calculadora }\end{array}$ \\
\hline Agrupamiento & Grupo. \\
\hline Situación & Patio del centro. Día soleado. \\
\hline Temporalización & Una sesión. \\
\hline Contenido & Espacio y forma. Cantidad. \\
\hline Situaciones & Educativa. \\
\hline Dificultad & Conexión. \\
\hline & \\
\hline Fases & Tarea de desarrollo. \\
\hline Función & Autorregulación. \\
\hline Acción & Construcción de aprendizaje. Apropiación de criterios. \\
\hline Propósito & Autonomía. \\
\hline Foco & O. Aplicar el Teorema de Tales para el cálculo de medidas indirectas. \\
\hline
\end{tabular}

\section{Gestión de la Tarea}

En el patio del centro educativo se dispondrán piezas de Tutakaboo.

El alumnado se agrupará en equipos de trabajo heterogéneos de 4-5 estudiantes.

Cada alumno debe hacer un diario de la tarea con los problemas, esquemas de la representación de las sombras, las medidas tomadas y los cálculos.

El docente guiará la actividad. 


\section{Introducción}

El docente planteará la actividad:

"Conocemos el enunciado del Teorema de Tales, vamos a ponerlo en práctica para medir distancias indirectas". A continuación, les contará la historia de como descubrió Tales el teorema al querer conocer la altura de las pirámides.

Posteriormente se les pedirá a los alumnos que monten un cubo con las piezas y un prisma cuadrangular de tres cuerpos.

\section{Actividad 1}

Calcular de forma indirecta la altura del prisma colocado en vertical a partir de la altura del cubo. Las sombras de ambos elementos no deben solaparse ni ser coincidentes. Se busca la aplicación de Tales con sombras paralelas.

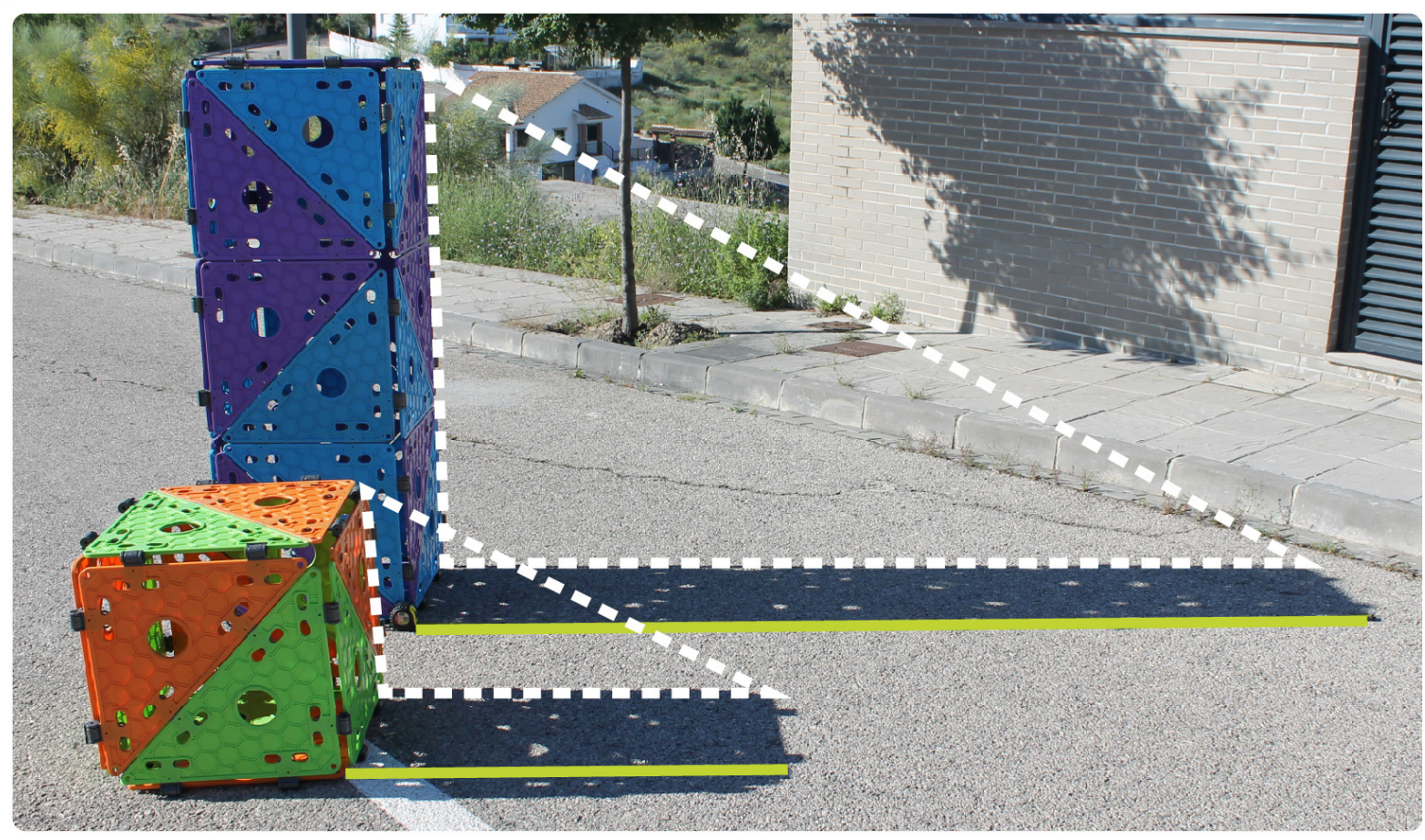

Figura 30. Construcción del Teorema de Tales con sombras paralelas

\section{Actividad 2}

Se procederá a realizar la misma actividad, pero ahora colocando ambos elementos de forma que sus sombras sean coincidentes.

Los alumnos tendrán que analizar qué distancias en el plano horizontal se miden en esta ocasión. 


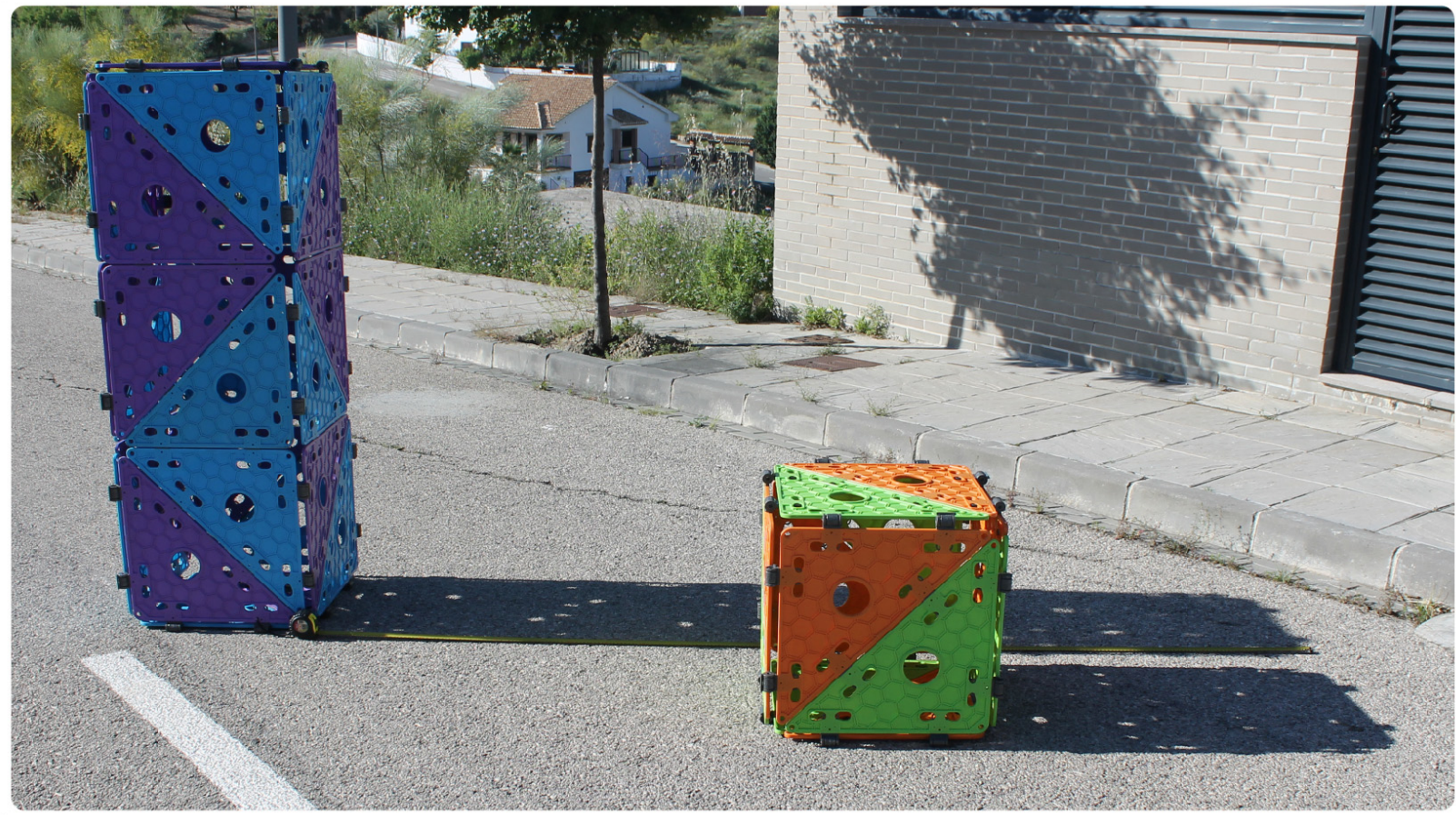

Figura 31.a. Construcción del Teorema de Tales con sombras coincidentes

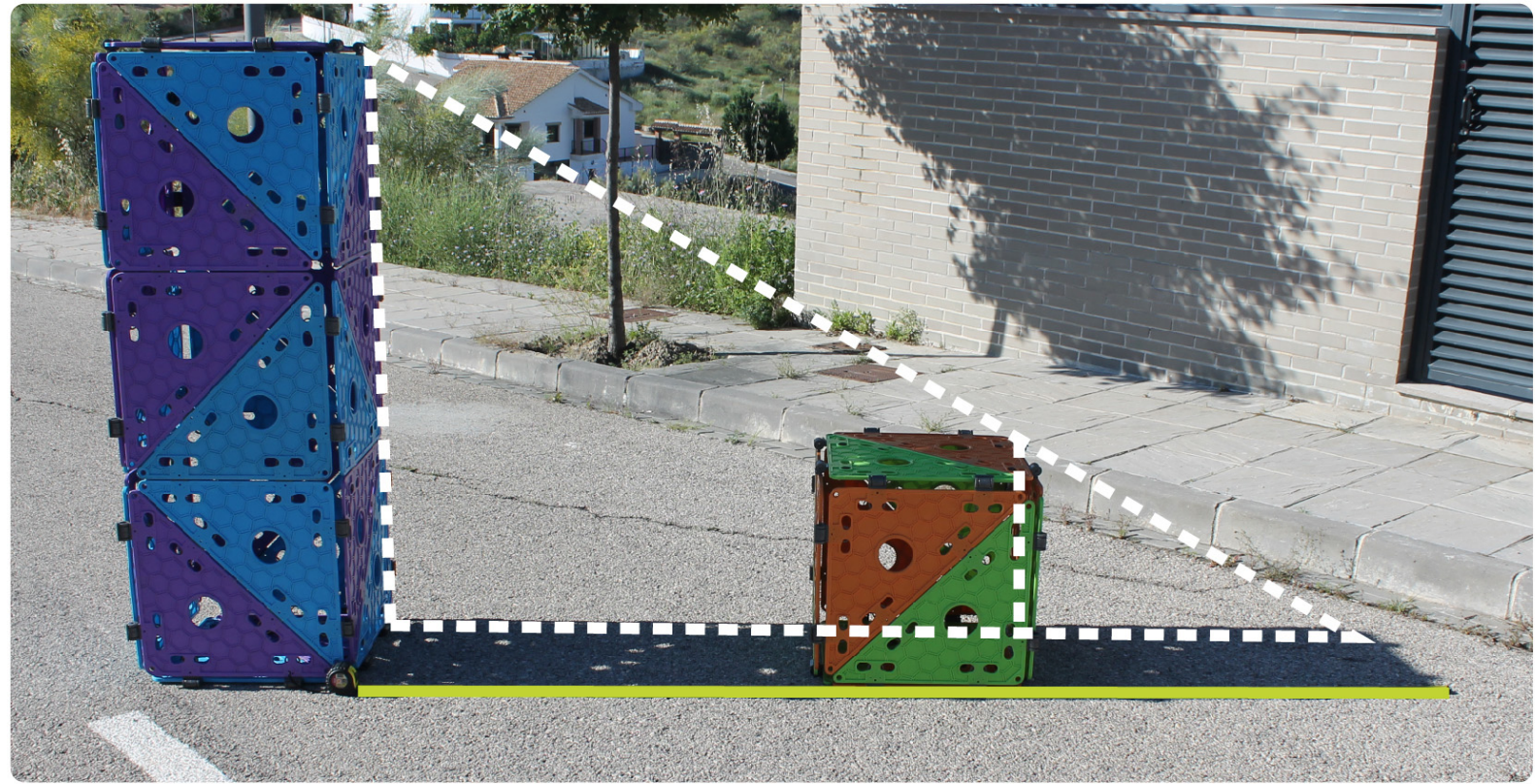

Figura 31.b. Construcción del Teorema de Tales con sombras coincidentes

\section{Cierre de las actividades 1 y 2}

Una vez realizadas las actividades 1 y 2 , en gran grupo, se procederá a medir la altura real del prisma. Se analizará el grado de error y a qué puede deberse: forma de medición, instrumento de medida, cálculos... 


\section{Actividad 3}

Aprovechando el gran grupo se les pedirá a los alumnos que estimen la altura del colegio.

A continuación, se les pedirá que utilicen Tales para su cálculo utilizando el prisma y la altura de algún compañero del grupo. Se guiará para que lleguen a este esquema:

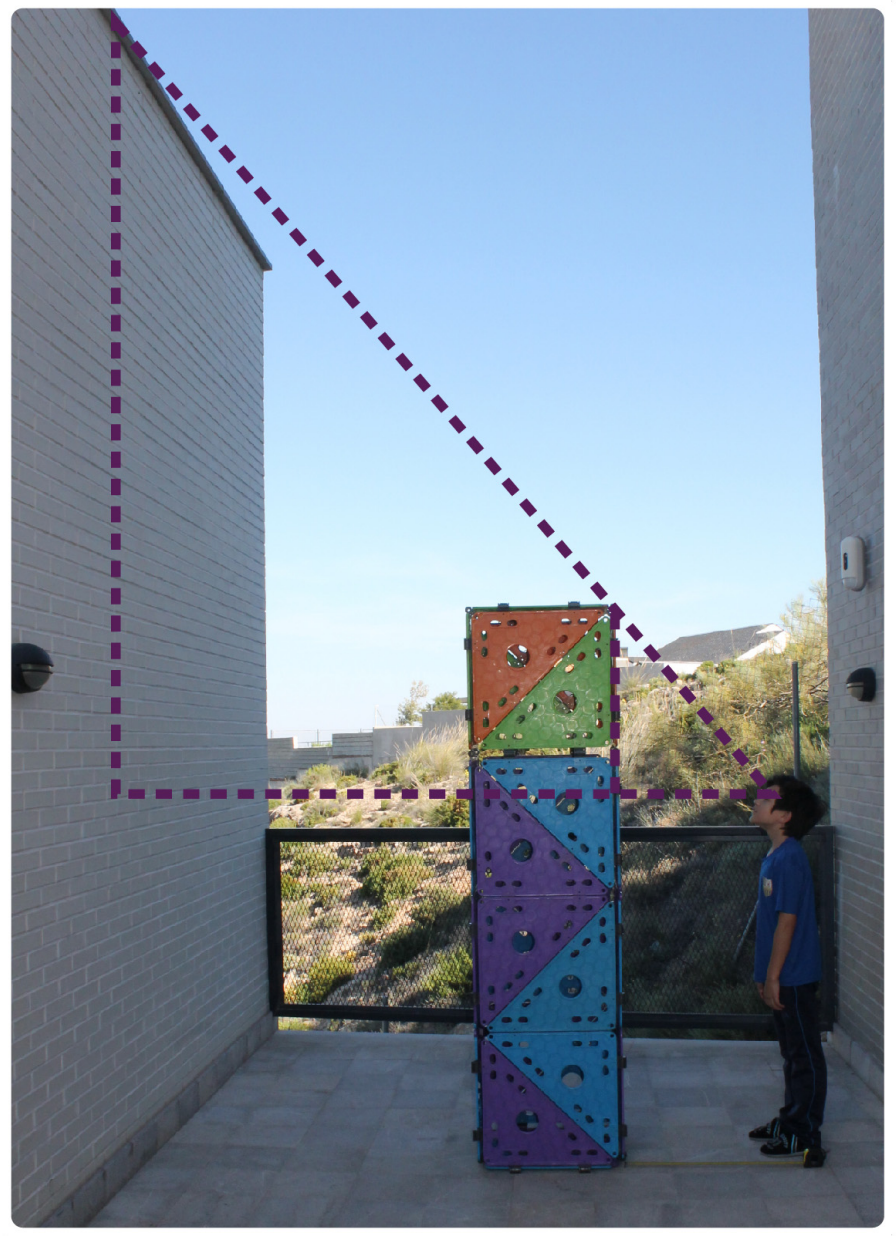

Figura 32. Construcción del Teorema de Tales para cálculo de altura de edificios

\section{Cierre}

Como cierre se abrirá la posibilidad de plantear otras opciones con Tales. El docente podrá llevar un espejo o también hacer la recreación de un entorno con las construcciones en el que la torreta sea un faro y otras menores sean barcos.

\section{Aporte}

El material permite generar de forma real y manipulativa la aplicación de Thales para medidas indirectas, creando diversas situaciones. Esto favorece la visualización real y en tres 
dimensiones de las situaciones. Por otro lado, al ser un juego de construcción las alturas de los bloques se adaptan en cada momento a las necesidades que el entorno y el grupo (altura de alumnado, edificio...). Además, los grupos pueden comprobar medidas y autocorregir los ejercicios (salvo el de la altura del edificio).

La actividad busca establecer situaciones reales para medir distancias indirectas, que incentiven la capacidad de desarrollo de estrategias y resolución de problemas en el alumnado. Finalmente, al crear entornos reales que deben plasmar en su cuaderno de clase, se trabajan la representación y la utilización de diferentes lenguajes: gráfico y matemático.

\section{TAREA 6: Reflexiones sobre triángulos isósceles/rectángulos y cuadrados}

Esta actividad está basada en Flores et al. (2015), p,131.

Tabla 6. Elaboración propia.

Análisis de Tarea: Triángulos isósceles/rectángulos y cuadrados

\begin{tabular}{|c|c|}
\hline \multicolumn{2}{|r|}{ ELEMENTOS } \\
\hline Meta & $\begin{array}{l}\text { Profundizar en las propiedades de cuadrados y triángulos, sus relaciones y } \\
\text { transformaciones. }\end{array}$ \\
\hline Formulación & "Explorar la construcción de cuadrados a partir de un triángulo base". \\
\hline Recursos & Piezas Tutakaboo (triángulos y uniones) \\
\hline Agrupamiento & Grupo. \\
\hline Situación & Patio del centro. \\
\hline Temporalización & Media sesión \\
\hline \multicolumn{2}{|r|}{ VARIABLES } \\
\hline Contenido & Espacio y forma. \\
\hline Situaciones & Educativa. \\
\hline Dificultad & Conexión. \\
\hline \multicolumn{2}{|r|}{ FASE } \\
\hline Fases & Tarea de cierre. \\
\hline Función & Síntesis y estructuración. \\
\hline Acción & Relacionar y orientar nuevos aprendizajes. \\
\hline Propósito & Representación grupal. \\
\hline \multicolumn{2}{|r|}{ ADECUACIÓN } \\
\hline Foco & Foco: Composición de figuras geométricas. \\
\hline O. Didácticos & $\begin{array}{l}\text { O1. Comprender las propiedades de triángulos y cuadrado. } \\
\text { O2. Aplicar la composición de figuras geométricas. }\end{array}$ \\
\hline
\end{tabular}




\section{Gestión de la Tarea}

En el patio del centro educativo se dispondrán piezas de Tutakaboo.

El alumnado se agrupará en equipos de trabajo heterogéneos de 4-5 estudiantes.

El profesor guiará la actividad planteando las siguientes construcciones que deberán mantenerse construidas hasta el final de la actividad:

"Formar triángulos semejantes."

"Construir un cuadrado que tenga por lado el lado pequeño del triángulo base."

"Construir un cuadrado que tenga por lado el lado largo del triángulo base y encontrar patrones para formar cuadrados mayores"

Las construcciones formadas deberán ser así:

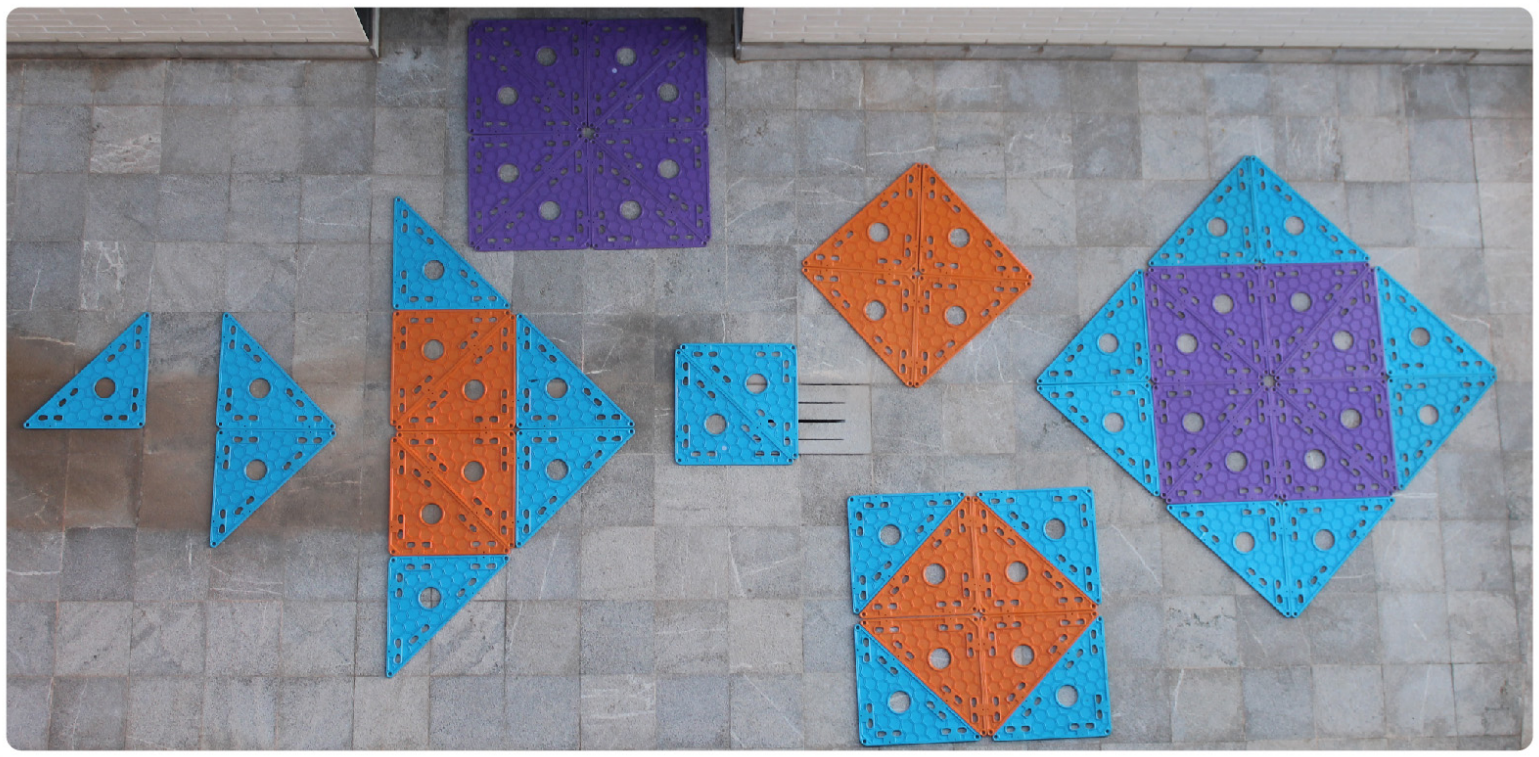

Figura 33. Actividad triángulos isorectángulos y cuadrados: construcción de figuras

Una vez finalizado, en el cuadrado construido formado por las piezas azules y naranjas, se analizarán:

- Centro.

- Diagonales.

- Medianas.

\section{Cierre}

Se comentará en gran grupo las reflexiones llevadas a cabo durante la tarea. 


\section{Aporte}

Gracias al triángulo isósceles/rectángulo podemos trabajar la composición de triángulos, rectángulos y cuadrado mayores. El uso de colores ayuda a comprender cómo a partir de la unidad base se forman cadenas de figuras superpuestas, que constituyen la mayor.

De este modo se trabajan las propiedades de la forma, las relaciones geométricas y movimientos, desde un ejercicio de visualización con las piezas, por lo que el Sentido Espacial se trabaja de forma integral.

Adicionalmente, se trabaja la conservación del área y la estimación, dentro de la medida.

\section{TAREA 7: Tangram: el puzzle de la pajarita}

Se seguirán las pautas de trabajo de Flores P. El puzzle de la pajarita. Se reforzará con cálculos de áreas y perímetros.

Tabla 7. Elaboración propia.

Análisis de Tarea: Tangram: puzzle de la pajarita

\begin{tabular}{ll}
\hline & \multicolumn{1}{c}{ ELEMENTOS } \\
\hline Meta & Duplicación de figuras y equivalencia de figuras por superposición. \\
\hline Formulación & "Un triángulo no es solo un triángulo" \\
\hline Recursos & Piezas Tutakaboo (triángulos y uniones) \\
\hline Agrupamiento & Grupo. \\
\hline Situación & Patio del centro. \\
\hline Temporalización & Una sesión \\
\hline Contenido & Espacio y forma. \\
\hline Situaciones & Educativa. \\
\hline Dificultad & Conexión. \\
\hline & \\
\hline Fases & Tarea de cierre. \\
\hline Función & Síntesis y estructuración. \\
\hline Acción & Relacionar y orientar nuevos aprendizajes. \\
\hline Propósito & Representación grupal. \\
\hline
\end{tabular}




\section{ADECUACIÓN}

\begin{tabular}{ll}
\hline Foco & Foco: Composición de figuras geométricas. \\
\hline O. Didácticos & $\begin{array}{l}\text { O1. Entender las posibilidades de la duplicación y superposición de figu- } \\
\text { ras geométricas. }\end{array}$ \\
\hline
\end{tabular}

\section{Gestión de la Tarea}

En el patio del centro educativo se dispondrán piezas de Tutakaboo.

El alumnado se agrupará en equipos de trabajo heterogéneos de 4-5 estudiantes.

El profesor guiará la actividad planteando los diferentes retos.

El alumnado reflejará cada paso en su cuaderno.

\section{Paso 1}

Composición de la pajarita con los triángulos rectángulos, según Ficha de AnexoII.

Se le preguntará posteriormente :

"Los lados del triángulo son: $48 \mathrm{~cm}$ y $68 \mathrm{~cm}$ "

“Cuál es la superficie de la pajarita?”

“Cuál es su superficie formulada en función de los triángulos base?”

"¿Y su perimetro?”

\section{Paso 2}

Modificar colores para agrupar por cuadrados y trapecios rectángulos.

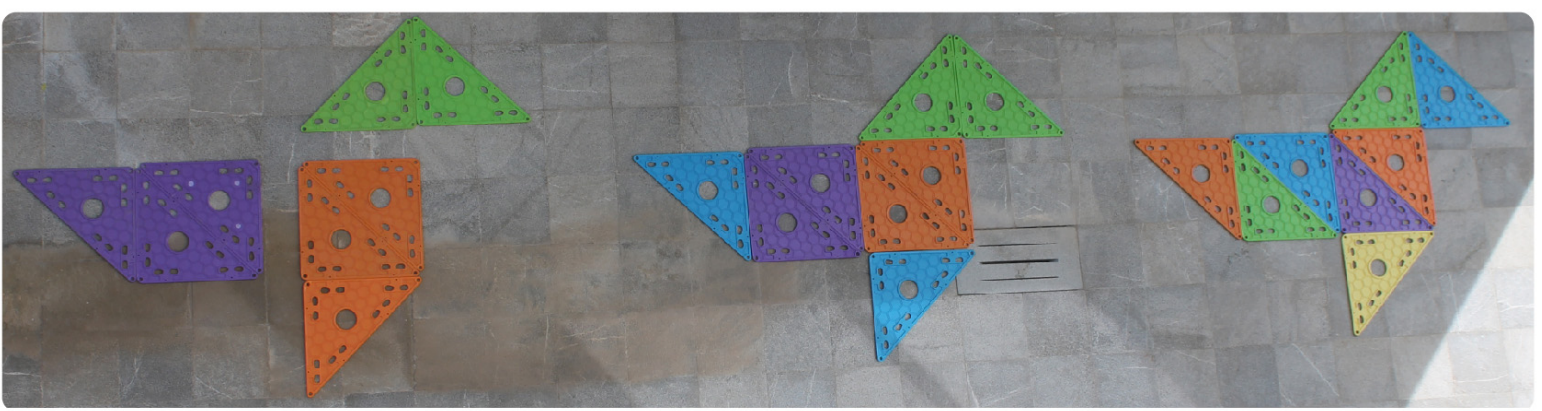

Figura 34. Formación pajarita con cuadrados, trapecios y triángulos

Cuestión:

"Expresa de forma rápida la superficie de los trapecios, cuadrados y triángulos formados y sus perímetros." 


\section{Paso 3}

Duplicar la pajarita: área doble.

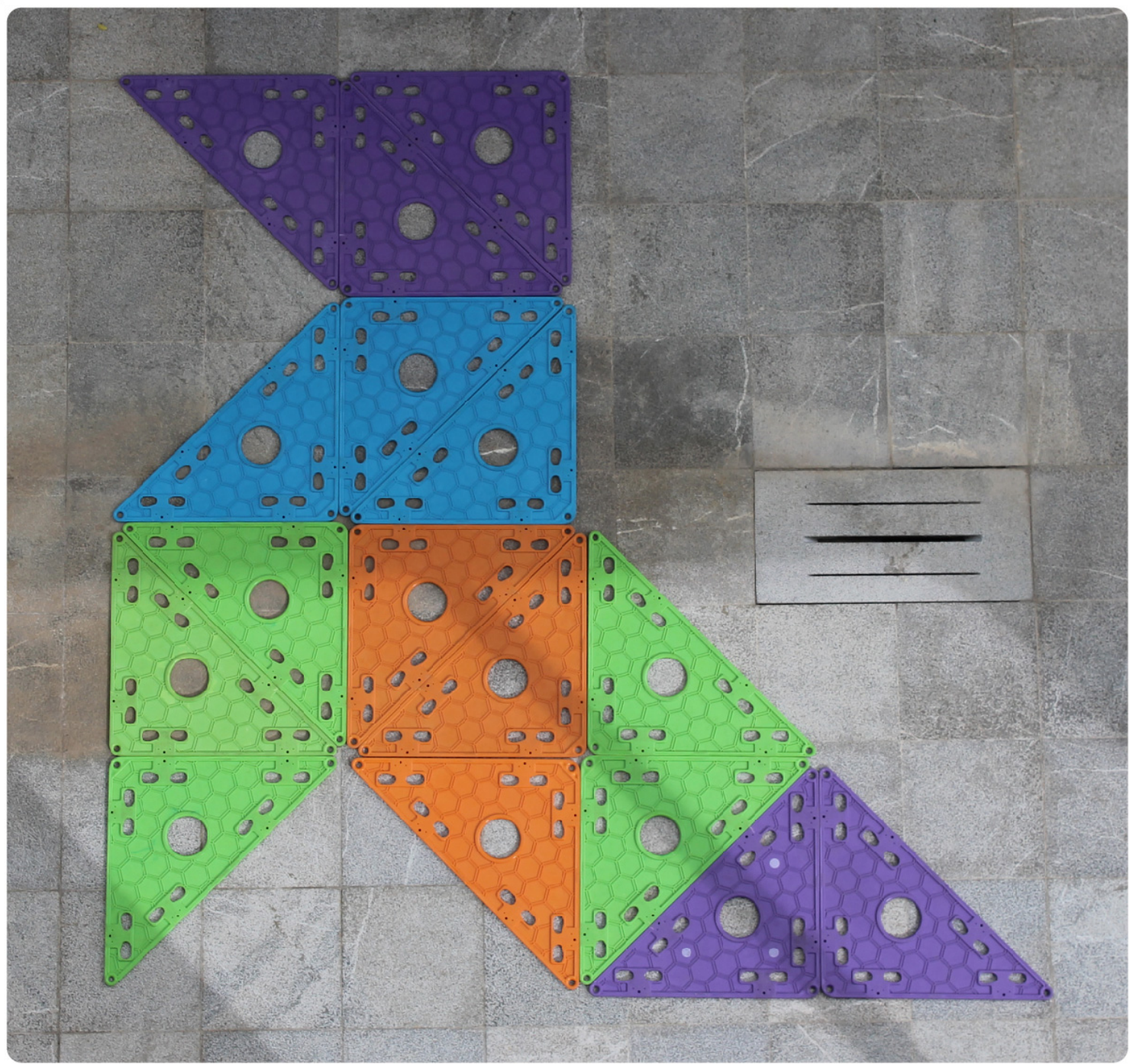

Figura 35. Formación pajarita doble

Cuestiones:

“ ¿Cuál es la superficie de la pajarita grande?”

“¿Cuál es su perímetro?”

“Qué relación hay entre el área de las figuras que la forman y la de la gran pajarita?"

“Pasa igual con su perímetro?”

“QQué reflexiones sacas?” 


\section{Paso 4}

Teselaciones: rellenar el espacio.

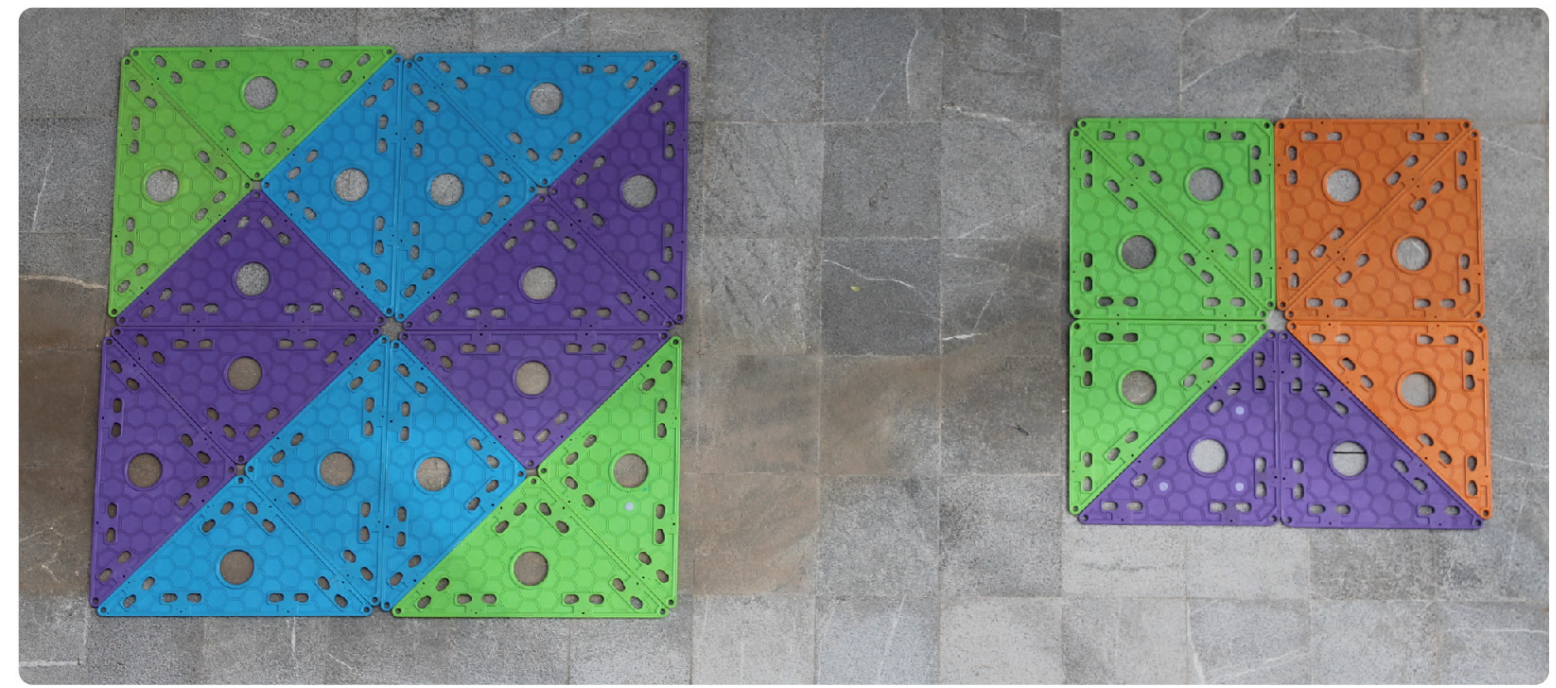

Figura 36. Formación cuadrados con las piezas de las pajaritas

Cuestiones:

"Calcula el área y el perímetro de los cuadrados. Busca relaciones con área y perímetro de las figuras que lo componen."

\section{Paso 5}

Polígono semejantes a sus teselas: triángulo rectángulo isósceles y trapecios rectángulos.

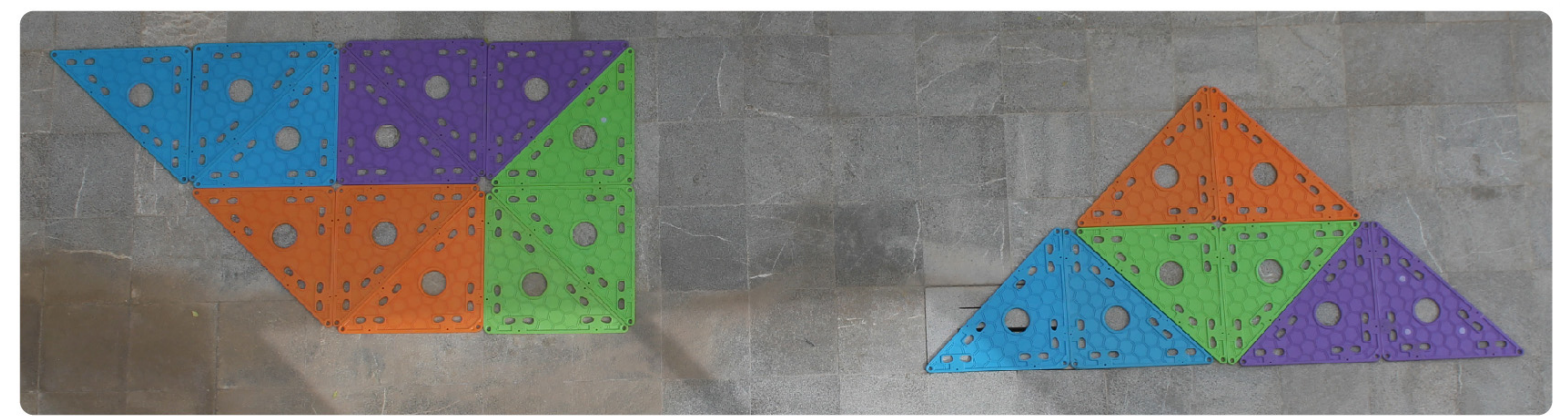

Figura 37. Formación triángulo isósceles y trapecios

Cuestiones:

“Calcula el área y el perímetro del trapecio y triángulo obtenidos. Busca relaciones con área y perímetro de las figuras que lo componen."

¿Qué reflexiones finales sacas sobre como crecen el área y el perímetro?” 


\section{Paso 6}

Espiral de pajaritas con todos los grupos.

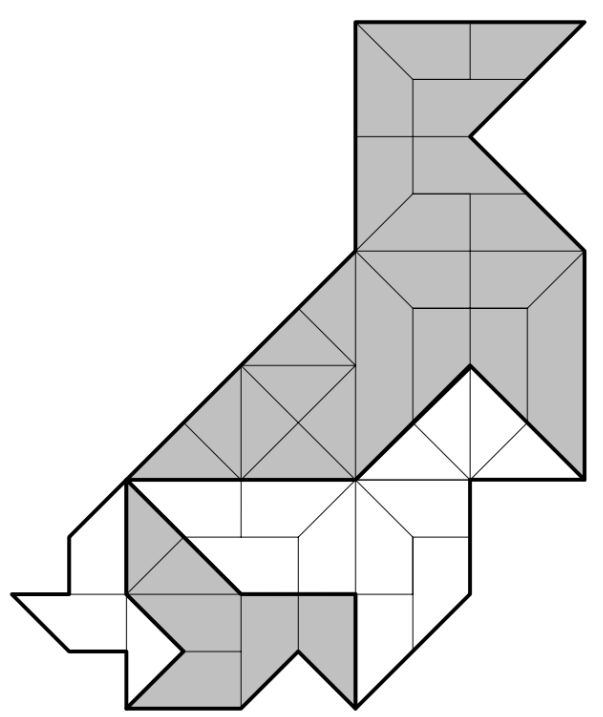

Figura 38. Espiral de pajaritas

Fuente: Flores

\section{Cierre}

Reflexiones finales en gran grupo de las respuestas llevadas a cabo en cada paso.

\section{Aporte}

Gracias al triángulo isósceles/rectángulo podemos trabajar la composición de triángulos para formar otras figuras. El uso de colores ayuda a comprender esas construcciones y cómo unas figuras van componiendo a otras.

El material facilita trabajar la visualización del Sentido Espacial a la vez que sus otros componentes: las propiedades de la forma, las relaciones geométricas y los movimientos. Este último adquiere una relevancia espacial en esta tarea y la composición de triángulos y trapecios por colores permite trabajarlo de forma sencilla y clara.

Adicionalmente, se trabaja la conservación del área y la estimación, dentro del Sentido de la Medida.

El paso de las instrucciones a la construcción y las anotaciones en el cuaderno de clase fomentan la utilización de diferentes lenguajes y sistemas de representación. 


\section{TAREA 8: Sólidos platónicos y arquimedianos}

Se plantean como reto para que el alumnado experimente con el material para la construcción de estos elementos.

Tabla 8. Elaboración propia.

Análisis de Tarea: Sólidos platónicos y arquimedianos

\begin{tabular}{|c|c|}
\hline \multicolumn{2}{|r|}{ ELEMENTOS } \\
\hline Meta & Visualización de la formación de estos sólidos. \\
\hline Formulación & "Vamos a construir". \\
\hline Recursos & Piezas Tutakaboo (triángulos y uniones), cuerdas de colores. \\
\hline Agrupamiento & Grupo. \\
\hline Situación & Patio del centro. \\
\hline Temporalización & Una sesión. \\
\hline \multicolumn{2}{|r|}{ VARIABLES } \\
\hline Contenido & Espacio y forma. \\
\hline Situaciones & Educativa. \\
\hline Dificultad & Conexión. \\
\hline \multicolumn{2}{|r|}{ FASE } \\
\hline Fases & Tarea de cierre. \\
\hline Función & Síntesis. \\
\hline Acción & Orientar nuevos aprendizajes. \\
\hline Propósito & Representación grupal. \\
\hline \multicolumn{2}{|r|}{ ADECUACIÓN } \\
\hline Foco & Foco: Cuerpos geométricos. \\
\hline O. Didácticos & $\begin{array}{l}\text { O. Construcción de cuerpos geométricos. } \\
\text { O. Relaciones entre cuerpos geométricos. }\end{array}$ \\
\hline
\end{tabular}

\section{Gestión de la Tarea}

En el patio del centro educativo se dispondrán piezas de Tutakaboo.

El alumnado se agrupará en equipos de trabajo heterogéneos de 4-5 estudiantes.

\section{Introducción}

El docente hará una breve descripción de los cuerpos platónicos y arquimedianos, sobre cuáles son las bases de formación y generación de estos grupos. 


\section{Actividad 1}

Cada grupo deberá construir un cubo de cuatro triángulos por cara. Posteriormente tendrá la libertad de desmontar aquellos triángulos para facilitar la visualización de las construcciones de las cuerdas (una esquina en la Figura39).

Siguiendo la ficha de la tarea del Anexo II y con dos colores de cuerdas se representará en su interior el tetraedro y el octaedro. Para ello utilizarán los huecos de paso de las esquinas de los triángulos .

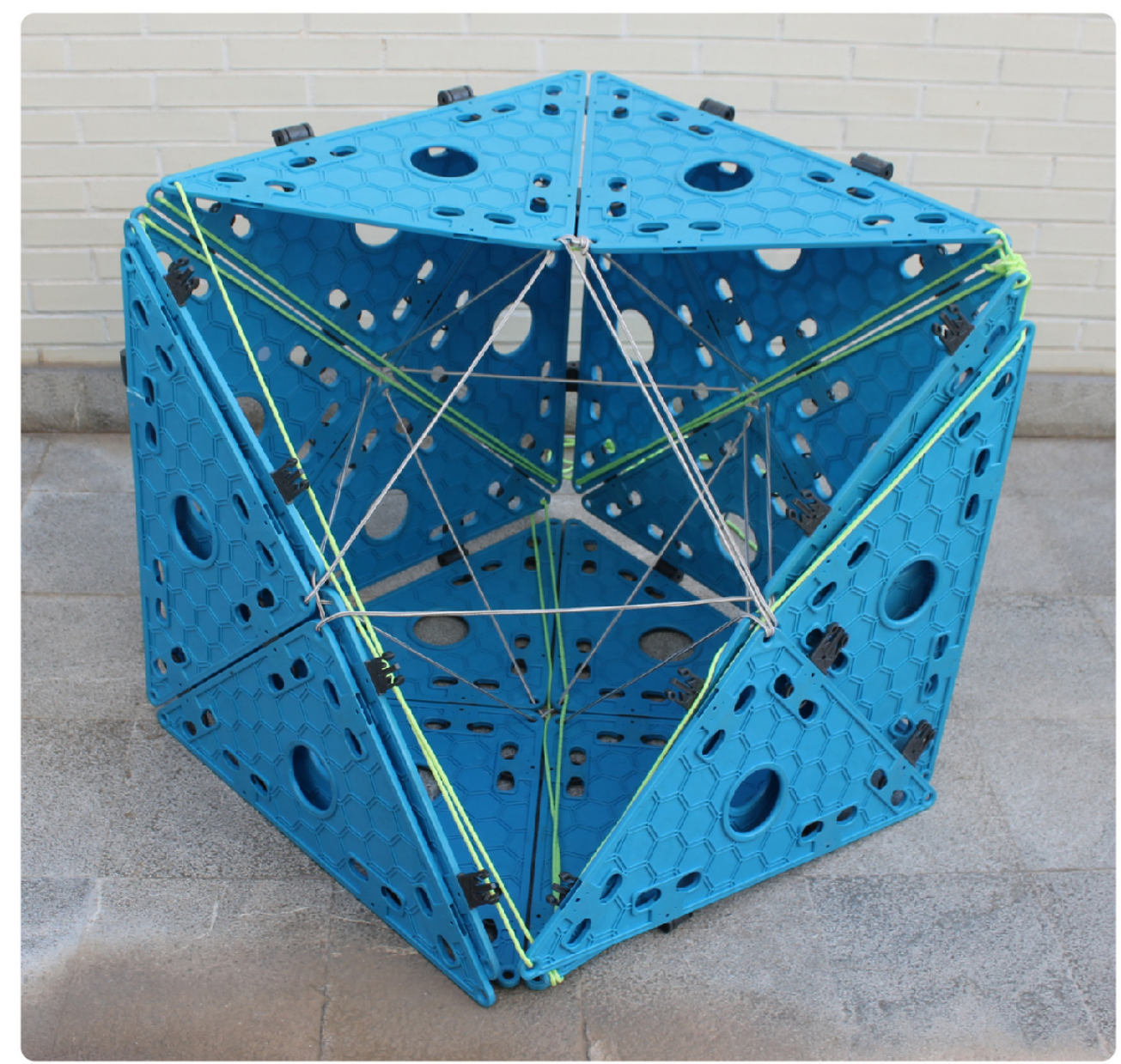

Figura 39. Cubo, tetraedro y octaedro

\section{Actividad 2}

A partir de la ficha de la actividad del Anexo II, cada grupo procederá a la construcción de un rombicuboctaedro y cuboctaedro.

Para solucionar el reto, deben visualizar y comprender que pese a que las piezas son triángulos isósceles y rectángulos, pueden construirse las figuras si las caras que precisan triángulos equiláteros quedan vacías. 

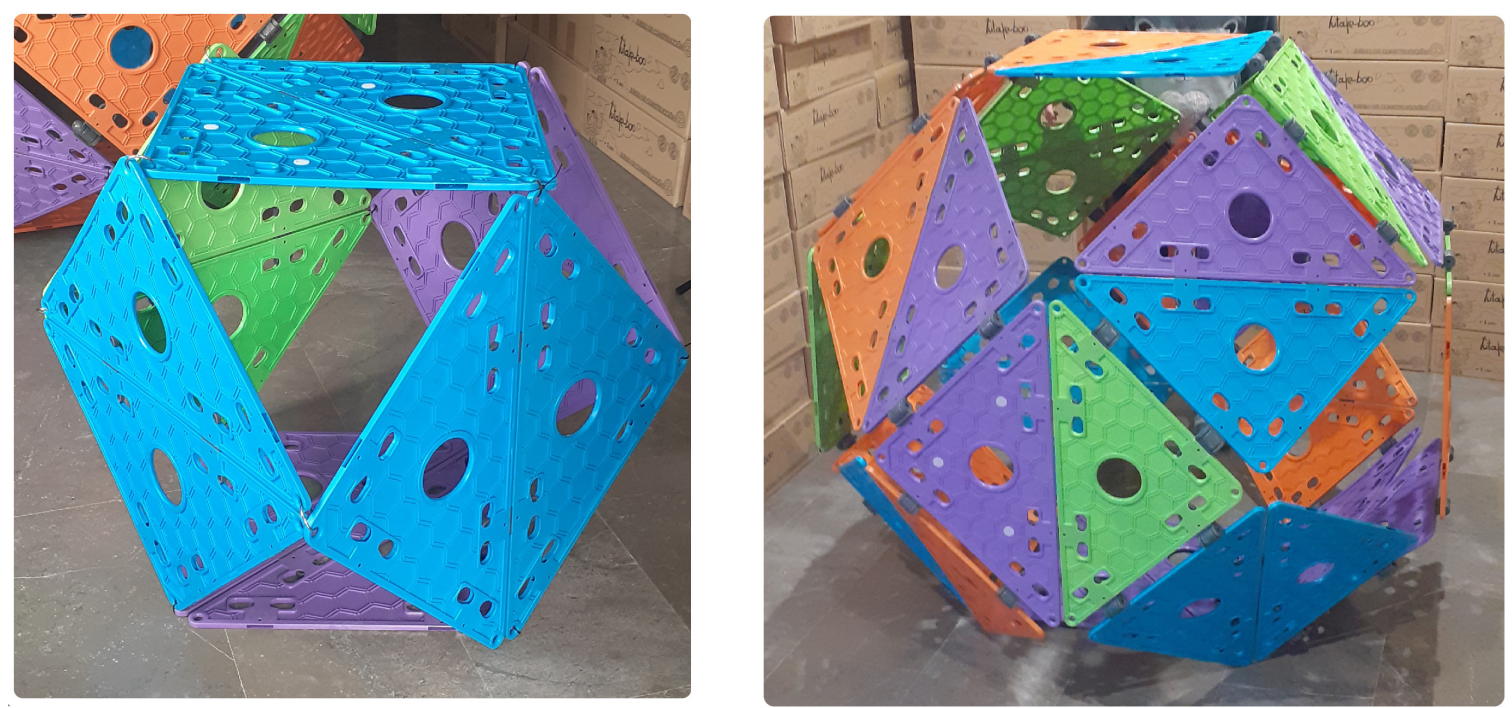

Figura 40. Rombicuboctaedro y cuboactaedro

\section{Aporte}

El material permite la visualización de los volúmenes con versatilidad y facilidad de montaje.

Al tener un sistema de montaje y desmontaje intuitivo, Tutakaboo favorece que el alumnado pueda llevar a cabo el trabajo en grupo de las construcciones sin instrucciones. Al no contar con triángulos equiláteros, estimula el desarrollo de estrategias y la reflexión de las imágenes, trabajando la espacialidad, la visualización y el resto de componentes del Sentido Espacial.

Por otro lado, al desmontar las construcciones, el material permite comprender los desarrollos de las figuras tridimensionales y que el alumnado visualice el paso de las superficies a los volúmenes.

\section{TAREA 9: Desarrollo del cubo}

Esta actividad está basada en el trabajo de Flores et al. (2015, p.139-140)

Tabla 5

Análisis de Tarea: Desarrollo del cubo

\begin{tabular}{ll}
\hline & \multicolumn{1}{c}{ ELEMENTOS } \\
\hline Meta & Conocer las propiedades del cubo y trabajar la visualización. \\
\hline Formulación & $\begin{array}{l}\text { ¿Cuántos desarrollos puede tener un cubo? ¿Podrías dibujar en ellos el re- } \\
\text { corrido de una cuerda por sus aristas?” }\end{array}$ \\
\hline
\end{tabular}




\begin{tabular}{|c|c|}
\hline Recursos & $\begin{array}{l}\text { Piezas Tutakaboo (triángulos y uniones), cuerdas, útiles de escritura y cal- } \\
\text { culadora. }\end{array}$ \\
\hline Agrupamiento & Grupo. \\
\hline Situación & Patio del centro. \\
\hline Temporalización & Una sesión. \\
\hline & VARIABLES \\
\hline Contenido & Espacio y forma. \\
\hline Situaciones & Educativa. \\
\hline Dificultad & Reflexión. \\
\hline & FASE \\
\hline Fases & Tarea de desarrollo. \\
\hline Función & Autorregulación. \\
\hline Acción & Construcción de aprendizaje. \\
\hline Propósito & Autonomía. \\
\hline & ADECUACIÓN \\
\hline Foco & Foco: Figuras geométricas, el cubo. \\
\hline O. Didácticos & O. Identificar las representaciones del cubo. \\
\hline
\end{tabular}

\section{Gestión de la Tarea}

En el patio del centro educativo se dispondrán piezas de Tutakaboo.

El alumnado se agrupará en equipos de trabajo heterogéneos de 4-5 estudiantes.

Cada alumno debe hacer un diario de la tarea con los desarrollos y recorridos propuestos en planta.

\section{Introducción}

Cada grupo formará un cubo de dos cuadrados por cara.

\section{Actividad 1}

Soltar algunas bisagras de las aristas para obtener un desarrollo posible del cubo. Hacerlo de varias formas diferentes. Dibujar el desarrollo obtenido.

Anexo III: ejemplos de solución a la actividad 


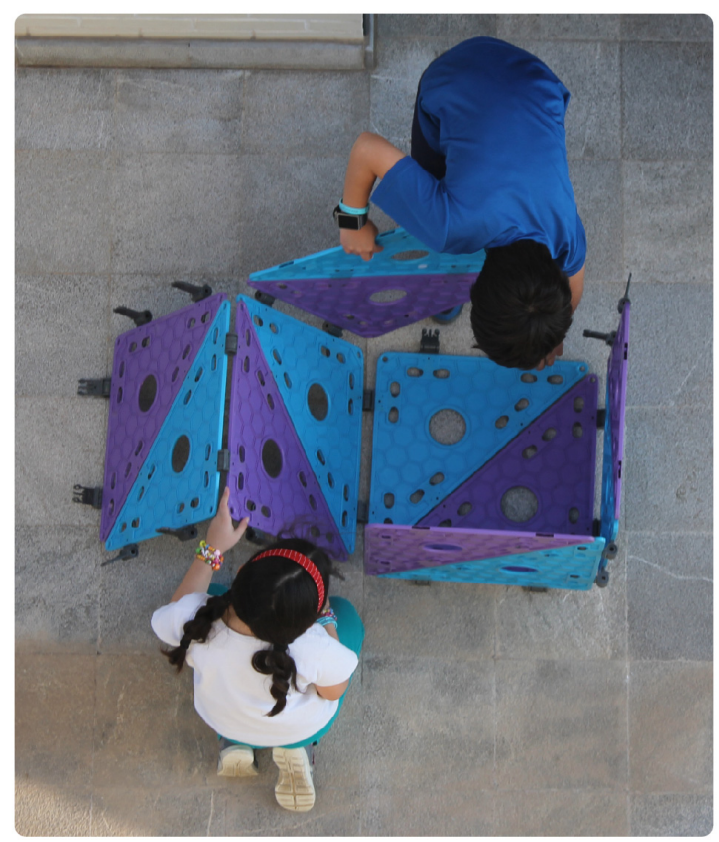

Figura 41. Montaje y desmontaje de cubo. Trabajar su desarrollo

\section{Actividad 2}

A cada grupo se le da una ficha del desarrollo del cubo concreto que va a tenerse en cuenta para la actividad y qué bisagras retirar para obtener ese mismo desarrollo. Ver ficha en Anexo II.

Cada grupo construirá su cubo y colocará una cuerda en el contorno del cubo en al menos seis aristas.

De forma individual, cada componente del grupo intentará dibujar en el desarrollo las aristas que llevan la cuerda (deben fijarse que van en una cara de la arista y no en otra).

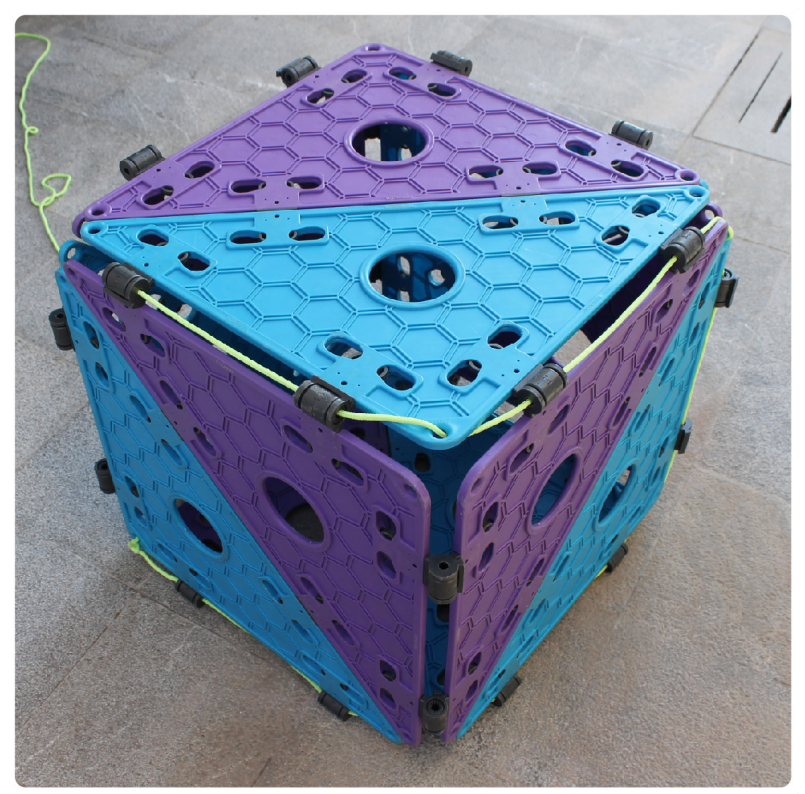

Figura 42. Montaje y desmontaje de cubo a partir de desarrollo 
Desmontarán el cubo siguiendo las instrucciones y comprobarán la solución.

Pueden volver a montar el cubo e intercambiarlo con otro equipo para proceder a realizar el nuevo trazado en el papel y su comprobación.

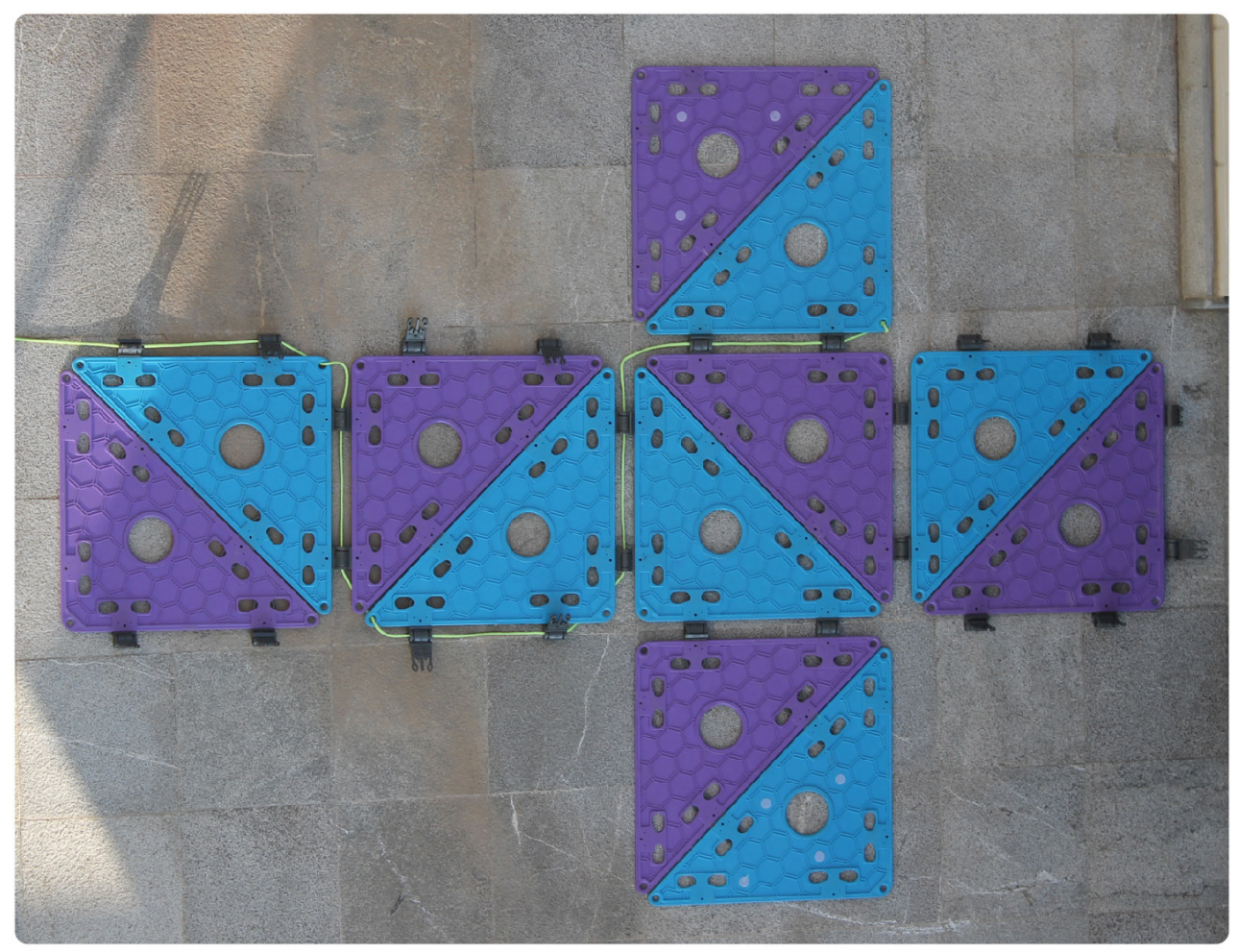

Figura 43. Desarrollo del cubo para comprobar la solución

\section{Aporte}

El material permite la visualización del recorrido y trabajar la autocorrección. Se trabaja el desarrollo de estrategias y la representación.

Tutakaboo ayuda a la visualización práctica y manipulativa de la relación del cubo y su envolvente, así como de las aristas. De este modo se trabajan los cuatro componentes del sentido espacial, con la visualización como elemento integrador, debido a la facilidad de pasar del plano a las tres dimensiones.

Pueden darse diferentes grados de dificultad, si las caras del cubo de referencia se montan con diferentes colores que ayuden a ubicar las caras en el desarrollo. 


\section{Evaluación}

La evaluación prevista de estas tareas se enmarca dentro de la evaluación continua de las unidades didácticas donde se inserten.

El alumnado deberá elaborar un diario de clase de las tareas largas que entregará de forma física, acompañado de un trabajo final en formato digital en el que mostrará sus reflexiones y conclusiones sobre la tarea.

Las tareas cortas se evaluarán por la observación y el registro anecdótico. En algunas de ellas, como las del Teorema de Tales, se solicitará el registro gráfico y matemático de los ejercicios manipulativos realizados y sus cálculos.

Se ha diseñado una rúbrica sobre la tarea Azulejos de la Alhambra: transformaciones y teselaciones, que ejemplifica el proceso de evaluación que se seguiría en el resto de tareas largas.

Tabla 6

Criterios de Evaluación y Estándares para tarea: Azulejos de la Alhambra

\begin{tabular}{ll}
\hline CRITERIOS DE EVALUACIÓN & ESTÁNDARES DE APRENDIZAJE \\
\hline Bloque 1 & \\
\hline
\end{tabular}

3. Describir y analizar situaciones de cambio, 3.1. Identifica patrones, regularidades y leyes mapara encontrar patrones, regularidades y leyes temáticas en situaciones de cambio, en contextos matemáticas, en contextos numéricos, geométri- numéricos, geométricos, funcionales, estadísticos cos, funcionales, estadísticos y probabilísticos, y probabilísticos valorando su utilidad para hacer predicciones.

CCL, CMCT, CAA

5. Elaborar y presentar informes sobre el proceso, 5.1. Expone y defiende el proceso seguido aderesultados y conclusiones obtenidas en los proce- más de las conclusiones obtenidas utilizando dissos de investigación. CCL, CAA, CSC, SIEP. tintos lenguajes: algebraico, gráfico, geométrico, estadístico/probabilístico.

Bloque 3

4. Reconocer las transformaciones que llevan de 4.1. Identifica los elementos más característicos una figura a otra mediante movimiento en el pla- de los movimientos en el plano presentes en la no, aplicar dichos movimientos y analizar diseños naturaleza, en diseños cotidianos u obras de arte.

cotidianos, obras de arte y configuraciones pre- 4.2 . Genera creaciones propias mediante la
sentes en la naturaleza. sentes en la naturaleza.

CMCT, CAA, CSC, CEC. composición de movimientos, empleando herramientas tecnológicas cuando sea necesario.

5. Identificar centros, ejes y planos de simetría de 5.3. Identifica centros, ejes y planos de simetría figuras planas y poliedros. CMCT. en figuras planas, poliedros y en la naturaleza, en el arte y construcciones humanas 
Tabla 7. Elaboración propia.

Rúbrica con los logros de aprendizajes

\begin{tabular}{|c|c|}
\hline \multirow{2}{*}{ EA } & LOGROS DE APRENDIZAJE \\
\hline & 4 \\
\hline B1. 3.1 & $\begin{array}{l}\text { Identifica en los azu- Identifica en los azu- Identifica en los No identifica en los } \\
\text { lejos la unidad base y lejos la unidad base azulejos la unidad azulejos la unidad } \\
\text { las reglas de las dife- y presenta dificultad base pero no puede base. } \\
\text { rentes composiciones en encontrar reglas encontrar las reglas } \\
\text { grupales. } \\
\begin{array}{l}\text { de las diferentes de las diferentes } \\
\text { composiciones gru- composiciones gru- }\end{array} \\
\text { pales. }\end{array}$ \\
\hline
\end{tabular}

B1.5.1 Utiliza el lenguaje Utiliza algunos tér- Utiliza muy pocos No maneja términos propio de la unidad al minos del lenguaje términos del lengua- del lenguaje propio de exponer el proceso propio de la unidad, je propio de la uni- la unidad o los confunseguido, tanto gráfica sin equivocarse, al dad y se confunde, de, presentando gran como manipulativa- exponer el proceso le cuesta exponer el dificultad al exponer el mente y las conclu- seguido, tanto gráfi- proceso seguido, proceso seguido, tanto siones. ca como manipulati- tanto gráfica como gráfica como manipuvamente y las con- manipulativamente lativamente y las conclusiones. $\quad y$ las conclusiones. clusiones.

B3. 4.1 Identifica en los azu- Identifica en los azu- Identifica en los No identifica en los lejos las traslaciones lejos las traslaciones azulejos las trasla- azulejos las traslacioy giros, reconociendo y giros, pero presen- ciones y giros, pero nes ni los giros.

el vector de traslación ta dificultades al re- no es capaz de recoo el centro y ángulo conocer el vector de nocer el vector de de giro. traslación o el centro traslación o el ceny ángulo de giro. tro y ángulo de giro.

B3. 4.2 Es capaz de compo- Es capaz de compo- Es capaz de compo- Es capaz de componer ner con las piezas y ner con las piezas y ner con las piezas y con las piezas y cuercuerdas una trasla- cuerdas tres de los cuerdas al menos das ningún movimiención, un giro, una si- cuatro movimientos. un movimiento. to. metría axial y una simetría central.

B3. 5.3 Identifica en los azu- Identifica en los azu- Identifica en los No identifica en los lejos las simetrías re- lejos las simetrías azulejos las sime- azulejos las simetrías. conociendo el eje o pero presenta difi- trías pero no recocentro de simetría. cultades al reconocer noce el eje o centro eje o centro de sime- de simetría. tría. 


\section{Atención a la Diversidad}

Para la Atención a la Diversidad se ha seleccionado la actividad Azulejos de la Alhambra: transformaciones $y$ teselaciones. Se han seguido las pautas propuestas por Ramírez (2016).

\section{Trabajo con las dificultades}

Para este refuerzo los alumnos seguirán las instrucciones que va marcando el docente sobre de la construcción manipulativa de los diferentes movimientos en el plano (Anexo II). Se llevará a cabo por cada alumno el registro personal de la actividad.

\section{Parte primera. Términos y notaciones}

Se analizará de forma visual cada uno de los términos que engloban esta unidad y se realizarán movimientos sencillos en los que puedan comprender cómo intervienen cada uno de los componentes y acompañarlos de las notaciones matemáticas.

Se recomienda el uso de tizas que faciliten la visualización de los términos y la escritura de las notaciones.

\section{Dificultades que se trabajan}

D.4. Comprender el concepto de vector libre asociado a una traslación.

\section{Parte Segunda. Trabajo de las destrezas}

En esta segunda etapa se propondrá que el alumnado pueda hallar los elementos clave en cada uno de los movimientos, aplicar transformaciones según las indicaciones dadas y encontrar y comprender los puntos invariantes.

\section{Dificultades que se trabajan}

D.3. Realizar el giro de una figura que no contiene el centro de giro.

Trabajo con las cuerdas, marcando diferentes centros del giro y marcando los arcos de giro.

D.4. Comprender el concepto de vector libre asociado a una traslación.

Este aspecto se trabaja con cuerdas con igual longitud, que representan el vector de giro. Cada cuerda se coloca en un punto de la figura. Colocadas paralelas, indican el punto 
trasladado de la figura.

D.5. Realizar transformaciones en las que las imágenes finales se solapan con la figura original.

Para ello se trabajará con cuerdas de diferentes tamaños.

D.6. Realizar traslaciones de formas poligonales con el vector traslación paralelo a uno de sus lados.

Una vez colocados los vectores traslación a una figura y a su imagen, se podrá ir jugando con esos vectores, colocándolos en diferentes posiciones, hasta alinearlos en paralelo a un lado.

\section{Enriquecimiento educativo}

Este alumnado que ya conoce los movimientos en el plano, realizará las construcciones de los azulejos y procederá a un análisis pormenorizado.

\section{Estudio de las unidades base}

El docente les expondrá:

"Contamos con diferentes unidades base en cada mosaico, todos formados a partir de un triángulo isósceles y rectángulo. ¿Qué movimientos en el plano se aplican a ese triángulo para generar esa base?"

Los alumnos comenzarán el trabajo. Las siguientes cuestiones a plantear:

“¿Varían esas transformaciones según el triángulo que consideremos inicial?

“¿Qué triángulo consideraríais como el origen de la transformación? ¿Por qué?”

\section{Estudio de las composiciones}

Ya se han estudiado las estructuras base. Ahora procederemos a analizar la composición de los azulejos como conjunto de estas unidades.

El docente propondrá:

“Analiza qué movimientos experimenta cada base para componer un mosaico”

"Los movimientos de la base como conjunto, ¿son los mismos que los que se llevan a cabo en cada uno de los triángulos de la base?"

“Al formar los mosaicos, además de las bases encontramos vacios, huecos. Esos 
vacíos:

- ¿En qué figuras se descomponen? ¿Están formados también por triángulos isósceles y rectángulos?"

- ¿Qué movimientos experimentan esos vacios en el mosaico?”

“ ¿Podéis encontrar algún patrón en cada mosaico?”

"En los mosaicos que una misma base genera diferentes vacios, ¿qué patrones encontráis? ¿Hay relación entre ellos?”

\section{Creación de la unidad base}

Finalmente se trabajará la creatividad. Tras los análisis realizados, los patrones estudiados, deberán proponer un mosaico propio, justificando la elección de la base y los patrones que se siguen para la generación de llenos y vacíos.

\section{Niveles de complejidad de la tarea}

La propuesta parte de considerar que esa actividad de varias sesiones se desarrollaría en una sola con tres niveles de trabajo:

El docente se encargaría de supervisar el correcto trabajo de la misma y prestar especial atención a la parte de refuerzo educativo.

La tarea se mantiene grupal pero en este caso con equipos homogéneos de acuerdo al nivel de competencia curricular del alumnado. Si algún grupo avanza más rápido siempre puede seguir las propuestas del grupo siguiente.

\section{Nivel Bajo}

Trabajo basado en la experiencia manipulativa de los movimientos en el plano, para afianzar los conceptos, elementos de cada movimiento, puntos invariables...

\section{Nivel Medio}

Partir de comprender con qué movimientos se genera una unidad base de los azulejos, luego trabajar composiciones en conjunto.

\section{Nivel Alto}

Descubrir los movimientos de unidades y de los conjuntos de las unidades. Analizar cómo los diferentes movimientos generan formas complejas jugando con el lleno y vacío. Distinguir y crear patrones. 


\section{Bibliografía}

Carmona Jiménez, J.L. (2019), TFM: Movimientos en el arte. Teselaciones. Granada UGR,

Fernández, J.A. (2016). Análisis de contenido. En A. Moreno y L. Rico. (Coords.) Elementos de didáctica de la matemática para el profesor de Secundaria. (p,103-118). Madrid, España: Ediciones Pirámide.

Flores, P. y Lupiañez, J.L. (2016). Expectativas de aprendizaje. En A. Moreno y L. Rico. (Coords.) Elementos de didáctica de la matemática para el profesor de Secundaria. (p,177-194). Madrid, España: Ediciones Pirámide.

Flores, P., Ramirez, R. y del Río, A. (2015). Sentido espacial. En P. Flores y L. Rico (Coords), Enseñanza y aprendizaje de las matemáticas en Educación Primaria. (p,125-146). Madrid, España: Ediciones Pirámide.

Gualdrón, E. (2006). Estrategias correctas y erróneas en tareas relacionadas con la semejanza. Universidad de Pamplona, Colombia. Universidad de Valencia, España.

Hart, K. (1984) Ratio: Children's strategies and errors. Windsor: NFER-Nelson

Lupiañez, J.L. (2016). Sistemas de representación. En A. Moreno y L. Rico. (Coords.) Elementos de didáctica de la matemática para el profesor de Secundaria. (p,119-138). Madrid, España: Ediciones Pirámide.

Lupiáñez, J.L. y Rico, L. (2015). Aprender las matemáticas escolares. En P. Flores y L. Rico (Coords), Enseñanza y aprendizaje de las matemáticas en Educación Primaria. (p,41-87). Madrid, España: Ediciones Pirámide.

Moreno, M.F., Gil, F. y Montoro, A.B. (2015). Sentido de la medida. En P. Flores y L. Rico (Coords), Enseñanza y aprendizaje de las matemáticas en Educación Primaria.(p,147-170). Madrid, España: Ediciones Pirámide. 
Moreno, A. y Ramírez, R. (2016). Variables y funciones de las tareas matemáticas. En A. Moreno y L. Rico. (Coords.) Elementos de didáctica de la matemática para el profesor de Secundaria. (p,243-258). Madrid, España: Ediciones Pirámide.

Moreno, A.; Rico, L. (Coords.) (2016) Elementos de didáctica de la matemática para el profesor de Secundaria. Madrid, España: Ediciones Pirámide.

Olmo, M. A. (1993). Superficie y volumen -¿algo más que el trabajo con fórmulas? Madrid, Síntesis.

Pérez, R. (2019) Alhambra. Belleza Abstracta. Granada, España: Patronato de la Alhambra y el Generalife.

Ramírez, R. (2016). Atención a la diversidad. En A. Moreno y L. Rico. (Coords.) Elementos de didáctica de la matemática para el profesor de Secundaria. (p,365379). Madrid, España: Ediciones Pirámide.

Serrano Luque, A.M. (2019) TFM: El sentido espacial en la enseñanza de la geometría: análisis de un libro de texto. Granada UGR

Wagman, H.G. (1975) The child's conception of area measure. En M. Rosskopf. (Ed) Children's mathematical concepts: six Piagetian studies in mathematical education. New York. Teacher College, Columbia University.

Flores, P. El puzzle de la pajarita. ttps://www.ugr.es/ pflores/textos/aRTICULOS/ Propuestas/PUZZLE_PAJARITA.pdf

http://sinewton.org/numeros/numeros/69/ideas_03.pdf

https://www.ugr.es/ sevimeco/documentos/edu_multimedia/areas/6.htm 


\section{Anexo I}

\section{Objetivos Generales}

El análisis curricular normativo se ha comenzado con los Objetivos Generales que marca la comunidad andaluza (BOJA 2016, pag 189-211). Aunque aparecen desglosados para cada curso y modalidad, son los mismos en todos ellos.

Se enumeran aquellos más acordes para el ámbito de la geometría y la medida:

1. Mejorar sus habilidades de pensamiento reflexivo y crítico e incorporar al lenguaje y modos de argumentación la racionalidad y las formas de expresión y razonamiento matemático, tanto en los procesos matemáticos, científicos y tecnológicos como en los distintos ámbitos de la actividad humana.

2. Reconocer y plantear situaciones susceptibles de ser formuladas en términos matemáticos, elaborar y utilizar diferentes estrategias para abordarlas y analizar los resultados utilizando los recursos más apropiados.

5. Identificar las formas y relaciones espaciales que encontramos en nuestro entorno, analizar las propiedades y relaciones geométricas implicadas y ser sensible a la belleza que generan, al tiempo que estimulan la creatividad y la imaginación.

6. Utilizar de forma adecuada las distintas herramientas tecnológicas (calculadora, ordenador, dispositivo móvil, pizarra digital interactiva, etc.) tanto para realizar cálculos como para buscar, tratar y representar informaciones de índole diversa y también como ayuda en el aprendizaje.

8. Elaborar estrategias personales para el análisis de situaciones concretas y la identificación y resolución de problemas, utilizando distintos recursos e instrumentos y valorando la conveniencia de las estrategias utilizadas en función del análisis de los resultados y de su carácter exacto o aproximado.

9. Manifestar una actitud positiva ante la resolución de problemas y mostrar confianza en su propia capacidad para enfrentarse a ellos con éxito, adquiriendo un nivel de autoestima adecuado que le permita disfrutar de los aspectos creativos, manipulativos, estéticos, prácticos y utilitarios de las matemáticas.

10. Integrar los conocimientos matemáticos en el conjunto de saberes que se van adquiriendo desde las distintas áreas de modo que puedan emplearse de forma creativa, analítica y crítica.

11. Valorar las matemáticas como parte integrante de la cultura andaluza, tanto desde un punto de vista histórico como desde la perspectiva de su papel en la sociedad 
actual, apreciar el conocimiento matemático acumulado por la humanidad y su aportación al desarrollo social, económico y cultural.

\section{Contenidos, criterios de evaluación y estándares de aprendizaje evaluables}

Se recogen los contenidos, criterios y estándares referidos a geometría y medida, tanto de la norma estatal (BOE, 2015, p. 389-422) como la andaluza, que es la que marca las competencias clave que se trabajan en cada estándar (BOJA, 2016, p. 189-211). Se ha desglosado Primero y Segundo de la ESO siguiendo la normativa de Andalucía, puesto que a nivel nacional los criterios y estándares a alcanzar se fijan sólo para el final de ciclo, no por cursos.

El Bloque 1, transversal y de aplicación en el resto de bloques, al igual que se ha visto con los objetivos generales, se repite en cada una de las asignaturas y modalidades, por lo que se incluirá una sola vez en este anexo.

Tabla 8.

Contenidos, criterios de evaluación y actitudes: Bloque 1. Todos los niveles y modalidades.

\begin{tabular}{|c|c|c|}
\hline Contenidos & Criterios de evaluación & Estándares aprendizaje eval. \\
\hline \multicolumn{3}{|c|}{ Bloque 1. Procesos, métodos y actitudes en matemáticas } \\
\hline \multirow{3}{*}{$\begin{array}{l}\text { Planificación del proceso de re- } \\
\text { solución de problemas. } \\
\text { Estrategias y procedimientos } \\
\text { puestos en práctica: uso del len- } \\
\text { guaje apropiado (gráfico, numé- } \\
\text { rico, algebraico, etc.), reformu- } \\
\text { lación del problema, resolver su- } \\
\text { bproblemas, recuento exhausti- } \\
\text { vo, empezar por casos particula- } \\
\text { res sencillos, buscar regularida- } \\
\text { des y leyes, etc. }\end{array}$} & $\begin{array}{l}\text { 1. Expresar verbalmente, de for- } \\
\text { ma razonada, el proceso seguido } \\
\text { en la resolución de un problema. } \\
\text { CCL, CMCT. }\end{array}$ & $\begin{array}{l}\text { 1.1. Expresa verbalmente, de } \\
\text { forma razonada, el proceso se- } \\
\text { guido en la resolución de un } \\
\text { problema, con el rigor y la pre- } \\
\text { cisión adecuada }\end{array}$ \\
\hline & \multirow{3}{*}{$\begin{array}{l}\text { 2. Utilizar procesos de razona- } \\
\text { miento y estrategias de resolu- } \\
\text { ción de problemas, realizando } \\
\text { los cálculos necesarios y com- } \\
\text { probando las soluciones obten- } \\
\text { das. } \\
\text { CMCT, CAA. }\end{array}$} & $\begin{array}{l}\text { 2.1. Analiza y comprende el } \\
\text { enunciado de los problemas (da- } \\
\text { tos, relaciones entre los datos, } \\
\text { contexto del problema). }\end{array}$ \\
\hline & & $\begin{array}{l}\text { 2.3. Realiza estimaciones y ela- } \\
\text { bora conjeturas sobre los resul- } \\
\text { tados de los problemas a resol- } \\
\text { ver, valorando su utilidad y efi- } \\
\text { cacia. }\end{array}$ \\
\hline $\begin{array}{l}\text { Reflexión sobre los resultados: } \\
\text { revisión de las operaciones utili- } \\
\text { zadas, asignación de unidades a } \\
\text { los resultados, comprobación e } \\
\text { interpretación de las soluciones } \\
\text { en el contexto de la situación, } \\
\text { búsqueda de otras formas de re- } \\
\text { solución, etc. }\end{array}$ & & $\begin{array}{l}\text { 2.4. Utiliza estrategias heurísti- } \\
\text { cas y procesos de razonamiento } \\
\text { en la resolución de problemas, } \\
\text { reflexionando sobre el proceso } \\
\text { de resolución de problemas. }\end{array}$ \\
\hline $\begin{array}{l}\text { Planteamiento de investigacio- } \\
\text { nes matemáticas escolares en } \\
\text { contextos numéricos, geométri- } \\
\text { cos, funcionales, estadísticos y }\end{array}$ & $\begin{array}{l}\text { 3. Describir y analizar situacio- } \\
\text { nes de cambio, para encontrar } \\
\text { patrones, regularidades y leyes } \\
\text { matemáticas, en contextos nu- } \\
\text { méricos, geométricos, funciona- } \\
\text { les, estadísticos y probabilísti- }\end{array}$ & $\begin{array}{l}\text { 3.1. Identifica patrones, regulari- } \\
\text { dades y leyes matemáticas en si- } \\
\text { tuaciones de cambio, en contex- } \\
\text { tos numéricos, geométricos, fun- } \\
\text { cionales, estadísticos y probabi- } \\
\text { lísticos }\end{array}$ \\
\hline
\end{tabular}


probabilísticos.

Práctica de los procesos de matematización y modelización, en contextos de la realidad y en contextos matemáticos.

Confianza en las propias capacidades para desarrollar actitudes adecuadas y afrontar las dificultades propias del trabajo científi- 6 . co.

Utilización de medios tecnológicos en el proceso de aprendizaje para:

c). facilitar la comprensión de propiedades geométricas o funcionales y la realización de cálculos de tipo numérico, algebraico o estadístico.

e). la elaboración de informes y documentos sobre los procesos llevados a cabo y los resultados y conclusiones obtenidos.

f). comunicar y compartir, en entornos apropiados, la información y las ideas matemáticas cos, valorando su utilidad para

hacer predicciones. CCL,

CMCT, CAA

5. Elaborar y presentar informes 5.1. Expone y defiende el procesobre el proceso, resultados y so seguido además de las conconclusiones obtenidas en los clusiones obtenidas utilizando procesos de investigación. distintos lenguajes: algebraico, CCL, CAA, CSC, SIEP.

gráfico, geométrico, estadístico/ probabilístico.

6. Desarrollar procesos de mate- 6.2. Establece conexiones entre matización en contextos de la un problema del mundo real y el realidad cotidiana (numéricos, mundo matemático: identificangeométricos, funcionales, esta- do el problema o problemas madísticos o probabilísticos) a par- temáticos que subyacen en él y tir de la identificación de proble- los conocimientos matemáticos mas en situaciones problemáti- necesarios.

cas de la realidad. CMCT, CAA,

CSC, SIEP.

9. Superar bloqueos e inseguri- 9.1. Toma decisiones en los prodades ante la resolución de si- cesos de resolución de probletuaciones desconocidas. CMCT, mas, de investigación y de mateCAA, SIEP. matización o de modelización, valorando las consecuencias de las mismas y su conveniencia por su sencillez y utilidad.

10. Reflexionar sobre las deci- 10.1. Reflexiona sobre los prosiones tomadas, aprendiendo de blemas resueltos y los procesos ello para situaciones similares futuras. CMCT, CAA, SIEP desarrollados, valorando la potencia y sencillez de las ideas claves, aprendiendo para situaciones futuras similares.

11. Emplear las herramientas 11.4. Recrea entornos y objetos tecnológicas adecuadas, de for- geométricos con herramientas ma autónoma, realizando cálcu- tecnológicas interactivas para los numéricos, algebraicos o es- mostrar, analizar y comprender tadísticos, haciendo representa- propiedades geométricas.

ciones gráficas, recreando situa-

ciones matemáticas mediante simu-

laciones o analizando con sentido críti-

co situaciones diversas que ayuden a la

comprensión de conceptos matemáticos

o a la resolución de problemas.

CMCT, CD, CAA.

12. Utilizar las tecnologías de la 12.1. Elabora documentos digiinformación y la comunicación tales propios (texto, presentade modo habitual en el proceso ción, imagen, video, sonido,...), de aprendizaje, buscando, anali- como resultado del proceso de zando y seleccionando informa- búsqueda, análisis y selección ción relevante en Internet o en de información relevante, con la otras fuentes, elaborando docu- herramienta tecnológica adecuamentos propios, haciendo expo- da, y los comparte para su discusiciones y argumentaciones de sión o difusión.

los mismos y compartiendo éstos 


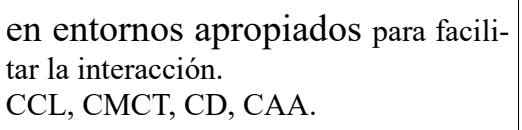

Nota: Elaboración propia a partir de BOE (2015) y BOJA (2016)

Para el resto de cursos se enumeran los tres elementos atendiendo a los focos que se van a trabajar.

Tabla 9 .

Contenidos, criterios de evaluación y actitudes: Bloque $3.3^{\circ}$ ESO Matemáticas Orientadas a Enseñanzas Académicas

\begin{tabular}{|c|c|c|}
\hline Contenidos & Criterios de evaluación & Estándares aprendizaje eval. \\
\hline \multicolumn{3}{|c|}{ Bloque 3. Geometría } \\
\hline \multirow{2}{*}{$\begin{array}{l}\text { Geometría del plano. } \\
\text { Lugar geométrico. } \\
\text { Teorema de Tales. } \\
\text { División de un segmento en par- } \\
\text { tes proporcionales. } \\
\text { Aplicación a la resolución de } \\
\text { problemas. }\end{array}$} & \multirow{3}{*}{$\begin{array}{l}\text { 2. Utilizar el teorema de Tales y } \\
\text { las fórmulas usuales para reali- } \\
\text { zar medidas indirectas de ele- } \\
\text { mentos inaccesibles y para obte- } \\
\text { ner las medidas de longitudes, } \\
\text { áreas y volúmenes de los cuer- } \\
\text { pos elementales, de ejemplos to- } \\
\text { mados de la vida real, represen- } \\
\text { taciones artísticas como pintura } \\
\text { o arquitectura, o de la resolución } \\
\text { de problemas geométricos. } \\
\text { CMCT, CAA, CSC, CEC }\end{array}$} & $\begin{array}{l}\text { 2.1. Calcula el perímetro y el } \\
\text { área de polígonos y de figuras } \\
\text { circulares en problemas contex- } \\
\text { tualizados aplicando fórmulas y } \\
\text { técnicas adecuadas. }\end{array}$ \\
\hline & & $\begin{array}{l}\text { 2.2. Divide un segmento en par- } \\
\text { tes proporcionales a otros dados } \\
\text { y establece relaciones de propor- } \\
\text { cionalidad entre los elementos } \\
\text { homólogos de dos polígonos se- } \\
\text { mejantes }\end{array}$ \\
\hline \multirow{5}{*}{$\begin{array}{l}\text { Traslaciones, giros y simetrías } \\
\text { en el plano. } \\
\text { Geometría del espacio. } \\
\text { Planos de simetría en los polie- } \\
\text { dros }\end{array}$} & & $\begin{array}{l}\text { 2.3. Reconoce triángulos seme- } \\
\text { jantes y, en situaciones de seme- } \\
\text { janza, utiliza el teorema de Tales } \\
\text { para el cálculo indirecto de lon- } \\
\text { gitudes en contextos diversos. }\end{array}$ \\
\hline & $\begin{array}{l}\text { 3. Calcular (ampliación o reduc- } \\
\text { ción) las dimensiones reales de } \\
\text { figuras dadas en mapas o planos, } \\
\text { conociendo la escala. } \\
\text { CMCT, CAA. }\end{array}$ & $\begin{array}{l}\text { 3.1. Calcula dimensiones reales } \\
\text { de medidas de longitudes y de } \\
\text { superficies en situaciones de se- } \\
\text { mejanza: planos, mapas, fotos } \\
\text { aéreas, etc. }\end{array}$ \\
\hline & \multirow{2}{*}{$\begin{array}{l}\text { 4. Reconocer las } \\
\text { transformaciones que llevan } \\
\text { de una figura a otra mediante } \\
\text { movimiento en el plano, } \\
\text { aplicar dichos movimientos y } \\
\text { analizar diseños cotidianos, } \\
\text { obras de arte y } \\
\text { configuraciones presentes en } \\
\text { la naturaleza. } \\
\text { CMCT, CAA, CSC, CEC. }\end{array}$} & $\begin{array}{l}\text { 4.1. Identifica los elementos más } \\
\text { característicos de los movimien- } \\
\text { tos en el plano presentes en la } \\
\text { naturaleza, en diseños cotidianos } \\
\text { u obras de arte. }\end{array}$ \\
\hline & & $\begin{array}{l}\text { 4.2. Genera creaciones propias } \\
\text { mediante la composición de mo- } \\
\text { vimientos, empleando herra- } \\
\text { mientas tecnológicas cuando sea } \\
\text { necesario. }\end{array}$ \\
\hline & $\begin{array}{l}\text { 5. Identificar centros, ejes y pla- } \\
\text { nos de simetría de figuras planas } \\
\text { y poliedros. } \\
\text { CMCT. }\end{array}$ & $\begin{array}{l}\text { 5.1. Identifica los principales } \\
\text { poliedros y cuerpos de revolu- } \\
\text { ción, utilizando el lenguaje con } \\
\text { propiedad para referirse a los }\end{array}$ \\
\hline
\end{tabular}




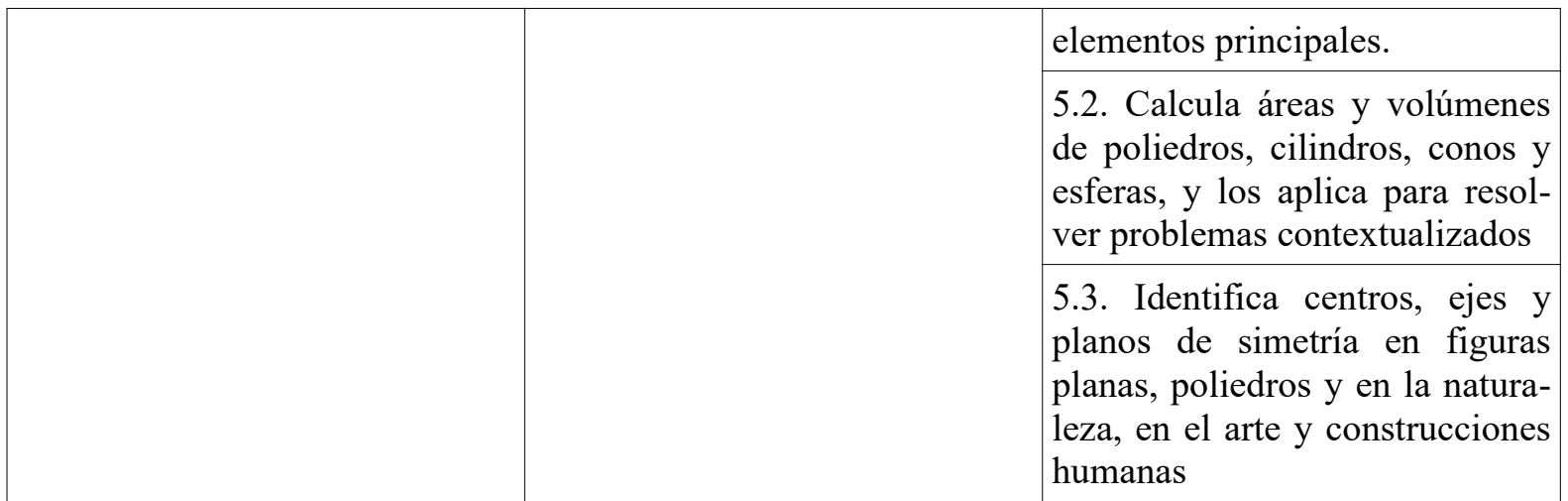

Nota: Elaboración propia a partir de BOE (2015) y BOJA (2016)

Tabla 10 .

Contenidos, criterios de evaluación y actitudes: Bloque 3. $4^{\circ}$ ESO Matemáticas Orientadas a Enseñanzas Académicas

\begin{tabular}{|c|c|c|}
\hline Contenidos & Criterios de evaluación & Estándares aprendizaje eval. \\
\hline \multicolumn{3}{|c|}{ Bloque 3. Geometría } \\
\hline \multirow{2}{*}{$\begin{array}{l}\text { Aplicación de los conocimientos } \\
\text { geométricos a la resolución de } \\
\text { problemas métricos en el mundo } \\
\text { físico: medida de longitudes, } \\
\text { áreas y volúmenes. } \\
\text { Semejanza. Figuras semejantes. } \\
\text { Razón entre longitudes, áreas y } \\
\text { volúmenes de cuerpos semejan- } \\
\text { tes. }\end{array}$} & \multirow{2}{*}{$\begin{array}{l}\text { 2. Calcular magnitudes efec- } \\
\text { tuando medidas directas e indi- } \\
\text { rectas a partir de situaciones rea- } \\
\text { les, empleando los instrumentos, } \\
\text { técnicas o fórmulas más adecua- } \\
\text { das y aplicando las unidades de } \\
\text { medida. } \\
\text { CMCT, CAA. }\end{array}$} & $\begin{array}{l}\text { 2.1. Utiliza las herramientas tec- } \\
\text { nológicas, estrategias y fórmulas } \\
\text { apropiadas para calcular ángu- } \\
\text { los, longitudes, áreas y volúme- } \\
\text { nes de cuerpos y figuras geomé- } \\
\text { tricas. }\end{array}$ \\
\hline & & $\begin{array}{l}\text { 2.3. Utiliza las fórmulas para } \\
\text { calcular áreas y volúmenes de } \\
\text { triángulos, cuadriláteros, círcu- } \\
\text { los, paralelepípedos, pirámides, } \\
\text { cilindros, conos y esferas y las } \\
\text { aplica para resolver problemas } \\
\text { geométricos, asignando las uni- } \\
\text { dades apropiadas. }\end{array}$ \\
\hline
\end{tabular}

Nota: Elaboración propia a partir de BOE (2015) y BOJA (2016)

Tabla 11.

Contenidos, criterios de evaluación y actitudes: Bloque 3. $3^{\circ}$ ESO Matemáticas Orientadas a Enseñanzas Aplicadas

\begin{tabular}{|l|l|l|}
\hline Contenidos & Criterios de evaluación & Estándares aprendizaje eval. \\
\hline \multicolumn{2}{|c|}{ Bloque 3. Geometría } \\
\hline $\begin{array}{l}\text { Teorema de Tales. } \\
\text { División de un segmento en par- } \\
\text { tes proporcionales. } \\
\begin{array}{l}\text { Aplicación a la resolución de } \\
\text { problemas. }\end{array}\end{array}$ & $\begin{array}{l}\text { 1. Reconocer y describir los } \\
\text { elementos y propiedades } \\
\text { características de las figuras } \\
\text { planas, los cuerpos } \\
\text { geométricos elementales y }\end{array}$ & $\begin{array}{l}\text { 1.4. Calcula el perímetro de po- } \\
\text { lígonos, la longitud de circunfe- } \\
\text { rencias, el área de polígonos y } \\
\text { de figuras circulares, en proble- } \\
\text { mas contextualizados aplicando } \\
\text { fórmulas y técnicas adecuadas. }\end{array}$ \\
\hline
\end{tabular}




\begin{tabular}{|c|c|c|}
\hline \multirow[t]{5}{*}{$\begin{array}{l}\text { en el plano. } \\
\text { Geometría del espacio: áreas y } \\
\text { volúmenes. }\end{array}$} & \multirow{2}{*}{$\begin{array}{l}\text { 2. Utilizar el teorema de Tales } \\
\text { y las fórmulas usuales para } \\
\text { realizar medidas indirectas de } \\
\text { elementos inaccesibles y para } \\
\text { obtener medidas de } \\
\text { longitudes, de ejemplos } \\
\text { tomados de la vida real, } \\
\text { representaciones artísticas } \\
\text { como pintura o arquitectura, o } \\
\text { de la resolución de problemas } \\
\text { geométricos. } \\
\text { CMCT, CAA, CSC, CEC. }\end{array}$} & $\begin{array}{l}\text { 2.1. Divide un segmento en par- } \\
\text { tes proporcionales a otros dados. } \\
\text { Establece relaciones de propor- } \\
\text { cionalidad entre los elementos } \\
\text { homólogos de dos polígonos se- } \\
\text { mejantes. }\end{array}$ \\
\hline & & $\begin{array}{l}\text { 2.2. Reconoce triángulos seme- } \\
\text { jantes, y en situaciones de seme- } \\
\text { janza utiliza el teorema de Tales } \\
\text { para el cálculo indirecto de lon- } \\
\text { gitudes. }\end{array}$ \\
\hline & $\begin{array}{l}\text { 3. Calcular (ampliación o } \\
\text { reducción) las dimensiones } \\
\text { reales de figuras dadas en } \\
\text { mapas o planos, conociendo } \\
\text { la escala. CMCT, CAA. }\end{array}$ & $\begin{array}{l}\text { 3.1. Calcula dimensiones reales } \\
\text { de medidas de longitudes en si- } \\
\text { tuaciones de semejanza: planos, } \\
\text { mapas, fotos aéreas, etc. }\end{array}$ \\
\hline & \multirow{2}{*}{$\begin{array}{l}\text { 4. Reconocer las } \\
\text { transformaciones que llevan } \\
\text { de una figura a otra mediante } \\
\text { movimiento en el plano, } \\
\text { aplicar dichos movimientos y } \\
\text { analizar diseños cotidianos, } \\
\text { obras de arte y } \\
\text { configuraciones presentes en } \\
\text { la naturaleza. } \\
\text { CMCT, CAA, CSC, CEC. }\end{array}$} & $\begin{array}{l}\text { 4.1. Identifica los elementos más } \\
\text { característicos de los movimien- } \\
\text { tos en el plano presentes en la } \\
\text { naturaleza, en diseños cotidianos } \\
\text { u obras de arte. }\end{array}$ \\
\hline & & $\begin{array}{l}\text { 4.2. Genera creaciones propias } \\
\text { mediante la composición de mo- } \\
\text { vimientos, empleando herra- } \\
\text { mientas tecnológicas cuando sea } \\
\text { necesario. }\end{array}$ \\
\hline
\end{tabular}

Nota: Elaboración propia a partir de BOE (2015) y BOJA (2016)

Tabla 12.

Contenidos, criterios de evaluación y actitudes: Bloque 3. $4^{\circ}$ ESO Matemáticas Orientadas a Enseñanzas Aplicadas

\begin{tabular}{|c|c|c|}
\hline Contenidos & Criterios de evaluación & Estándares aprendizaje eval. \\
\hline \multicolumn{3}{|c|}{ Bloque 3. Geometría } \\
\hline \multirow{3}{*}{$\begin{array}{l}\text { Figuras semejantes. } \\
\text { Teoremas de Tales y Pitágoras. } \\
\text { Aplicación de la semejanza para } \\
\text { la obtención indirecta de medi- } \\
\text { das. } \\
\text { Razón entre longitudes, áreas y } \\
\text { volúmenes de figuras y cuerpos } \\
\text { semejantes. Resolución de pro- } \\
\text { blemas geométricos en el mundo } \\
\text { físico: medida y cálculo de lon- } \\
\text { gitudes, áreas y volúmenes de } \\
\text { diferentes cuerpos. }\end{array}$} & \multirow{3}{*}{$\begin{array}{l}\text { 1. Calcular magnitudes efec- } \\
\text { tuando medidas directas e indi- } \\
\text { rectas a partir de situaciones rea- } \\
\text { les, empleando los instrumentos, } \\
\text { técnicas o fórmulas más adecua- } \\
\text { das, y aplicando, así mismo, la } \\
\text { unidad de medida más acorde con la } \\
\text { situación descrita. } \\
\text { CMCT, CAA. }\end{array}$} & $\begin{array}{l}\text { 1.1. Utiliza los instrumentos } \\
\text { apropiados, fórmulas y técnicas } \\
\text { apropiadas para medir ángulos, } \\
\text { longitudes, áreas y volúmenes } \\
\text { de cuerpos y figuras geométri- } \\
\text { cas, interpretando las escalas de } \\
\text { medidas. }\end{array}$ \\
\hline & & $\begin{array}{l}\text { 1.2. Emplea las propiedades de } \\
\text { las figuras y cuerpos (simetrías, } \\
\text { descomposición en figuras más } \\
\text { conocidas, etc.) y aplica el teo- } \\
\text { rema de Tales, para estimar o } \\
\text { calcular medidas indirectas }\end{array}$ \\
\hline & & 1.3. Utiliza las fórmulas para \\
\hline
\end{tabular}




\begin{tabular}{|l|l|}
\hline & $\begin{array}{l}\text { calcular perímetros, áreas y vo- } \\
\text { lúmenes de triángulos, rectángu- } \\
\text { los, círculos, prismas, pirámides, } \\
\text { cilindros, conos y esferas, y las } \\
\text { aplica para resolver problemas } \\
\text { geométricos, asignando las uni- } \\
\text { dades correctas. }\end{array}$ \\
$\begin{array}{l}\text { 1.4. Calcula medidas indirectas } \\
\text { de longitud, área y volumen me- } \\
\text { diante la aplicación del teorema } \\
\text { de Pitágoras y la semejanza de } \\
\text { triángulos. }\end{array}$ \\
\hline
\end{tabular}

Nota: Elaboración propia a partir de BOE (2015) y BOJA (2016)

Tabla 13.

Contenidos, criterios de evaluación y actitudes: Bloque 3. $1^{\circ}$ ESO Matemáticas

\begin{tabular}{|c|c|c|}
\hline Contenidos & Criterios de evaluación & Estándares aprendizaje eval. \\
\hline \multicolumn{3}{|c|}{ Bloque 3. Geometría } \\
\hline \multirow{2}{*}{$\begin{array}{l}\text { Elementos básicos de la geometría del } \\
\text { plano. } \\
\text { Relaciones y propiedades de figuras en } \\
\text { el plano: paralelismo } \\
\text { y perpendicularidad. } \\
\text { Propiedades. Figuras planas } \\
\text { elementales: triángulo, cuadrado, } \\
\text { figuras poligonales. } \\
\text { Clasificación de triángulos y } \\
\text { cuadriláteros. } \\
\text { Propiedades y relaciones. } \\
\text { Cálculo de áreas y perímetros de } \\
\text { figuras planas. } \\
\text { Cálculo de áreas por descomposición en } \\
\text { figuras simples. }\end{array}$} & \multirow{3}{*}{$\begin{array}{l}\text { 1. Reconocer y describir figuras } \\
\text { planas, sus elementos y propie- } \\
\text { dades características para clasi- } \\
\text { ficarlas, identificar situaciones, } \\
\text { describir el contexto físico, y } \\
\text { abordar problemas de la vida co- } \\
\text { tidiana. }\end{array}$} & $\begin{array}{l}\text { 1. Reconoce y describe las pro- } \\
\text { piedades características de los } \\
\text { polígonos regulares: ángulos in- } \\
\text { teriores, ángulos centrales, dia- } \\
\text { gonales, apotema, simetrías, etc. }\end{array}$ \\
\hline & & $\begin{array}{l}\text { 1.2. Define los elementos carac- } \\
\text { terísticos de los triángulos, tra- } \\
\text { zando los mismos y conociendo } \\
\text { la propiedad común a cada uno } \\
\text { de ellos, y los clasifica atendien- } \\
\text { do tanto a sus lados como a sus } \\
\text { ángulos. }\end{array}$ \\
\hline \multirow[t]{3}{*}{$\begin{array}{l}\text { Uso de herramientas informáticas para } \\
\text { estudiar formas, configuraciones y } \\
\text { relaciones geométricas. }\end{array}$} & & $\begin{array}{l}\text { 1.3. Clasifica los cuadriláteros y } \\
\text { paralelogramos atendiendo al } \\
\text { paralelismo entre sus lados } \\
\text { opuestos y conociendo sus pro- } \\
\text { piedades referentes a ángulos, } \\
\text { lados y diagonales }\end{array}$ \\
\hline & $\begin{array}{l}\text { 2. Utilizar estrategias, herra- } \\
\text { mientas tecnológicas y técnicas } \\
\text { simples de la geometría analítica } \\
\text { plana para la resolución de pro- } \\
\text { blemas de perímetros, áreas y } \\
\text { ángulos de figuras planas, utili- } \\
\text { zando el lenguaje matemático } \\
\text { adecuado expresar el procedi- } \\
\text { miento seguido en la resolución. }\end{array}$ & $\begin{array}{l}\text { 2.1. Resuelve problemas relacio- } \\
\text { nados con distancias, períme- } \\
\text { tros, superficies y ángulos de fi- } \\
\text { guras planas, en contextos de la } \\
\text { vida real, utilizando las herra- } \\
\text { mientas tecnológicas y las técni- } \\
\text { cas geométricas más apropiadas. }\end{array}$ \\
\hline & $\begin{array}{l}\text { 6. Resolver problemas que con- } \\
\text { lleven el cálculo de longitudes, } \\
\text { superficies y volúmenes del } \\
\text { mundo físico, utilizando propie- } \\
\text { dades, regularidades y relacio- }\end{array}$ & $\begin{array}{l}\text { 6.1. Resuelve problemas de la } \\
\text { realidad mediante el cálculo de } \\
\text { áreas y volúmenes de cuerpos } \\
\text { geométricos, utilizando los len- } \\
\text { guajes geométrico y algebraico }\end{array}$ \\
\hline
\end{tabular}




\begin{tabular}{|l|l|l|}
\hline & nes de los poliedros. & adecuados. \\
\hline
\end{tabular}

Nota: Elaboración propia a partir de BOE (2015) y BOJA (2016)

Tabla 14.

Contenidos, criterios de evaluación y actitudes: Bloque 3. 2 ESO Matemáticas

\begin{tabular}{|c|c|c|}
\hline Contenidos & Criterios de evaluación & Estándares aprendizaje eval. \\
\hline \multicolumn{3}{|c|}{ Bloque 3. Geometría } \\
\hline \multirow{2}{*}{$\begin{array}{l}\text { Triángulos rectángulos. } \\
\text { El teorema de Pitágoras. } \\
\text { Justificación geométrica y } \\
\text { aplicaciones. } \\
\text { Poliedros y cuerpos de } \\
\text { revolución. Elementos } \\
\text { característicos, clasificación. } \\
\text { Áreas y volúmenes. } \\
\text { Propiedades, regularidades y } \\
\text { relaciones de los poliedros. } \\
\text { Cálculo de longitudes, } \\
\text { superficies y volúmenes del } \\
\text { mundo físico. }\end{array}$} & \multirow{2}{*}{$\begin{array}{l}\text { 3. Reconocer el significado } \\
\text { aritmético del Teorema de } \\
\text { Pitágoras (cuadrados de } \\
\text { números, ternas pitagóricas) y } \\
\text { el significado geométrico } \\
\text { (áreas de cuadrados } \\
\text { construidos sobre los lados) y } \\
\text { emplearlo para resolver } \\
\text { problemas geométricos. }\end{array}$} & $\begin{array}{l}\text { 3.1. Comprende los significados } \\
\text { aritmético y geométrico del Teo- } \\
\text { rema de Pitágoras y los utiliza } \\
\text { para la búsqueda de ternas pita- } \\
\text { góricas o la comprobación del } \\
\text { teorema construyendo otros po- } \\
\text { lígonos sobre los lados del trián- } \\
\text { gulo rectángulo. }\end{array}$ \\
\hline & & $\begin{array}{l}\text { 3.2. Aplica el teorema de Pitágo- } \\
\text { ras para calcular longitudes des- } \\
\text { conocidas en la resolución de } \\
\text { triángulos y áreas de polígonos } \\
\text { regulares, en contextos geomé- } \\
\text { tricos o en contextos reales }\end{array}$ \\
\hline \multirow{2}{*}{$\begin{array}{l}\text { Semejanza: figuras } \\
\text { semejantes. Criterios de } \\
\text { semejanza. } \\
\text { Razón de semejanza y escala. } \\
\text { Razón entre longitudes, áreas } \\
\text { y volúmenes de cuerpos } \\
\text { semejantes. }\end{array}$} & \multirow{2}{*}{$\begin{array}{l}\text { 4. Analizar e identificar } \\
\text { figuras semejantes, } \\
\text { calculando la escala o razón } \\
\text { de semejanza y la razón entre } \\
\text { longitudes, áreas y volúmenes } \\
\text { de cuerpos semejantes }\end{array}$} & $\begin{array}{l}\text { 4.1. Reconoce figuras semejan- } \\
\text { tes y calcula la razón de seme- } \\
\text { janza y la razón de superficies y } \\
\text { volúmenes de figuras semejan- } \\
\text { tes. }\end{array}$ \\
\hline & & $\begin{array}{l}\text { 4.2. Utiliza la escala para resol- } \\
\text { ver problemas de la vida cotidia- } \\
\text { na sobre planos, mapas y otros } \\
\text { contextos de semejanza. }\end{array}$ \\
\hline \multirow{4}{*}{$\begin{array}{l}\text { Uso de herramientas } \\
\text { informáticas para estudiar } \\
\text { formas, configuraciones y } \\
\text { relaciones } \\
\text { geométricas. }\end{array}$} & \multirow{3}{*}{$\begin{array}{l}\text { 5. Analizar distintos cuerpos } \\
\text { geométricos (cubos, ortoedros, } \\
\text { prismas, pirámides, cilindros, } \\
\text { conos y esferas) e identificar sus } \\
\text { elementos característicos (vérti- } \\
\text { ces, aristas, caras, desarrollos } \\
\text { planos, secciones al cortar con } \\
\text { planos, cuerpos obtenidos me- } \\
\text { diante secciones, simetrías, etc.). }\end{array}$} & $\begin{array}{l}\text { 5.1. Analiza e identifica las ca- } \\
\text { racterísticas de distintos cuerpos } \\
\text { geométricos, utilizando el len- } \\
\text { guaje geométrico adecuado. }\end{array}$ \\
\hline & & $\begin{array}{l}\text { 5.2. Construye secciones senci- } \\
\text { llas de los cuerpos geométricos, } \\
\text { a partir de cortes con planos, } \\
\text { mentalmente y utilizando los } \\
\text { medios tecnológicos adecuados. }\end{array}$ \\
\hline & & $\begin{array}{l}\text { 5.3. Identifica los cuerpos geo- } \\
\text { métricos a partir de sus desarro- } \\
\text { llos planos y recíprocamente. }\end{array}$ \\
\hline & $\begin{array}{l}\text { 6. Resolver problemas que con- } \\
\text { lleven el cálculo de longitudes, } \\
\text { superficies y volúmenes del } \\
\text { mundo físico, utilizando propie- } \\
\text { dades, regularidades y relacio- } \\
\text { nes de los poliedros. }\end{array}$ & $\begin{array}{l}\text { 6.1. Resuelve problemas de la } \\
\text { realidad mediante el cálculo de } \\
\text { áreas y volúmenes de cuerpos } \\
\text { geométricos, utilizando los len- } \\
\text { guajes geométrico y algebraico } \\
\text { adecuados. }\end{array}$ \\
\hline
\end{tabular}

Nota: Elaboración propia a partir de BOE (2015) y BOJA (2016) 


\section{Anexo II}

Tarea 3: Sistema de cuerdas y tizas para el trabajo manipulativo con movimientos en el plano y piezas Tutakaboo

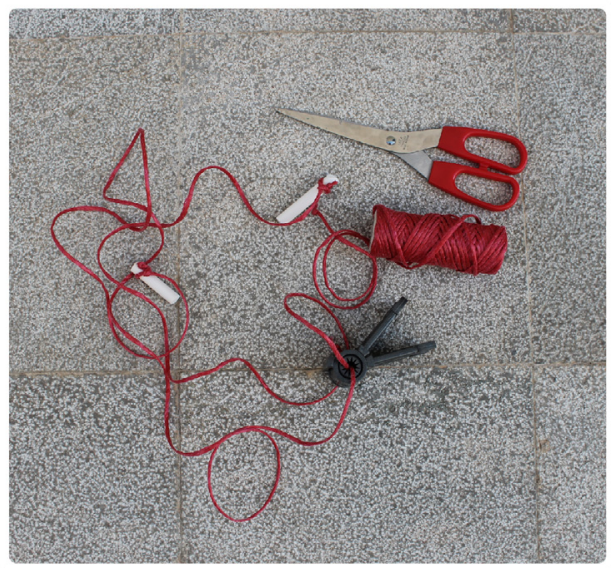

Figura 44. Material utilizado junto a Tutakaboo: cuerdas, tijeras, tizas

\section{Traslaciones}

Para representar el vector de traslación se cortan cuerdas de igual longitud. Cada una de ellas se fija a un vértice.

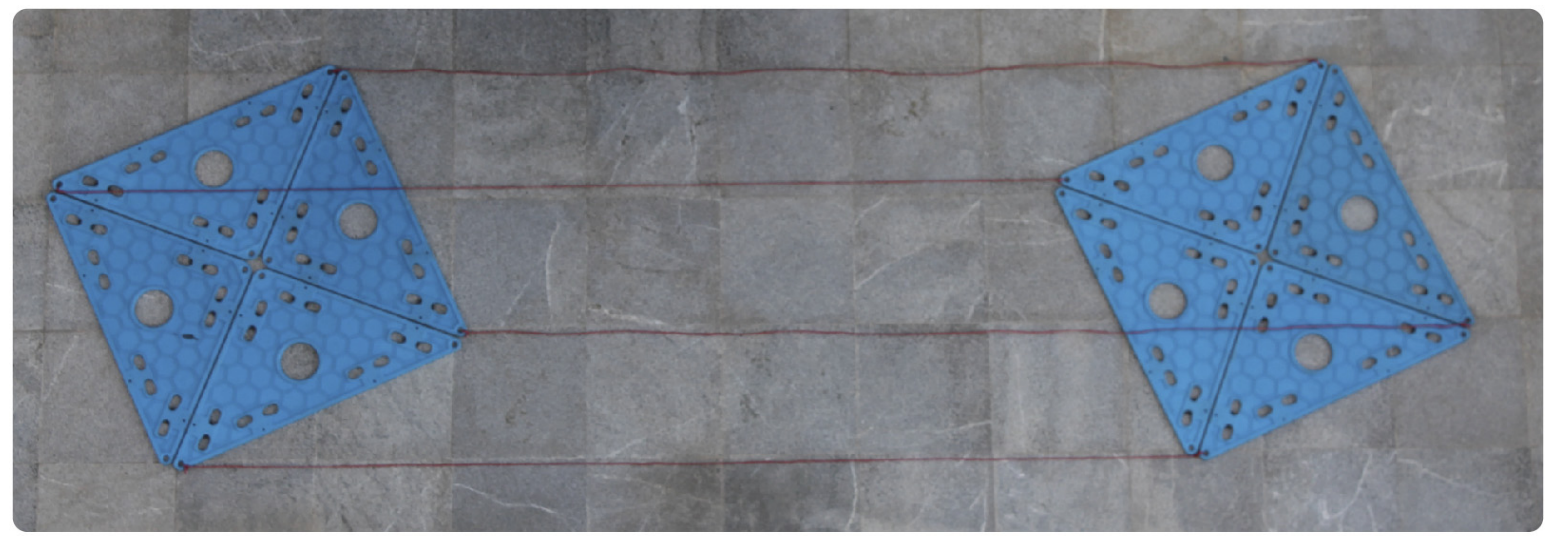

Figura 45. Ejemplo de traslación

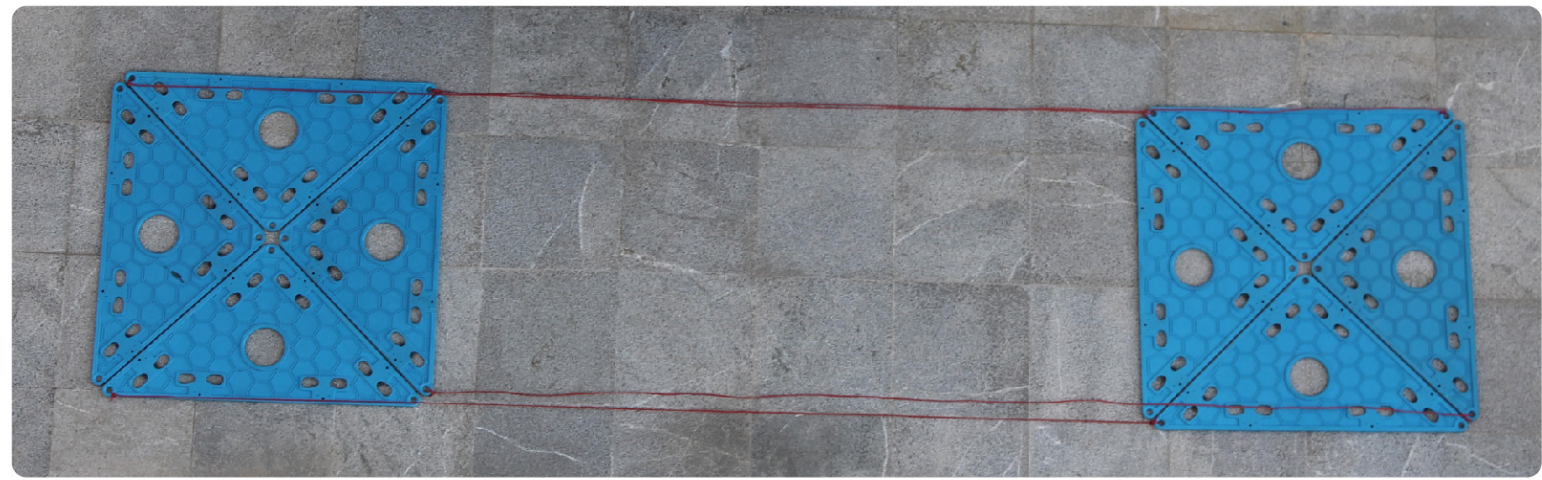

Figura 46. Ejemplo de traslación con vector paralelo a uno de los lados de la figura. 


\section{Simetría central}

Para representar el centro de simetría utilizamos una bisagra con el tornillo. Las cuerdas simbolizan las distancias entre el punto original, el centro y el simétrico.

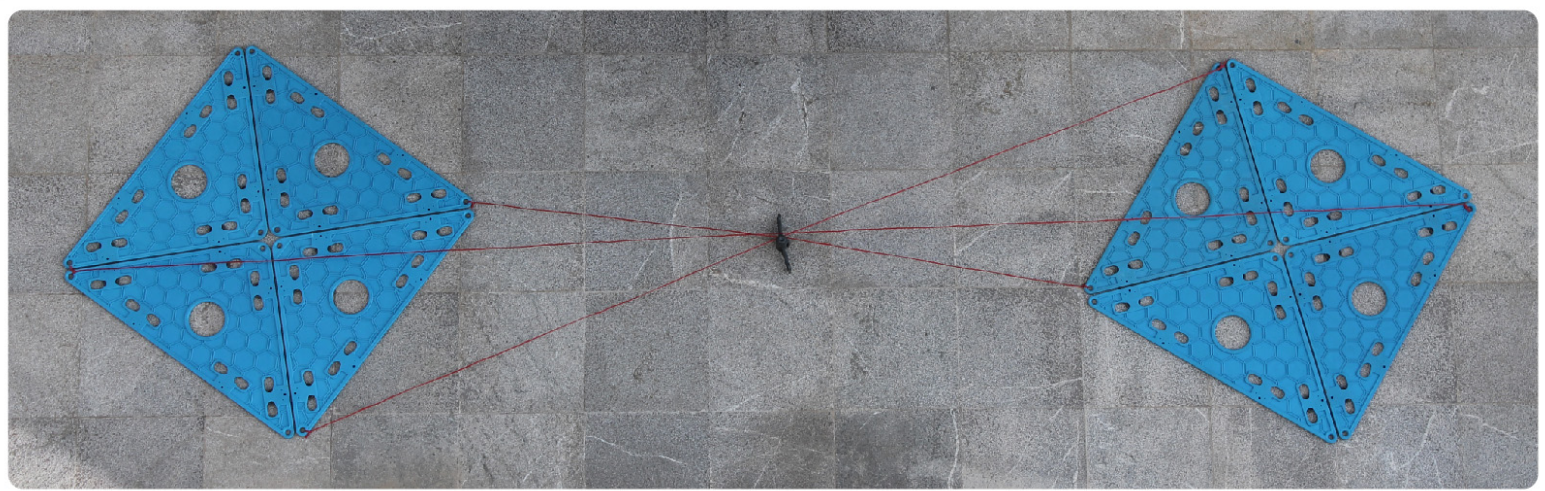

Figura 47. Ejemplo de simetría central.

\section{Simetría axial}

Para representar el eje de simetría utilizamos una cuerda o listón. A las cuerdas que muestran las distancias entre punto, eje y punto reflejado se les realiza un nudo de pescador en el entro por el que pasaremos el eje.

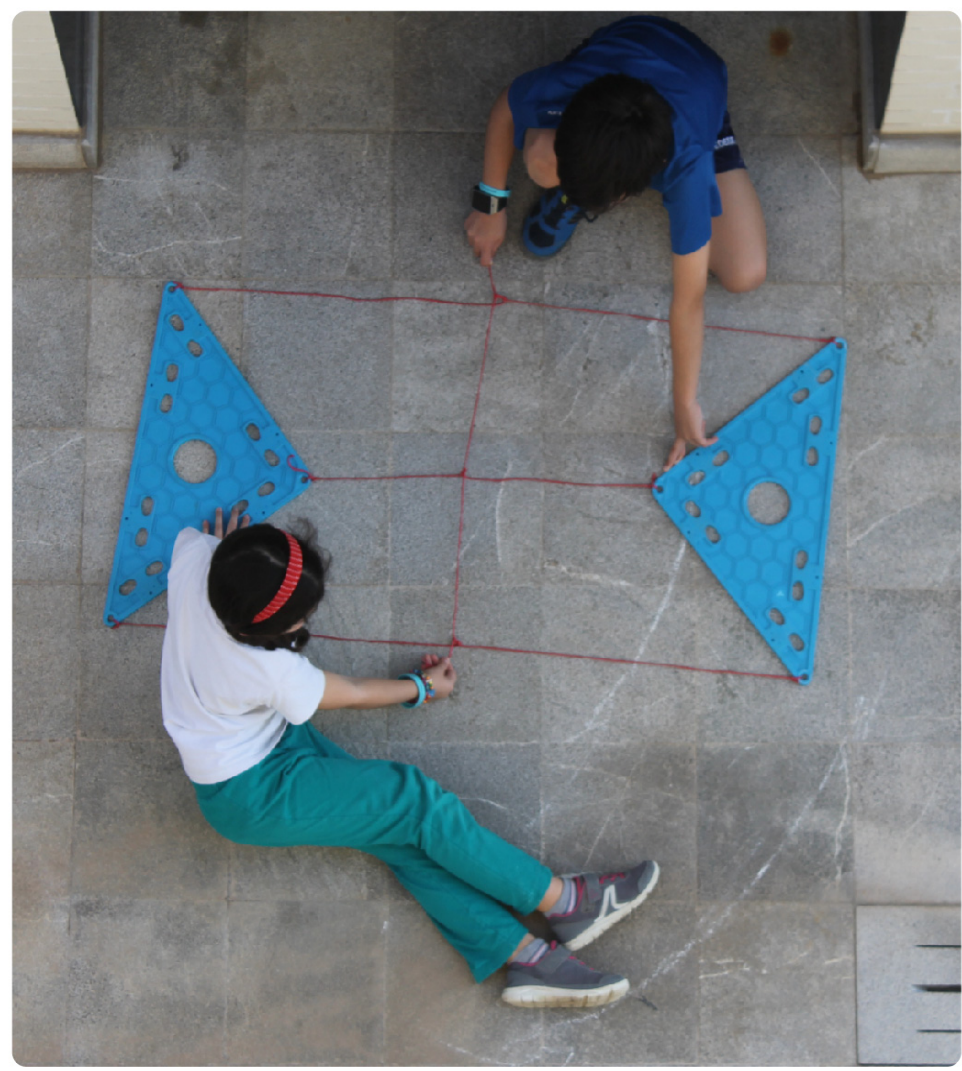

Figura 48. Ejemplo de simetría axial. 
Posteriormente pueden trabajar sin las cuerdas la composición de figuras simétricas.

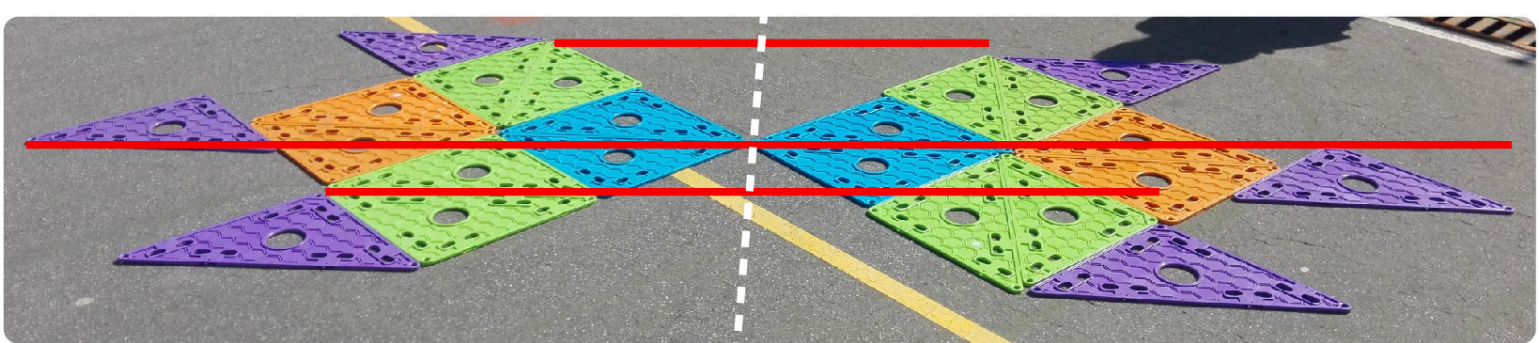

Figura 49. Ejemplo de simetría axial.

Fuente: banco de imágenes de Tutakaboo: Colegio Virgen de la Paz de Otura (Granada)

Para esta parte se les proporcionará fichas de este tipo:

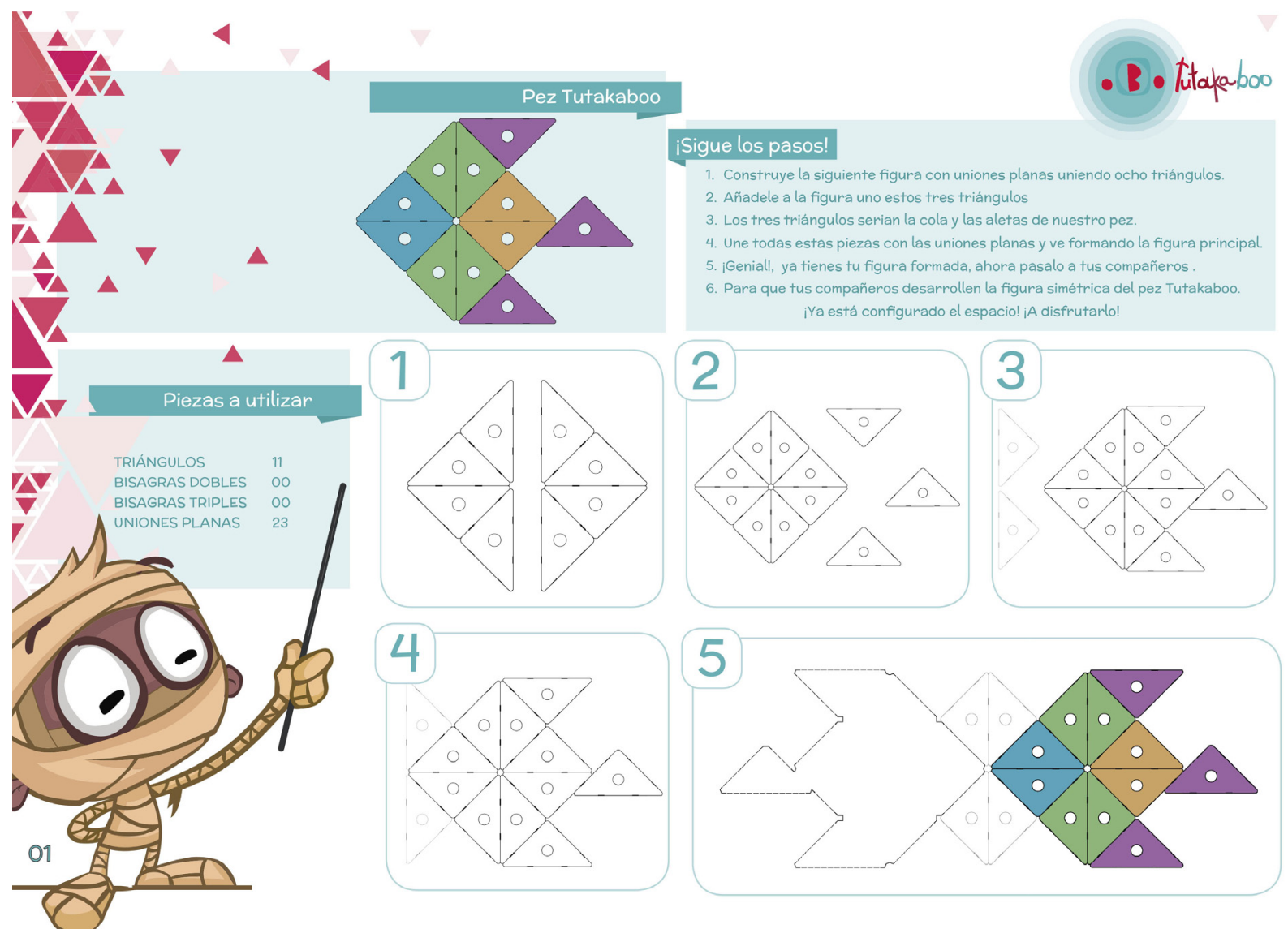

Figura 50. Ficha de composición de figuras y simetría axial

Fuente: Tutakaboo. García, A. y Medina, P. 


\section{Giro}

Para representar el giro tomamos unas cuerdas con un extremo fijo en la bisagra, que actúa como centro de giro. El otro extremo lleva un nudo corredizo al que se le fija una tiza. Se ajusta la tensión de la cuerda a cada punto de giro y se dibuja con la tiza el recorrido.
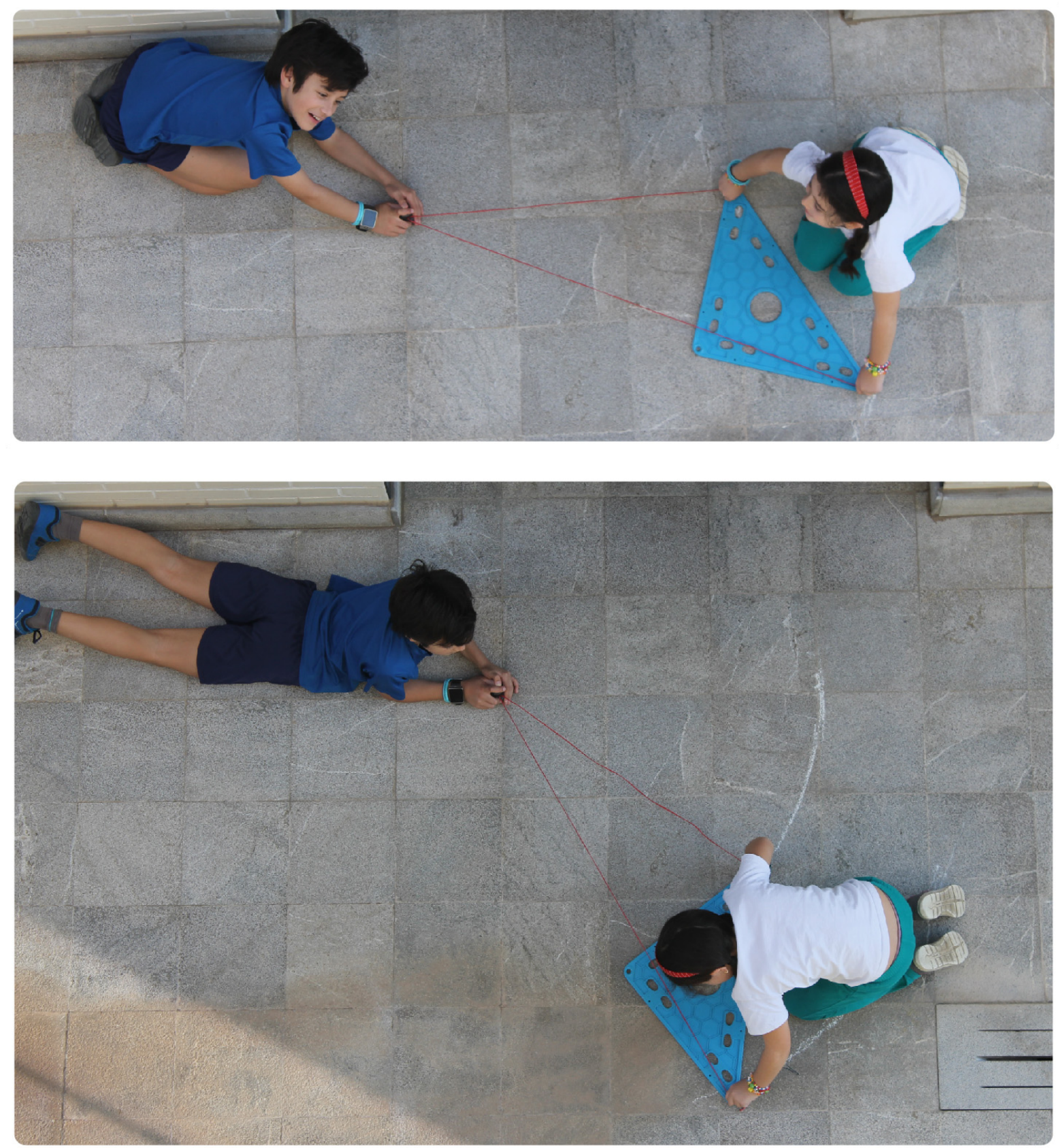

Figura 51. Trazado del giro. 


\section{Tarea 3: Fichas de mosaicos}

Estas fichas han sido elaboradas por García, A. y Medina, P. con información aportada por Pérez, R. sobre sus estudios sobre los azulejos de la Alhambra.

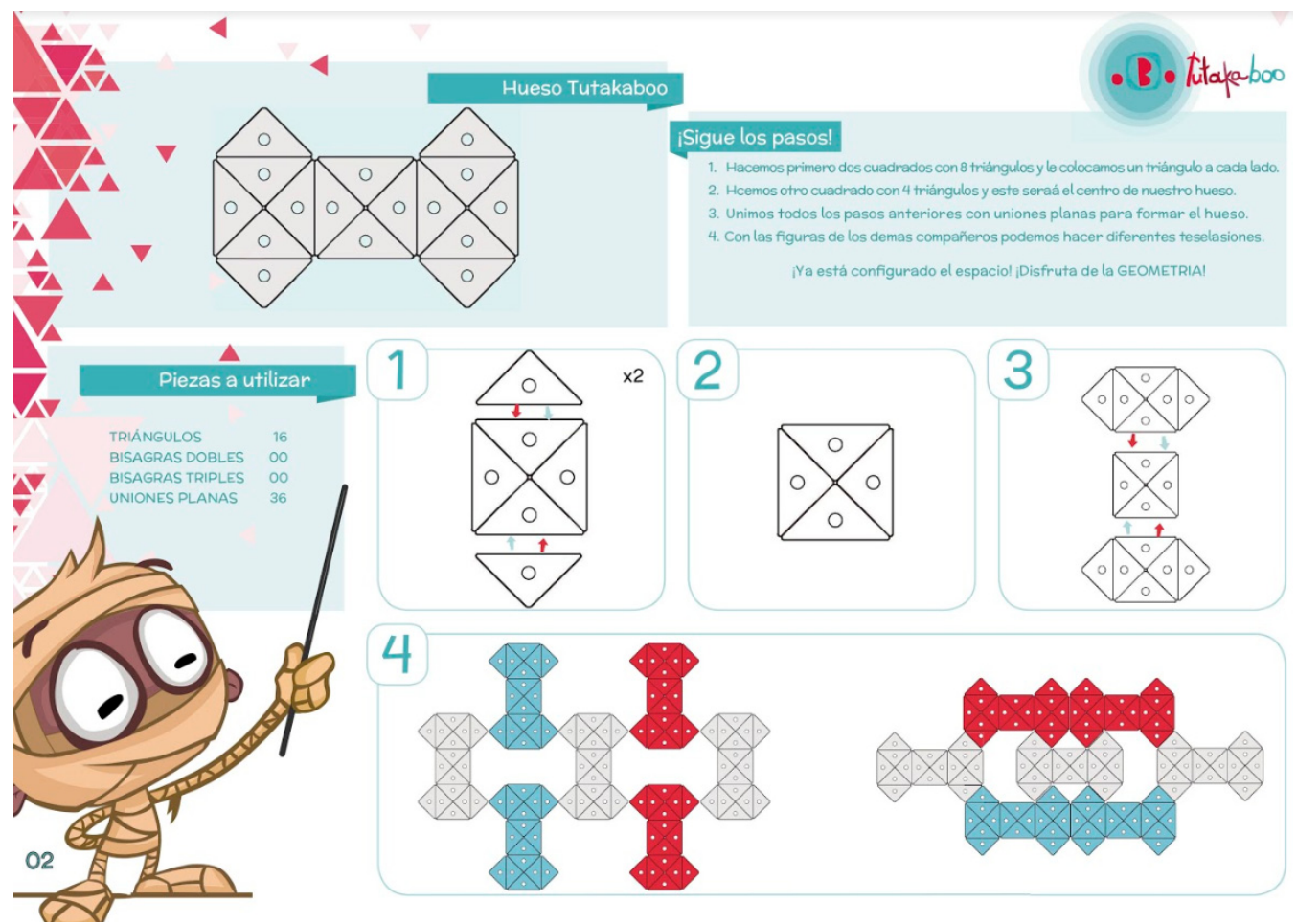

Figura 52. Ficha pata construcción del azulejo hueso

Fuente: Tutakaboo. García, A. y Medina, P.

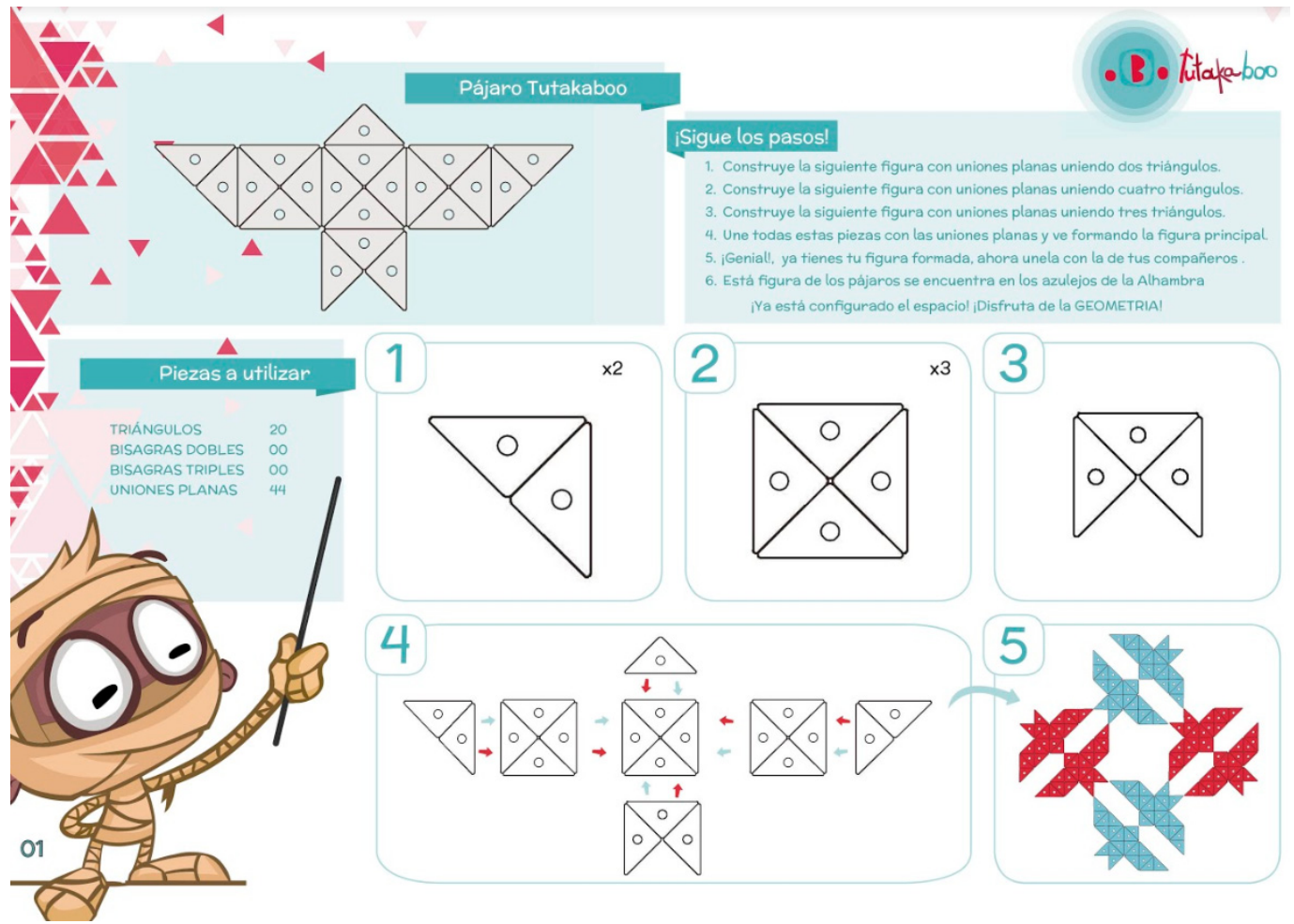

Figura 53. Ficha pata construcción del azulejo pájaro

Fuente: Tutakaboo. García, A. y Medina, P. 


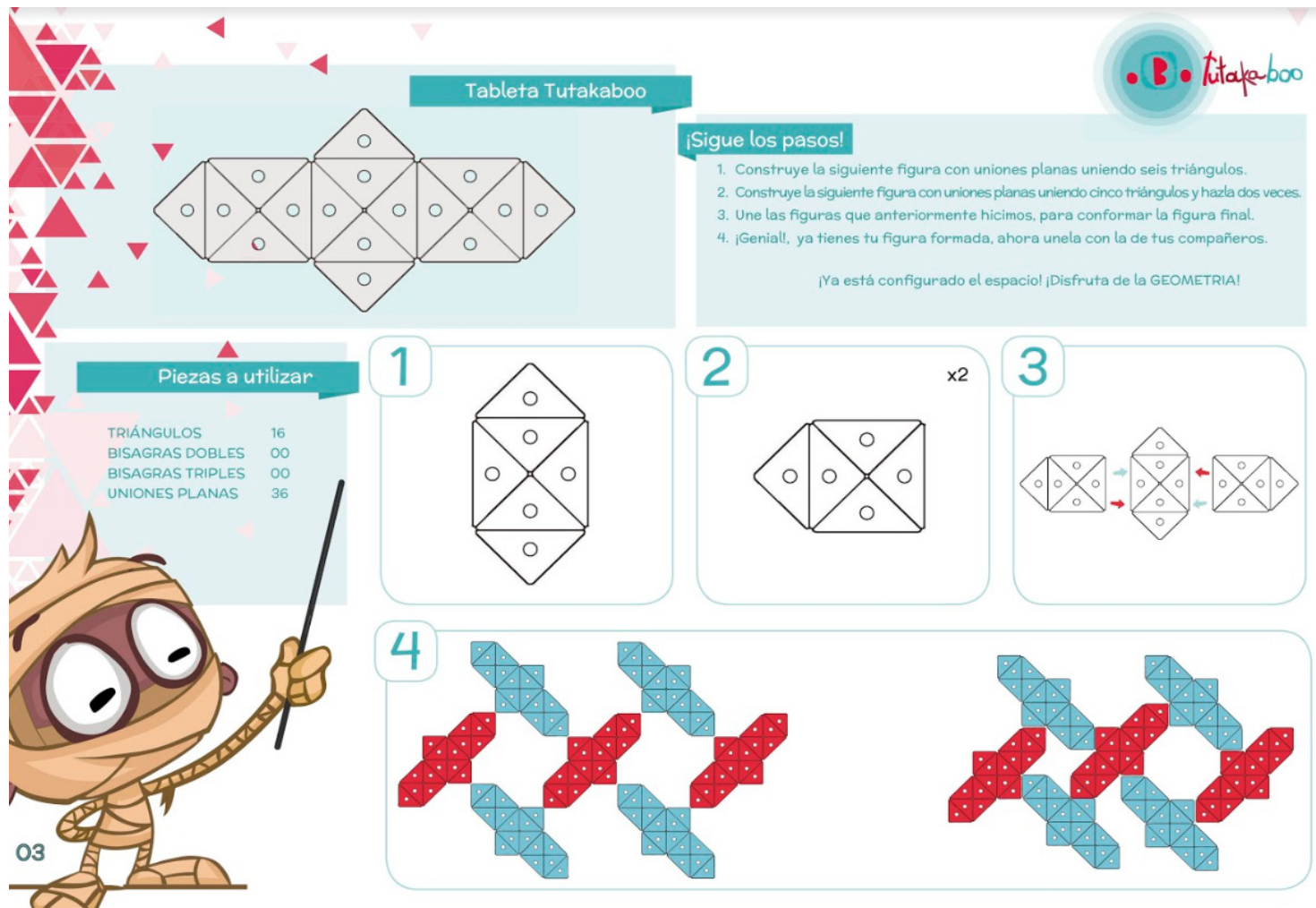

Figura 54. Ficha pata construcción del azulejo tableta

Fuente: Tutakaboo. García, A. y Medina, P.

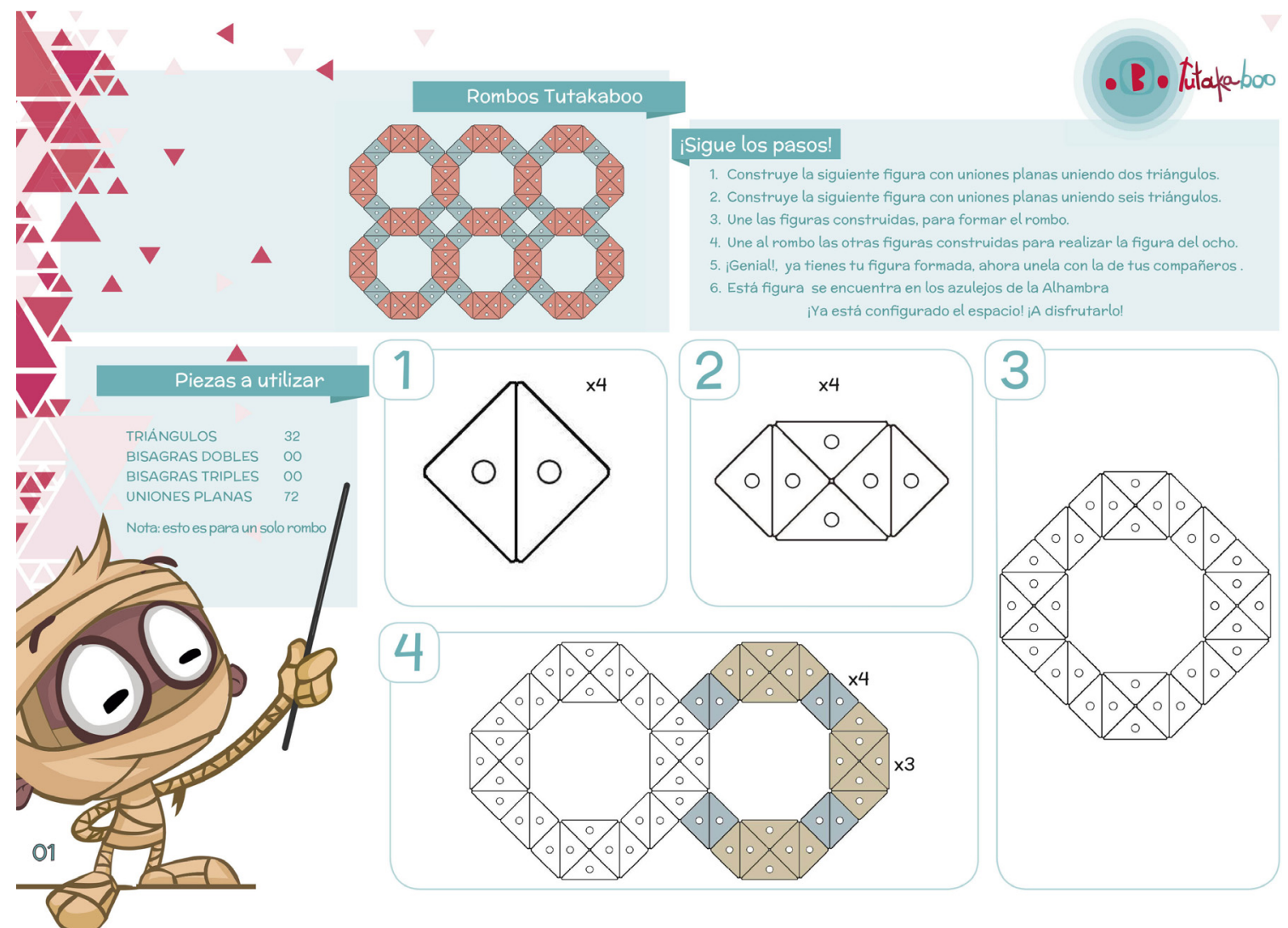

Figura 55. Ficha pata construcción del azulejo rombos

Fuente: Tutakaboo. García, A. y Medina, P. 


\section{Tarea 7: Ficha de desarrollo del cubo}

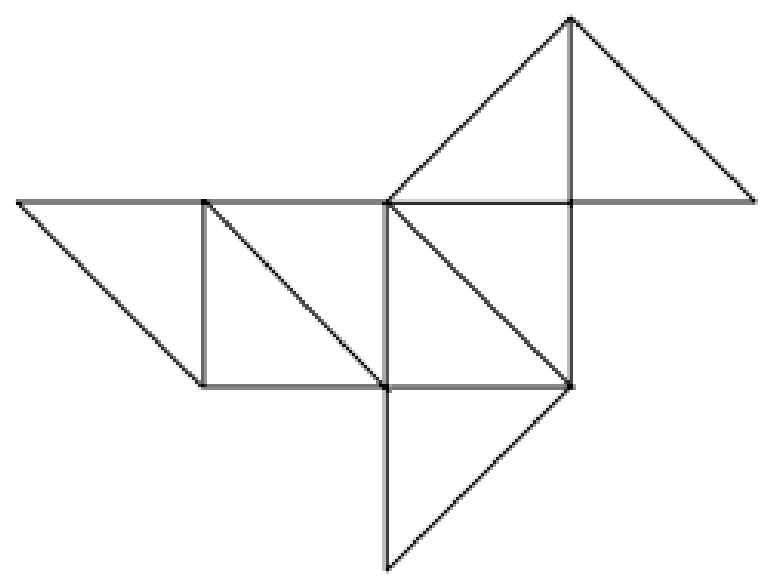

Figura 56. Imagen de la pajarita con triángulos Fuente: Flores, P.

Tarea 8: Ficha de sólidos platónicos

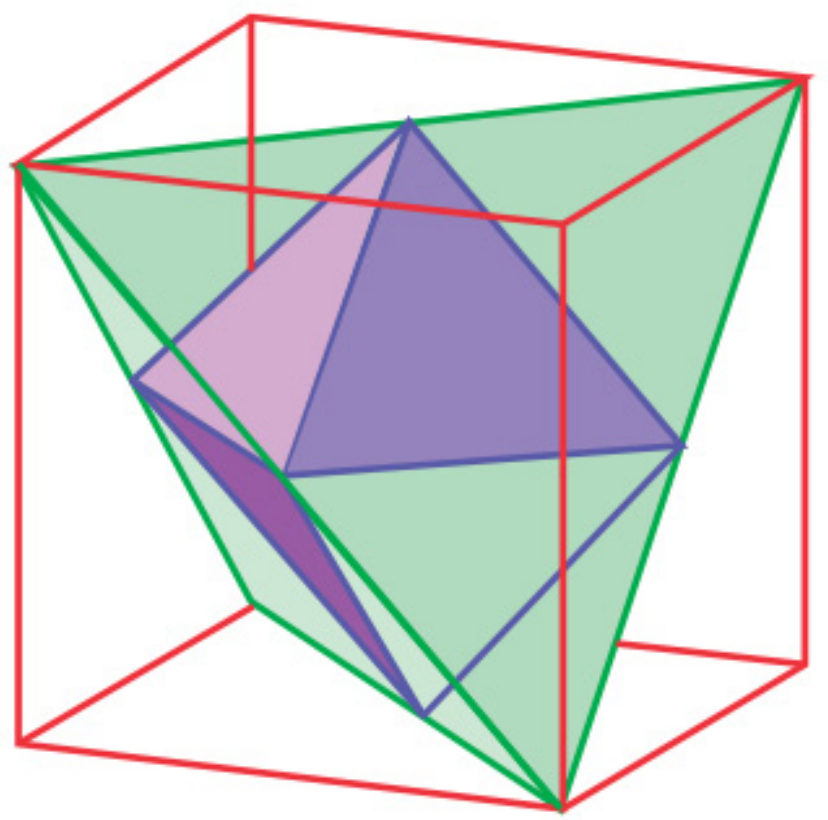

Figura 57. Ficha cubo con tetraedro y octaedro 


\section{Tarea 8: Ficha de sólidos arquimedianos}
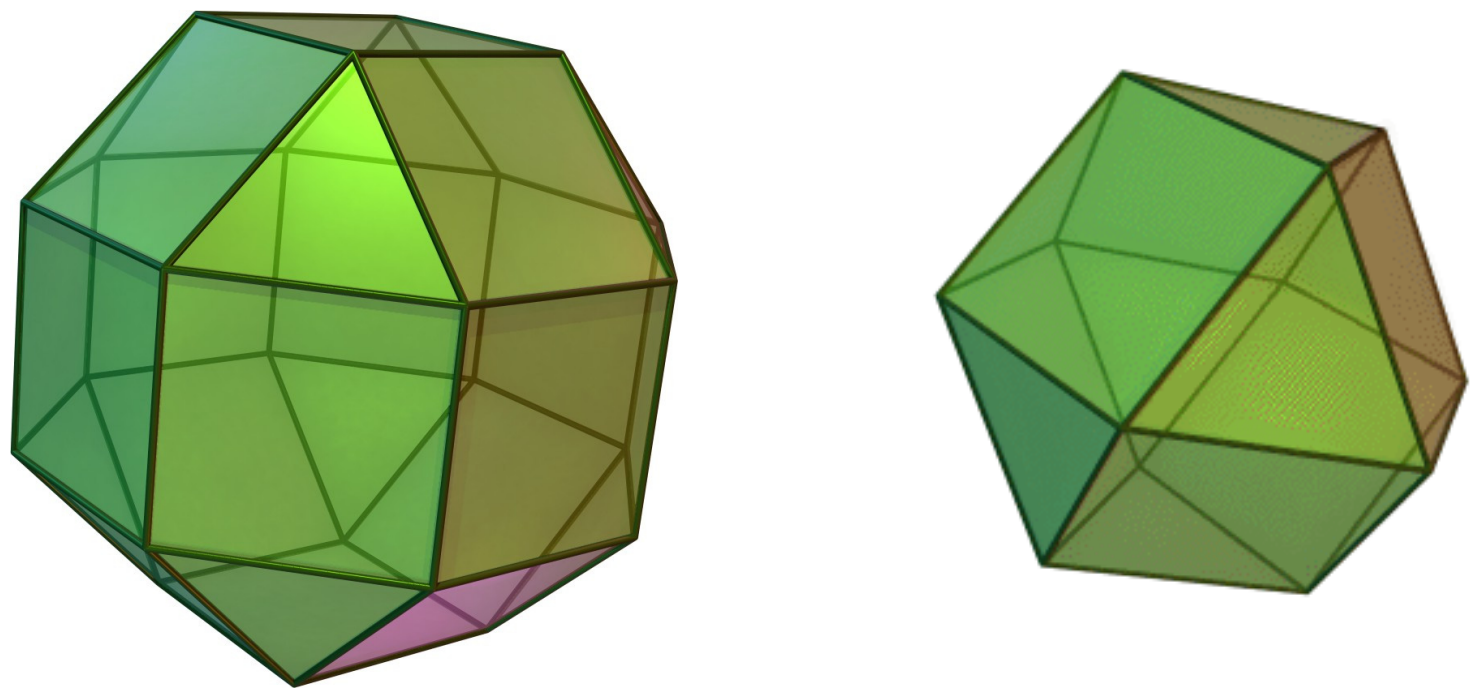

Figura 58. Ficha cubo con tetraedro e icosaedro

Fuente: Wikipedia

\section{Tarea 9: Ficha de desarrollo del cubo}

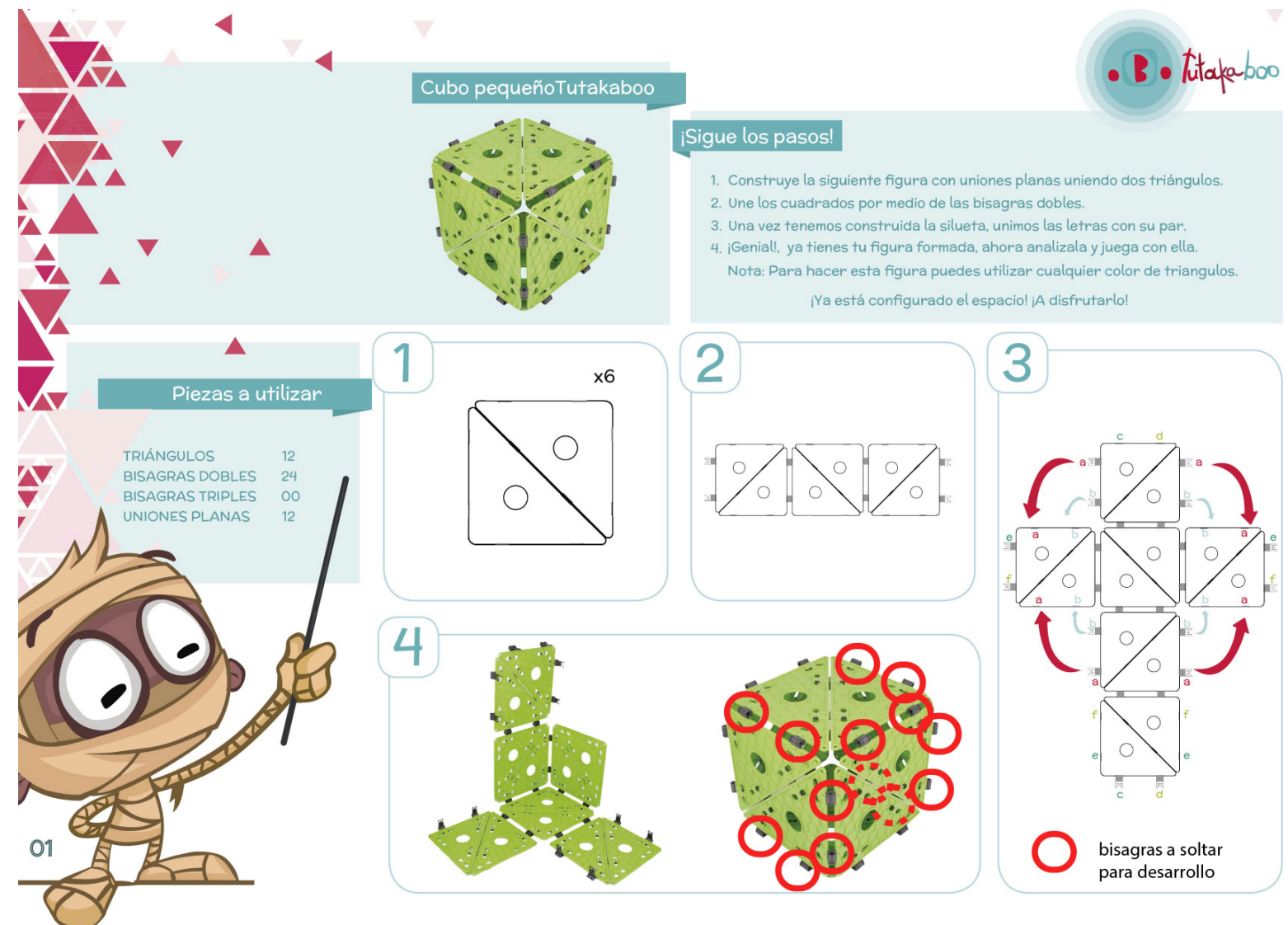

Figura 59. Ficha desarrollo del cubo

Fuente: Tutakaboo. García, A. y Medina, P. Adaptada para le actividad de cuerdas en aristas. 


\section{Anexo III}

Tarea 1: Resultados de conservación de volumen

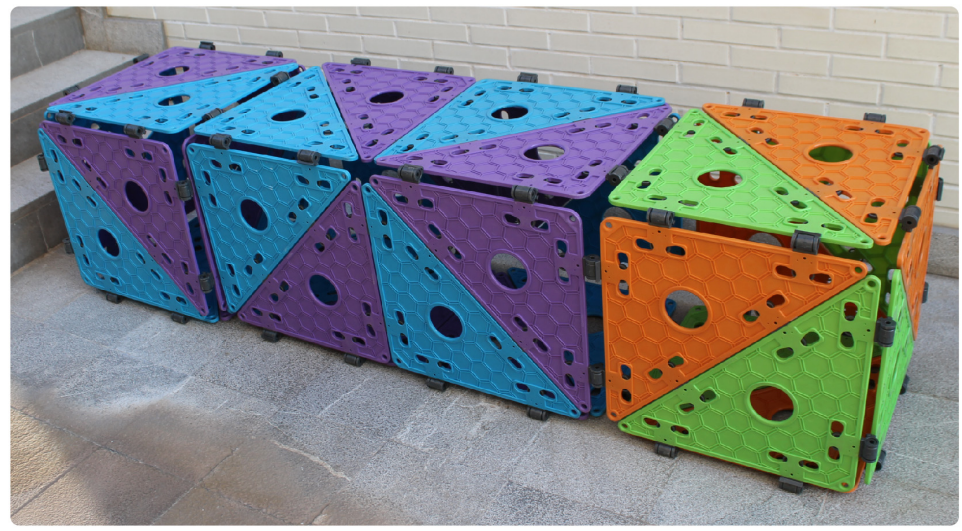

Figura 60. Figura cuatro cubos disposición 1

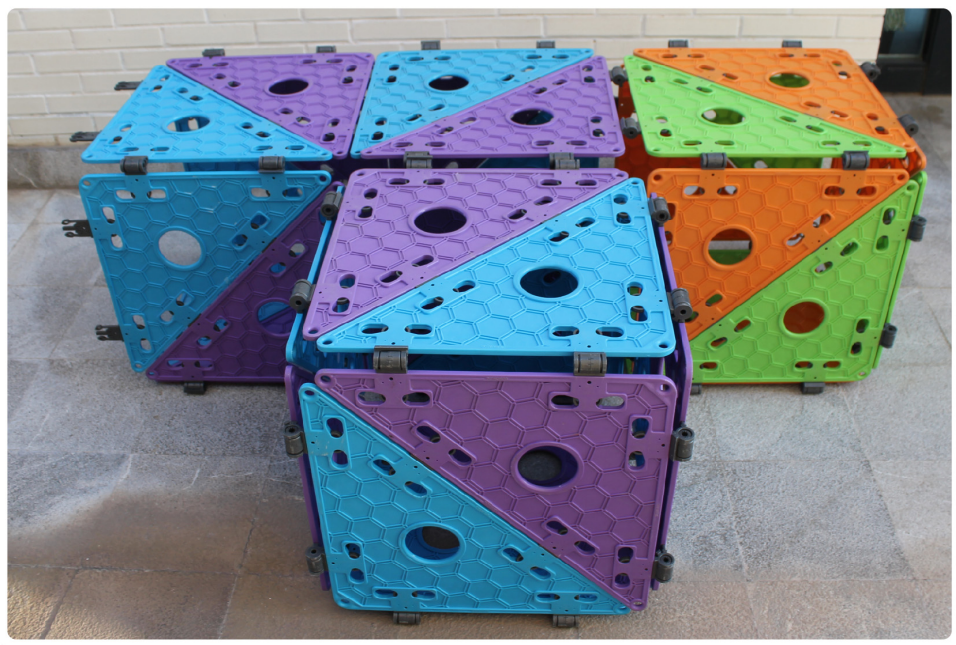

Figura 61 Figura cuatro cubos disposición 2

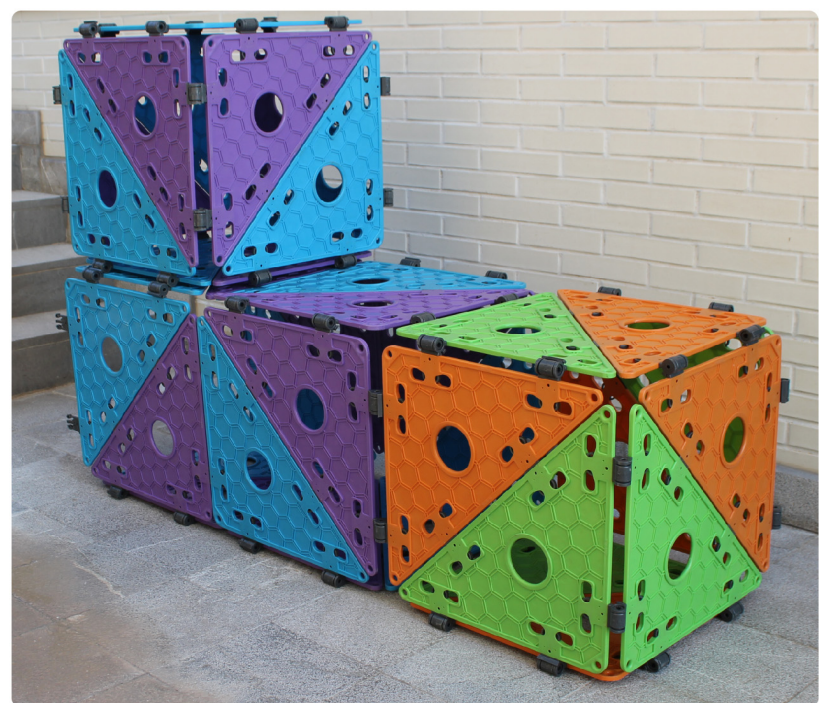

Figura 62. Figura cuatro cubos disposición 3 
Tarea 1: Resultados de conservación de superficie

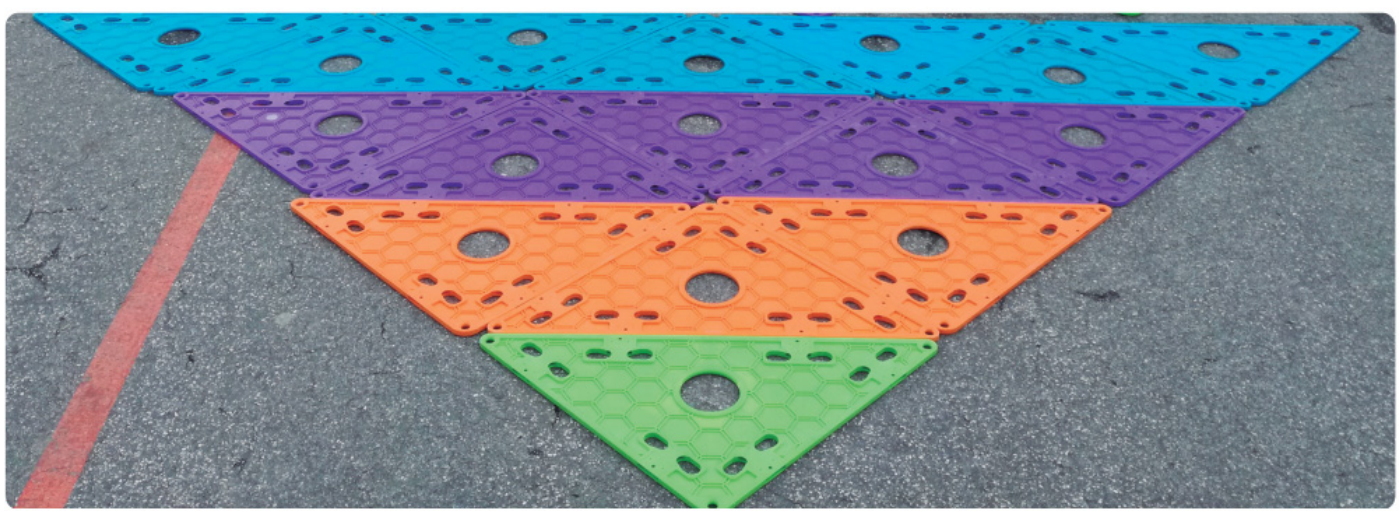

Figura 63. Figura 16 triángulos 01

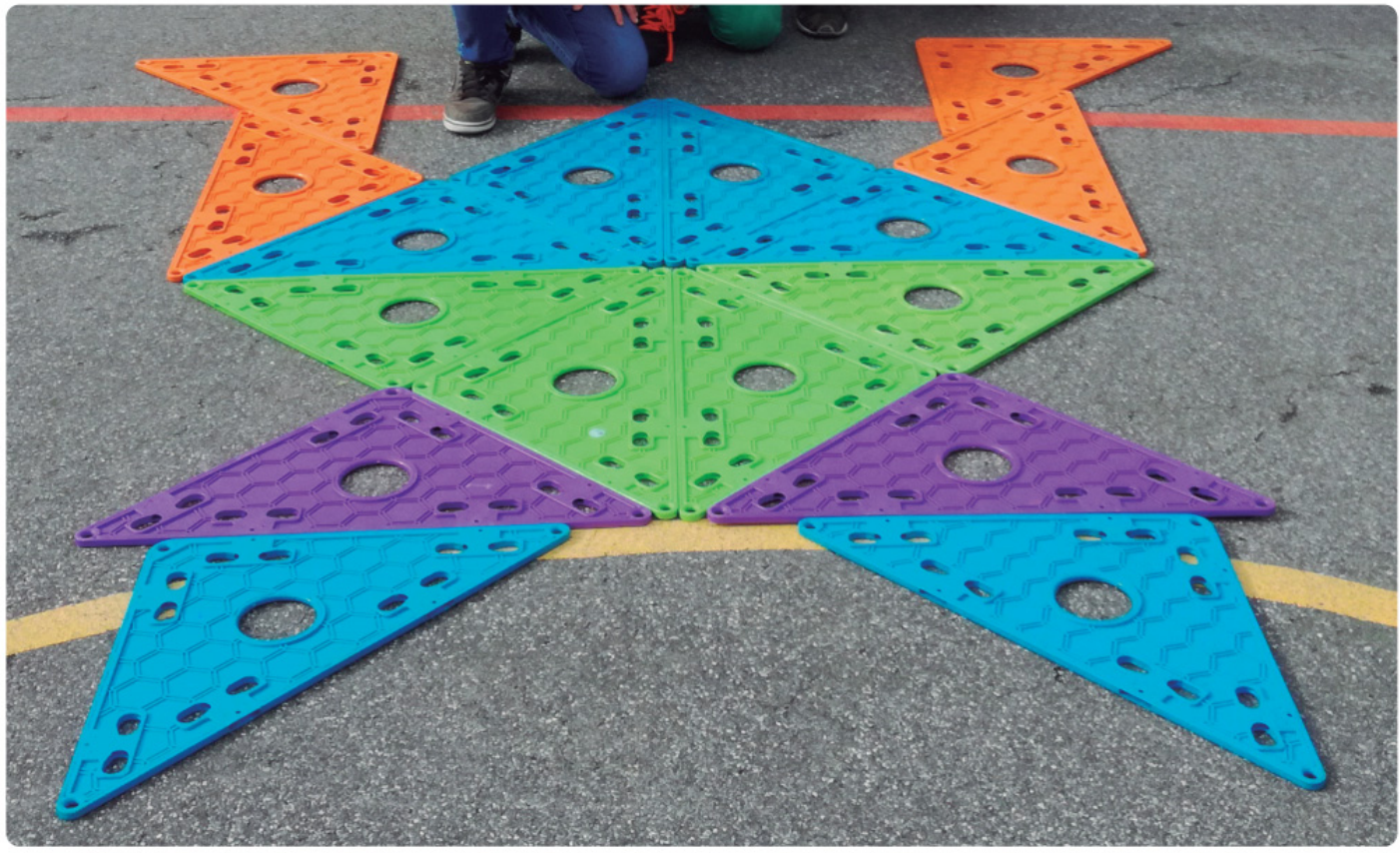

Figura 64. Figura cuatro cubos disposición 3 
Tarea 9: Ejemplos de soluciones a la actividad: Desarrollos del cubo

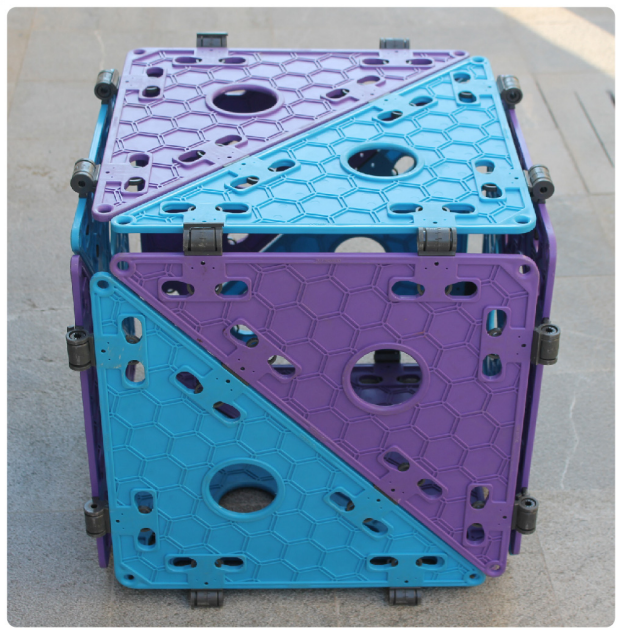

Figura 65. Cubo

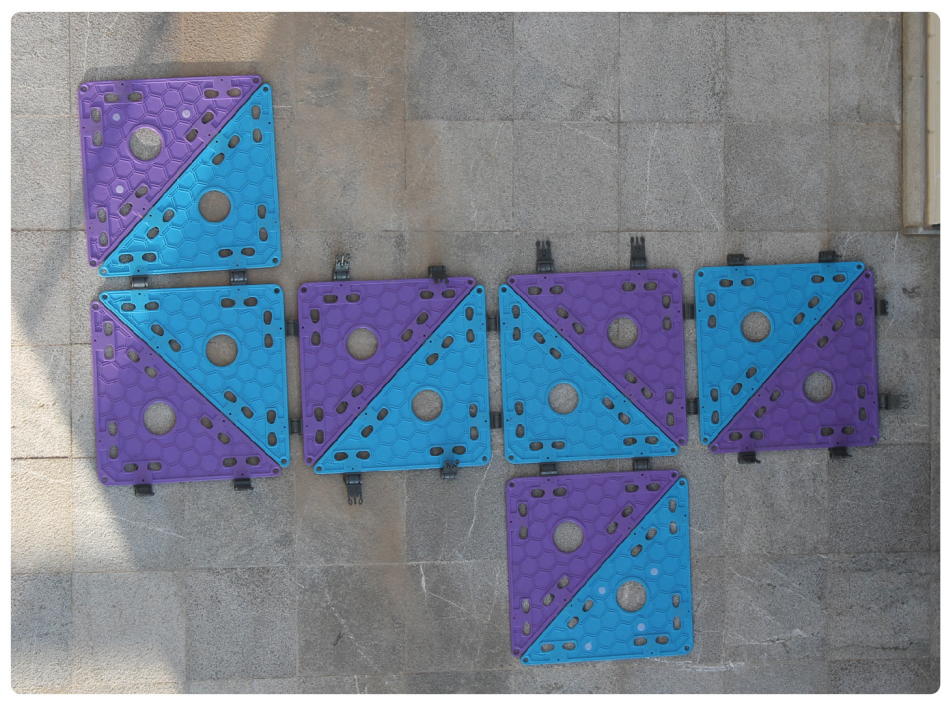

Figura 66. Desarrollo 1

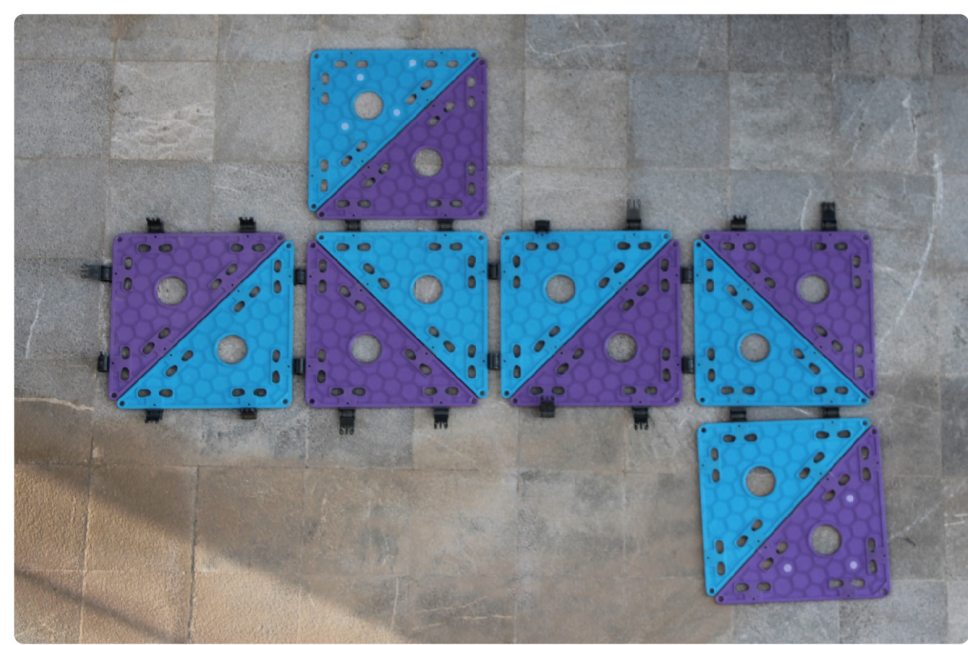

Figura 67 Desarrollo 2 